\title{
Time and space variability of freshwater content, heat content and seasonal ice melt in the Arctic Ocean from 1991 to 2011
}

\author{
M. Korhonen ${ }^{1,2}$, B. Rudels ${ }^{1,2}$, M. Marnela ${ }^{1,2}$, A. Wisotzki ${ }^{3}$, and J. Zhao ${ }^{4}$ \\ ${ }^{1}$ Finnish Meteorological Institute, Helsinki, Finland \\ ${ }^{2}$ Department of Physics, University of Helsinki, Helsinki, Finland \\ ${ }^{3}$ Alfred Wegener Institute, Bremerhaven, Germany \\ ${ }^{4}$ College of Physical and Environmental Oceanography, Ocean University of China, Qingdao, China
}

Correspondence to: M. Korhonen (meri.korhonen@fmi.fi)

Received: 6 June 2012 - Published in Ocean Sci. Discuss.: 1 August 2012

Revised: 11 October 2013 - Accepted: 19 October 2013 - Published: 2 December 2013

\begin{abstract}
Changes in the hydrography of the Arctic Ocean have recently been reported. The upper ocean has been freshening and pulses of warm Atlantic Water have been observed to spread into the Arctic Ocean. Although these changes have been intensively studied, salinity and temperature variations have less frequently been considered together. Here hydrographic observations, obtained by icebreaker expeditions conducted between 1991 and 2011, are analyzed and discussed. Five different water masses in the upper $1000 \mathrm{~m}$ of the water column are examined in five sub-basins of the Arctic Ocean. This allows for studying the variations of the distributions of the freshwater and heat contents in the Arctic Ocean not only in time but also laterally and vertically. In addition, the seasonal ice melt contribution is separated from the permanent, winter, freshwater content of the Polar Mixed Layer. Because the positions of the icebreaker stations vary between the years, the icebreaker observations are at each specific point in space and time compared with the Polar Science Center Hydrographic Climatology to separate the effects of space and time variability on the observations. The hydrographic melt water estimate is discussed and compared with the potential ice melt induced by atmospheric heat input estimated from the ERA-Interim and NCEP/NCAR reanalyses. After a period of increased salinity in the upper ocean during the 1990s, both the Polar Mixed Layer and the upper halocline have been freshening. The increase in freshwater content in the Polar Mixed Layer is primarily driven by a decrease in salinity, not by changes in Polar Mixed Layer depth, whereas the freshwater is accumulating in the upper halocline mainly through the increasing thickness of the
\end{abstract}

halocline. This is especially evident in the Northern Canada Basin, where the most substantial freshening is observed. The warming, and to some extent also the increase in salinity, of the Atlantic Water during the early 1990s extended from the Nansen Basin into the Amundsen and Makarov basins, while the warm and saline inflows occurring during the 2000s appear to be confined to the Nansen Basin, suggesting that the warm and saline inflow through Fram Strait largely recirculates in the Nansen Basin.

\section{Introduction}

Direct precipitation and runoff provide two thirds of the total freshwater input to the Arctic Ocean. The remaining onethird derives from the low salinity Pacific water advected through the Bering Strait (Aagaard and Carmack, 1989; Serreze et al., 2006; Dickson et al., 2007). In addition, especially in the Canada Basin, recent reduction in sea ice volume is suggested to decrease the surface salinity and thus contribute to the freshwater content in the upper ocean (YamamotoKawai et al., 2009).

Most of the oceanic heat transported to the Arctic Ocean derives from the Atlantic. Particularly the heat carried through the Fram Strait is well conserved as the warm and saline inflow becomes decoupled from the atmosphere north of Svalbard, where the upper part of the inflow is transformed into a fairly fresh surface layer by melting sea ice and mixing with meltwater. Because of the advection of heat, the large freshwater input and storage are generally considered 
a prerequisite for the maintenance of the perennial ice cover in the Arctic Ocean. The freshwater flux stabilises the surface layer and insulates sea ice from heat stored in the Atlantic layer (Aagaard and Coachman, 1975; Aagaard et al., 1981; Rudels et al., 1996). Generally, not even the convection induced by ice formation and subsequent brine rejection is able to reach the thermocline. Only in the Nansen Basin does the weak stratification enable sufficiently deep winter convection to possibly mix the warm Atlantic Water upward (Rudels et al., 1996; Kikuchi et al., 2004). However, changes in wind-driven ocean advection have been observed to weaken the upper ocean stratification, possibly increasing vertical mixing also in the Amundsen and Makarov basins (Proshutinsky and Johnson, 1997; Steele and Boyd, 1998).

In the late 1980s and early 1990s, the prevailing atmospheric circulation pattern, described by the Arctic Oscillation (AO) index (Thompson and Wallace, 1998), was considered to largely regulate changes in the Arctic freshwater content, heat content and seasonal ice melt. The amplified ice export through the Fram Strait, together with the enhanced Atlantic heat flux to sea ice, were suggested to contribute to the accelerated decline in sea ice extent (Maslanik et al., 1996; Vinje, 2001; Rigor et al., 2002). The export of freshwater and sea ice had further consequences in the Nordic Seas and in the North Atlantic subpolar gyre, where the salinity of the North Atlantic Deep Water was reduced (Dickson et al., 2002; Curry et al., 2003; Curry and Mauritzen, 2005).

Since the mid-1990s the wind-driven circulation has favoured accumulation of freshwater (Björk et al., 2002; Boyd et al., 2002; Proshutinsky et al., 2009). Nevertheless, the sea ice volume has continued to diminish with startling speed (Comiso, 2011; Cavalieri and Parkinson, 2012; Stroeve et al., 2012). Thus, although the presence of the halocline is still regarded essential for providing insulation between the Atlantic heat storage and the sea ice, the heat stored in the Atlantic layer is no longer considered the main threat to the perennial ice cover. Instead, by reducing surface albedo, the declining ice cover has dramatically increased the solar heating of surface waters (Maykut and McPhee, 1995; Perovich et al., 2007a).

Because the heat entrained into the Polar Mixed Layer eventually is either used to melt ice or lost to the atmosphere, the surface temperature generally remains near the freezing point and heat content in surface layer is practically negligible (Coachman and Barnes, 1961). However, a seasonal temperature maximum around a depth of $20-30 \mathrm{~m}$, not yet reported by Coachman and Barnes, was observed during AIDJEX (Arctic Ice Dynamics Joint Experiment, 1975). Maykut and McPhee (1995) attributed this feature to penetrating short wave radiation. The near-surface temperature maximum has become more pronounced in recent years, indicating that the amount of absorbed solar radiation has increased, particularly in the Chukchi and southwestern Beaufort seas where the most notable ice loss has occurred during the past decades (McPhee et al., 1998; Shimada et al., 2001; Perovich et al., 2008; Jackson et al., 2010).

In addition to the role of radiative processes in recent ice loss, Pacific waters have been suggested to supply additional heat to the upper ocean, which possibly influences the ice cover. Previously the heat content in the waters deriving from the Pacific Ocean was presumed to be negligible. Nevertheless, the Pacific waters are, at least during summer, comparatively warm and fresh and, due to their low density, inject heat close to the ocean surface (Stigebrandt, 1984). The direct measurements of the Bering Strait transports carried out since the early 1990s reveal variability in both temperature and volume of the Bering Strait inflow (Roach et al., 1995; Woodgate et al., 2010). Although no permanent increase in temperature or heat content is documented, Shimada et al. (2001) and Steele et al. (2004) proposed a possible warming of the Alaskan Coastal Water during the late 1990s, and more recently Woodgate et al. (2010) discussed the anomalously large heat imports to the Arctic Ocean through the Bering Strait in 2004 and 2007, the latter being due to both increased temperature and large volume flux. Furthermore, Shimada et al. (2006) noted that the atmospheric forcing could influence the spreading of the relatively warm Alaskan Coastal Water northward and thus accelerate the ice loss.

Previous studies have revealed the spatial concentration and recent accumulation of freshwater in the Canada Basin (Aagaard and Carmack, 1989; Proshutinsky et al., 2009; Rabe et al., 2011; Giles et al., 2012). However, these studies do not discuss the vertical distribution, origin and lateral and temporal variations of the freshwater content in different water masses in such detail as is attempted here. In addition to the freshwater content, this study aims to assess variability in the oceanic heat stored in each discussed water mass, including the Atlantic Water located deep in the water column, and possible connection of both, the freshwater and heat content, to the seasonal ice melt. Oceanographic observations covering the past two decades are used to examine possible heat sources in the upper ocean and to assess the role of diminishing sea ice in the recent freshening of the Arctic Ocean.

\section{Approach}

\subsection{Data}

The analysed hydrographic data are obtained from selected icebreaker cruises conducted in July-September. The data cover the $20 \mathrm{yr}$ period from 1991 to 2011 and offer summertime snapshots of the local conditions. Data are collected as conductivity-temperature-depth (CTD) surveys, from which potential temperature and salinity profiles are analysed to distinguish the different water masses and compute freshwater content, heat content and seasonal ice melt as described below in this section. Figure 1 and Table 1 offer more 
Table 1. The icebreaker expeditions offering the data for this study and a reference for additional information about instruments and their accuracies. Number of casts in each sub-basin as well as the areal coverage of the available casts (in parentheses) is shown.

\begin{tabular}{|c|c|c|c|c|c|c|c|c|}
\hline Year & Month & Vessel & Reference & $\begin{array}{r}\text { Nansen } \\
\text { Basin }\end{array}$ & $\begin{array}{r}\text { Amundsen } \\
\text { Basin }\end{array}$ & $\begin{array}{r}\text { Makarov } \\
\text { Basin }\end{array}$ & $\begin{array}{r}\text { North Canada } \\
\text { Basin }\end{array}$ & $\begin{array}{r}\text { South Canada } \\
\text { Basin }\end{array}$ \\
\hline 1991 & Aug/Oct & Oden & $\begin{array}{l}\text { Anderson et al. } \\
\text { (1994) }\end{array}$ & $4(30 \%)$ & $13(35 \%)$ & $3(5 \%)$ & - & - \\
\hline 1993 & Aug/Sept & Henry Larsen & $\begin{array}{l}\text { Carmack et al. } \\
\text { (1995) }\end{array}$ & - & - & - & $5(10 \%)$ & $7(20 \%)$ \\
\hline 1994 & Jul/Aug & $\begin{array}{l}\text { Louis S. } \\
\text { St-Laurent }\end{array}$ & $\begin{array}{l}\text { Swift et al. } \\
\text { (1997) }\end{array}$ & $3(15 \%)$ & $3(10 \%)$ & $8(20 \%)$ & $8(15 \%)$ & - \\
\hline 1996 & Aug & Polarstern & $\begin{array}{l}\text { Schauer and Rohardt } \\
\text { (1998) }\end{array}$ & $12(20 \%)$ & $12(20 \%)$ & $10(25 \%)$ & - & - \\
\hline 1997 & Sept/Oct & $\begin{array}{l}\text { Louis S. } \\
\text { St-Laurent }\end{array}$ & $\begin{array}{l}\text { McLaughlin et al. } \\
\text { (2004) }\end{array}$ & - & - & - & - & $12(25 \%)$ \\
\hline 2001 & Jul/Aug & Oden & $\begin{array}{l}\text { Björk et al. } \\
(2002)\end{array}$ & $9(35 \%)$ & $13(35 \%)$ & $3(5 \%)$ & - & - \\
\hline 2002 & Aug/Sept & Polar Star & $\begin{array}{l}\text { Woodgate et al. } \\
\text { (2007) }\end{array}$ & - & - & - & $24(25 \%)$ & $10(15 \%)$ \\
\hline 2002 & Sept & Mirai & $\begin{array}{l}\text { Shimada et al. } \\
\text { (2005) }\end{array}$ & - & - & - & - & $16(29 \%)$ \\
\hline 2003 & Aug/Sept & Xuelong & $\begin{array}{l}\text { Zhang } \\
\text { (2004) }\end{array}$ & - & - & - & $13(20 \%)$ & $18(35 \%)$ \\
\hline 2005 & Aug & Oden & $\begin{array}{l}\text { Björk et al. } \\
\text { (2007) }\end{array}$ & $2(15 \%)$ & $6(15 \%)$ & $6(20 \%)$ & $5(20 \%)$ & $7(25 \%)$ \\
\hline 2007 & Aug/Sept & Polarstern & $\begin{array}{l}\text { Schauer and Wisotzki } \\
\text { (2010) }\end{array}$ & $18(50 \%)$ & $9(20 \%)$ & $10(25 \%)$ & - & - \\
\hline 2007 & Jul/Aug & $\begin{array}{l}\text { Louis S. } \\
\text { St-Laurent }\end{array}$ & $\begin{array}{l}\text { Zimmermann et al. } \\
\text { (2007) }\end{array}$ & - & - & - & $12(30 \%)$ & $54(90 \%)$ \\
\hline 2008 & Aug/Sept & Xuelong & $\begin{array}{l}\text { Bourgain et al. } \\
\text { (2013) }\end{array}$ & - & - & - & $16(50 \%)$ & $27(55 \%)$ \\
\hline 2011 & Aug/Sept & Polarstern & $\begin{array}{l}\text { Schauer et al. } \\
\text { (2012) }\end{array}$ & $21(40 \%)$ & $18(35 \%)$ & $10(30 \%)$ & $5(10 \%)$ & - \\
\hline 2011 & Jul/Aug & $\begin{array}{l}\text { Louis S. } \\
\text { St-Laurent }\end{array}$ & $\begin{array}{l}\text { Williams and Zimmermann } \\
\text { (2011) }\end{array}$ & - & - & - & $4(20 \%)$ & $30(90 \%)$ \\
\hline
\end{tabular}

information on the expeditions. Table 1 also includes references for more specific information on the used instruments and their accuracies.

To review the spatial distribution of water masses and the variability of their freshwater and heat contents, the Nansen, Amundsen, Makarov and Canada basins are discussed separately. The Canada Basin is further divided into a southern and a northern part as shown in Fig. 2. Shelf areas are excluded from this study and the focus is on the deep basins.

\subsection{Water masses}

In the intermediate and deep layers, the time and space variability of salinity and temperature is modest and slow compared to the uppermost $1000 \mathrm{dbar}$. Therefore, the freshwater and heat contents are studied only in the upper $1000 \mathrm{dbar}$ water column, which is here separated into six water masses with distinct properties (Fig. 3, Table 2). It should be noted, however, that apart from the definitions adopted here several other classifications and names of the water masses, especially of the halocline waters, exist (e.g. Guay and Falkner,
1997; Morison et al., 1998; Kikuchi et al., 2004; Steele et al., 2004; Proshutinsky et al., 2009).

Following Rudels et al. (1996) the thickness of the Polar Mixed Layer (PML) is defined by the temperature minimum, considered as a remnant of the previous winter convection and homogenization. If the temperature minimum is absent or ambiguous, the rapid change in magnitude of the salinity gradient may be used to identify the mixed layer depth. The upper halocline (UHC) is here defined as the layer between temperature minimum and salinity 34 . The upper halocline mainly derives from the Bering Strait inflow, which consists of three different water masses: Alaskan Coastal Water (ACW), Bering Sea Summer Water (BSSW) and Bering Sea Winter Water (BSWW) (Steele et al., 2004). Furthermore, runoff from the Siberian rivers also contributes to the waters composing the upper halocline. This makes the upper halocline, particularly in the Canada Basin, a very heterogenous water mass comprising several temperature maxima (ACW and BSSW) and a minimum (BSWW).

The lower halocline (LHC) is generally formed when the saline surface layer in the Nansen Basin advects further into 
Table 2. The definitions of water masses with salinity and temperature.

\begin{tabular}{lll}
\hline Water mass & Upper limit $\left(z_{1}\right)$ & Lower limit $\left(z_{2}\right)$ \\
\hline Polar Mixed Layer (PML) & $p=0 \mathrm{dbar}$ & $\theta=\theta_{\min }$ \\
Upper halocline (UHC) & $\theta=\theta_{\min }$ & $S=34$ \\
Lower halocline (LHC) & $S=34$ & $\theta=0^{\circ} \mathrm{C}$ \\
Upper Atlantic Water (AW1) & $\theta=0^{\circ} \mathrm{C}$ & $\theta=\theta_{\max }$ \\
Lower Atlantic Water (AW2) & $\theta=\theta_{\max }$ & $\theta=0^{\circ} \mathrm{C}$ \\
Upper Polar Deep Water (UPDW) & $\theta=0^{\circ} \mathrm{C}$ & $p=1000 \mathrm{dbar}$ \\
\hline
\end{tabular}

Table 3. Decadal trends in water mass thickness $\left(\mathrm{m} \mathrm{decade}^{-1}\right.$ ) for period 1991-2011. Linear trends are computed from the anomalies (shown in Figs. 6-10) using least-squares regression. The trends within the standard $95 \%$ level of statistical significance are emphasized, $90 \%$ confidence level is indicated with italics.

\begin{tabular}{lrrrrr}
\hline Water mass & Nansen & Amundsen & Makarov & N Canada & S Canada \\
\hline PML & $\mathbf{- 1 9} \pm \mathbf{1 4}$ & $-1.4 \pm 2.2$ & $-1.8 \pm 7.2$ & $7.6 \pm 6.0$ & $6.3 \pm 3.6$ \\
UHC & -- & $3.3 \pm 4.5$ & $4.5 \pm 8.8$ & $24 \pm 16$ & $-1.2 \pm 7.5$ \\
LHC & $-11 \pm 10$ & $-1.7 \pm 6.5$ & $-\mathbf{1 5} \pm \mathbf{4}$ & $\mathbf{- 2 3} \pm \mathbf{6}$ & $\mathbf{- 2 0} \pm \mathbf{4}$ \\
AW1 & $-0.3 \pm 13$ & $7.1 \pm 18$ & $-32 \pm 21$ & $-7.9 \pm 11$ & $-11 \pm 12$ \\
AW2 & $22 \pm 29$ & $11 \pm 32$ & $56 \pm 26$ & $\mathbf{6 7} \pm \mathbf{1 5}$ & $26 \pm 19$ \\
\hline
\end{tabular}

the Arctic Ocean and becomes submerged by low salinity shelf water that enters the deep basins mainly from the Laptev Sea and other marginal seas farther east (Rudels et al., 1996). Because of its origins, the upper boundary of the lower halocline is set by the isohaline 34. The Arctic Atlantic Water is commonly defined by temperatures above zero and thus the zero-isotherm marks the boundary between the lower halocline and Atlantic layer. As a consequence the lower halocline also comprises the upper part of the thermocline. The temperature maximum shown in Fig. 3 is used to separate the Atlantic layer into an upper (AW1) and a lower (AW2) part.

The deeper zero-isotherm indicates the lower limit of the Atlantic Water. In the Canada Basin, this boundary generally lies around 900-1000 dbar while in the Eurasian basin it is located at 600-800 dbar. The water mass beneath the Atlantic layer is identified as the Upper Polar Deep Water (UPDW), which, however, extends deeper than $p=1000 \mathrm{dbar}$ and is not discussed in this study.

\subsection{Representativeness of data}

The unfortunate fact remains that icebreaker cruises are limited in their spatial extent, sometimes covering rather a basinwide section than an extensive area. As seen in Fig. 1, the uneven spatial and temporal coverage makes it challenging to unambiguously detect and quantify hydrographic variability.

The spatial representativeness of available data is illustrated by the coverage percentages approximated from the grid shown in Fig. 1 and presented in Table 1. The coverage in a grid cell is set to $100 \%$ when any number of casts are available within the cell. The most extensive data coverage is attained in the Canada Basin during the 2000s. However, the data from the 1990s are more limited and comparison between the two decades becomes difficult. In the Nansen and Amundsen basins, the coverage reaches $50 \%$ at the most.

To mitigate the effects of combined spatial and temporal variability, hydrographic observations are compared with the Polar Science Center Hydrographic Climatology (PHC, Steele et al., 2001). From the climatology the seasonal summer (July-August-September) fields are extracted for temperature and salinity in the upper $1000 \mathrm{dbar}$ water column. Each hydrographic cast is then compared to the nearest grid point in PHC. This comparison, however, introduces a problem when water masses are studied separately as the climatological data are given at uneven intervals $(10,20,30,50$, $75,100,125,150,200,250,300,400,500,600,700,800$, $900,1000 \mathrm{~m}$ ). In order to compare climatology to the discussed water masses, climatological data have been interpolated with $1 \mathrm{~m}$ intervals. Then, the mean anomalies in salinity and temperature, observations - climatology, for each water mass in each basin and each year are computed. Thus the possible effect of spatial variability is removed from the linear trends computed from the anomalies. The linear trends for layer thickness, salinity and temperature are estimated with least squares regression and shown with standard error in Tables 3-5.

\subsection{Approach to freshwater and heat contents}

Since there is no salt exchange between the ocean surface and the atmosphere, the change in salinity $S$ results directly from the freshwater added to, or extracted from, the observed water body with a chosen reference salinity $S_{\text {ref. }}$. In this study 

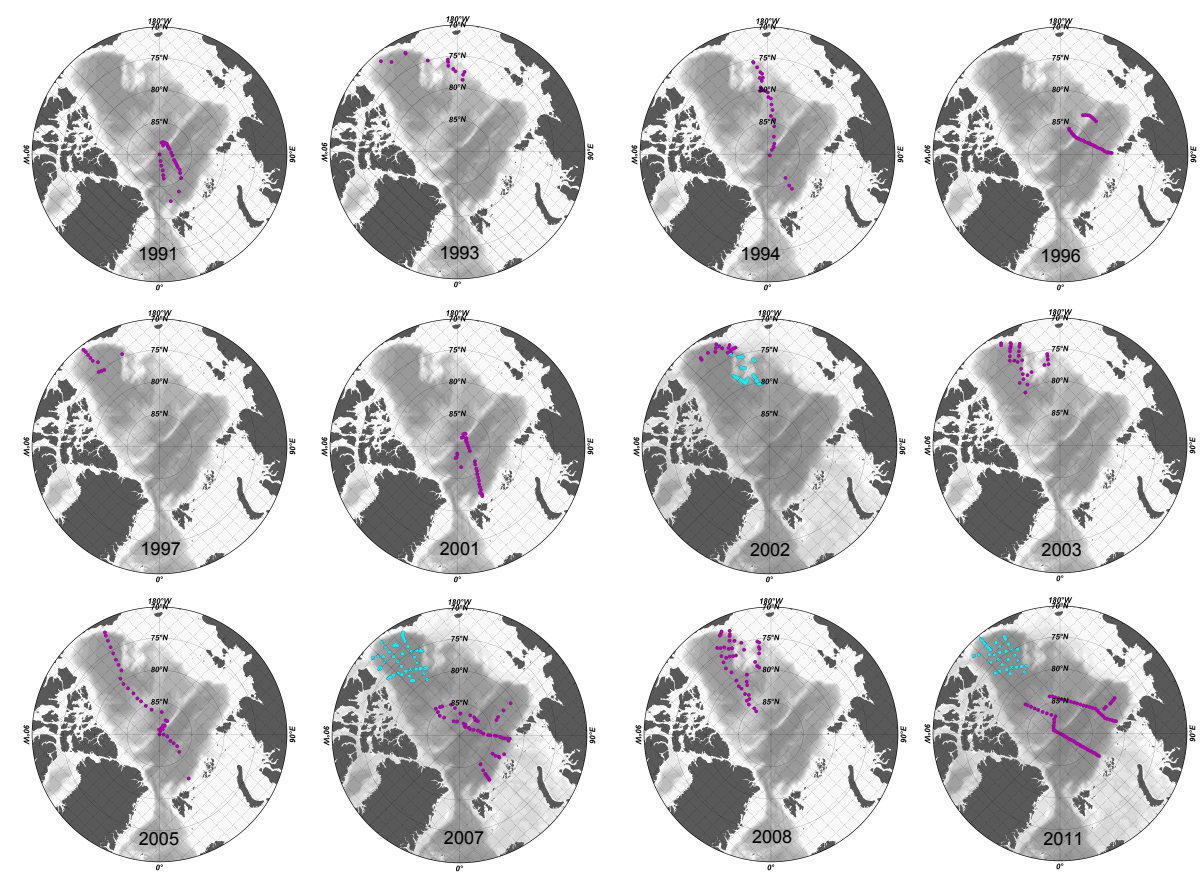

Fig. 1. The selected icebreaker cruises used in this study. Different colors are used to distinguish between cruises during the same year. The grid (approximately $1.8^{\circ} \times 1.8^{\circ}$ ) is used to compute areal coverages shown in Table 1 . See Table 1 also for exact number of casts.

Table 4. Decadal salinity trends (pptdecade ${ }^{-1}$ ) for period 1991-2011. Linear trends are computed from the anomalies (shown in Figs. 1120) using least-squares regression. The trends within the standard $95 \%$ level of statistical significance are emphasized, $90 \%$ confidence level is indicated with italics.

\begin{tabular}{lrrrrr}
\hline Water mass & Nansen & Amundsen & Makarov & N Canada & S Canada \\
\hline PML & $-0.19 \pm 0.16$ & $-0.39 \pm 0.27$ & $-0.74 \pm 0.41$ & $-0.92 \pm 0.41$ & $-0.60 \pm 0.25$ \\
UHC & -- & $-0.10 \pm 0.10$ & $-0.12 \pm 0.12$ & $-0.09 \pm 0.11$ & $-0.11 \pm 0.07$ \\
LHC & $-0.04 \pm 0.05$ & $0.01 \pm 0.02$ & $-0.03 \pm 0.02$ & $-0.02 \pm 0.01$ & $-0.08 \pm 0.01$ \\
AW1 & $0.02 \pm 0.02$ & $-0.003 \pm 0.013$ & $-0.03 \pm 0.01$ & $0.001 \pm 0.004$ & $\mathbf{- 0 . 0 2} \pm \mathbf{0 . 0 1}$ \\
AW2 & $0.003 \pm 0.013$ & $-0.003 \pm 0.005$ & $-0.008 \pm 0.004$ & $\mathbf{0 . 0 2 0} \pm \mathbf{0 . 0 0 4}$ & $0 \pm 0.002$ \\
\hline
\end{tabular}

the reference salinity is set to equal the mean salinity of Fram Strait outflow, 34.9 , which is also close to the mean salinity of the upper Polar Deep Water (Rudels et al., 1994). Relative freshwater content $F W C$ is given by

$\mathrm{FWC}=\int_{z_{1}}^{z_{2}} \frac{S_{\mathrm{ref}}-S(z)}{S_{\text {ref }}} \mathrm{d} z$,

which yields freshwater content as metres in a water column with horizontal cross section of $1 \mathrm{~m}^{2}$. The upper $z_{1}$ and lower $z_{2}$ vertical limits for each water mass are defined as described in Sect. 2.3. The CTD-data give salinity $S$ as 1 or $2 \mathrm{dbar}$ averages which, with a good approximation $(1 \mathrm{dbar}=0.99 \mathrm{~m})$, equals 1 (2) $\mathrm{m}$ in the upper $1000 \mathrm{dbar}$ and from here on pressure and depth are considered interchangeable.

Similar to the freshwater content, also the heat content is defined as a relative quantity. Here the choice of reference temperature $\theta_{\text {ref }}$ is set to $-1.9^{\circ} \mathrm{C}$, which is slightly below the typical freezing point temperature in the Nansen Basin. The highest surface salinities, roughly 34.2 , are observed in the Nansen Basin and thus the corresponding freezing point temperature, $-1.88^{\circ} \mathrm{C}$, is the lowest. Consequently, the choice of reference temperature yields the heat available for potential ice melt. The reference temperature is kept the same in all the discussed sub-basins although surface salinity, and therefore also the freezing point temperature, have large spatial variability in the Arctic Ocean.

The heat content $Q$ is given by

$Q=c_{p} \int_{z_{1}}^{z_{2}} \rho(z) \delta \theta \mathrm{d} z$,

where the specific heat capacity $c_{p}$ equals $3985 \mathrm{~J} \mathrm{~kg}^{-1} \mathrm{~K}^{-1}$ for seawater at salinity 35 , temperature $\theta=0^{\circ} \mathrm{C}$ and at the surface pressure. The potential density $\rho$ (referenced to 
Table 5. Decadal temperature trends $\left({ }^{\circ} \mathrm{Cdecade}^{-1}\right)$ for period 1991-2011. Linear trends are computed from the anomalies (shown in Figs. $21-$ 30) using least-squares regression. The trends within the standard $95 \%$ level of statistical significance are emphasized.

\begin{tabular}{lrrrrr}
\hline Water mass & Nansen & Amundsen & Makarov & N Canada & S Canada \\
\hline PML & $0.10 \pm 0.06$ & $0.03 \pm 0.01$ & $0.05 \pm 0.03$ & $\mathbf{0 . 3 0} \pm \mathbf{0 . 0 5}$ & $-0.41 \pm 0.19$ \\
UHC & -- & $0.03 \pm 0.04$ & $0.03 \pm 0.01$ & $\mathbf{0 . 1 4} \pm \mathbf{0 . 0 4}$ & $-0.01 \pm 0.05$ \\
LHC & $0.13 \pm 0.10$ & $0.07 \pm 0.07$ & $0.05 \pm 0.04$ & $\mathbf{0 . 1 7} \pm \mathbf{0 . 0 1}$ & $0 \pm 0.02$ \\
AW1 & $0.39 \pm 0.20$ & $-0.02 \pm 0.11$ & $0.09 \pm 0.09$ & $0.13 \pm 0.07$ & $\mathbf{0 . 1 5} \pm \mathbf{0 . 0 4}$ \\
AW2 & $\mathbf{0 . 2 8} \pm \mathbf{0 . 1 0}$ & $0.01 \pm 0.05$ & $\mathbf{0 . 1 0} \pm \mathbf{0 . 0 3}$ & $\mathbf{0 . 0 9} \pm \mathbf{0 . 0 3}$ & $\mathbf{0 . 0 7} \pm \mathbf{0 . 0 2}$ \\
\hline
\end{tabular}

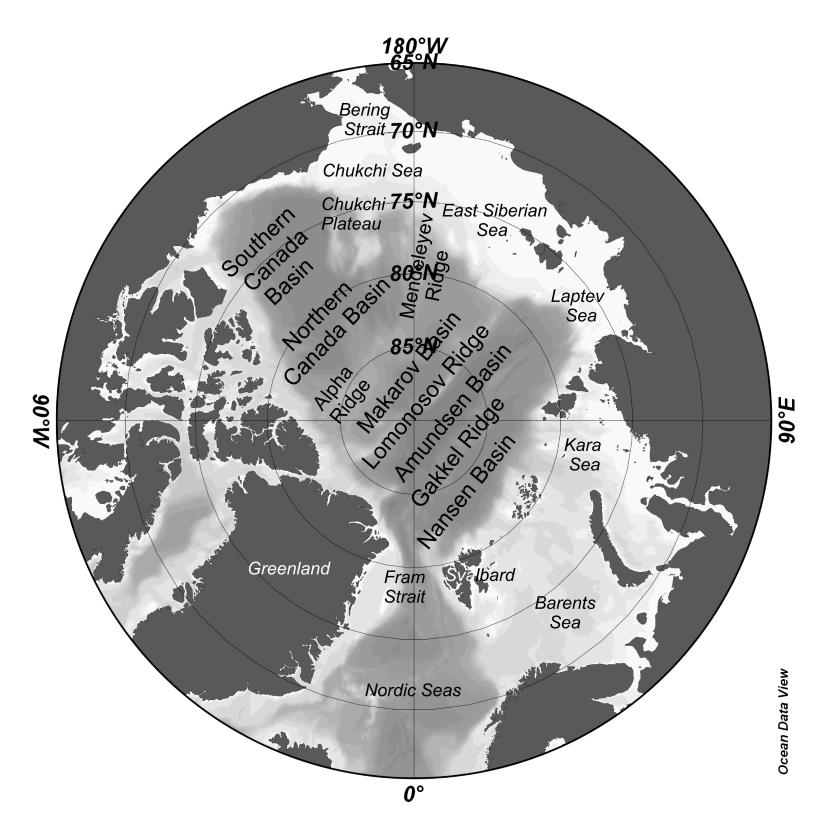

Fig. 2. The sub-basins in the Arctic Ocean and other locations referred to in the text.

surface) is computed from the data acquired from the hydrographic observations. $\delta \theta$ is the difference between $-1.9^{\circ} \mathrm{C}$ and the observed potential temperature.

\subsection{Approach to seasonal ice melt}

Seasonal ice melt has positive influence on freshwater inventory whereas freezing extracts freshwater from the water column (Macdonald et al., 1995). The icebreaker expeditions in the Arctic Ocean are commonly conducted close to the end of the melt season, between July and September, when the seasonal ice melt can add up to $2 \mathrm{~m}$ to the freshwater content. Consequently, the summertime stratification of the upper ocean is much stronger than during winter. Strong stratification limits the heat exchange between surface and deeper layers whereas in winter vertical mixing and haline convection might cause some heat from below to reach the mixed layer and the ice cover. To correctly assess the possible upward oceanic heat transport, knowledge of the stratification in winter, rather than in summer, is needed. Thus, to be able to use the more numerous summer observations for this purpose, the meltwater fraction, which is expected to be refrozen into the sea ice in winter, must be removed from the permanent freshwater content in the Polar Mixed Layer.

During winter, brine rejection induces convection that erodes the summer halocline and homogenizes the vertical temperature structure in the Polar Mixed Layer. Figure 4 illustrates how the structure of the Polar Mixed Layer changes during summer. The seasonal ice melt gradually decreases the salinity from that of winter homogenization and therefore, following Rudels et al. (1996), all salinities less than the salinity at the depth of temperature minimum are assumed to result from melting. Thus meltwater content $M W C$ can be computed in a way similar to the freshwater content, substituting the constant reference salinity $S_{\text {ref }}$ of 34.9 in Eq. (1) with salinity $S_{\mathrm{m}}$ at the depth of temperature minimum. The salinity of the temperature minimum varies spatially and must be determined from each CTD-cast. The freshwater content in the actual Polar Mixed Layer is computed using the chosen reference salinity $S_{\text {ref }}=34.9$ and treating the layer as if it was at a constant salinity $S_{\mathrm{m}}$, the reference salinity determining the meltwater content (Fig. 5).

It should be noted that this method is not able to distinguish river runoff from the actual seasonal ice melt. The river runoff, however, is mixed into the Polar Mixed Layer during winter. Since the river discharge is at largest in late spring and early summer with a peak in June (Serreze et al., 2006), it is unlikely that the river runoff would have reached the locations of most hydrographic stations by the end of summer. To travel the nearly $1000 \mathrm{~km}$ distance in three months flow speeds above $10 \mathrm{~cm} \mathrm{~s}^{-1}$ are required. According to Kwok and Morison (2011) typical current speeds at the Eurasian shelf break are $2 \mathrm{~cm} \mathrm{~s}^{-1}$, at the most $5 \mathrm{~cm} \mathrm{~s}^{-1}$. Only in the Southern Canada Basin do the nearest hydrographic stations lie within the reach of the Mackenzie River discharge and there the seasonal ice melt estimates may incorporate significant amounts of river runoff. Nonetheless, bearing in mind the general difficulties and uncertainties in determining the seasonal melt rate from measurements of ice extent and thickness, estimating changes in salinity, by looking directly at the added freshwater, can provide a valuable alternative. Moreover, un- 

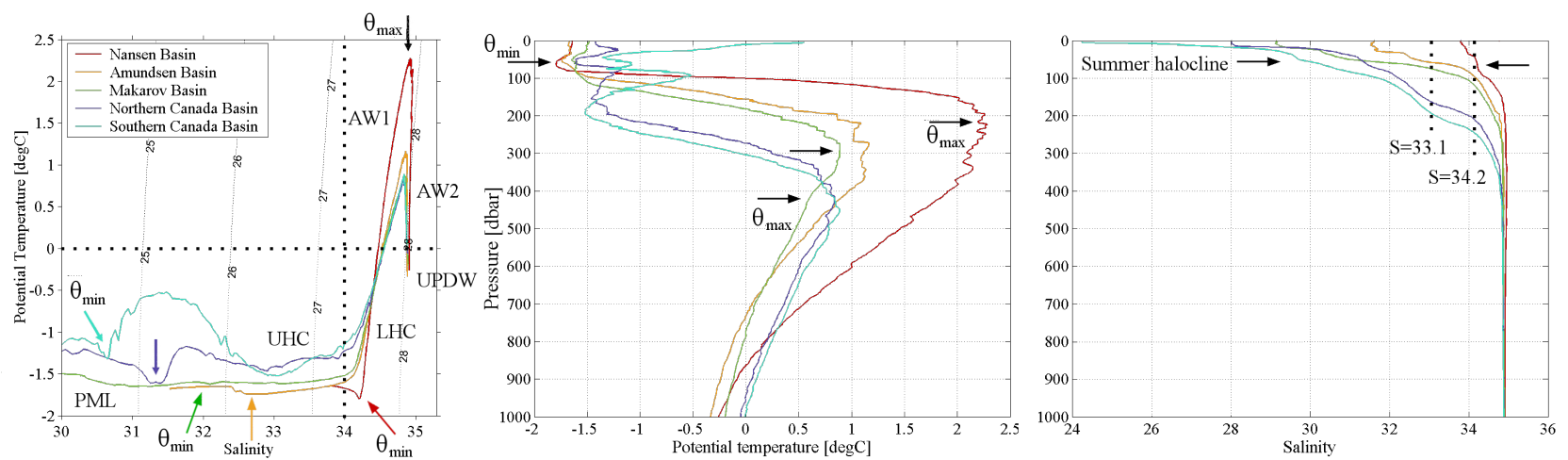

Fig. 3. The $\theta S$-diagram as well as the potential temperature and salinity profiles showing the definitions of water masses (PML-Polar Mixed Layer, UHC - upper halocline, LHC - lower halocline, AW1 - upper Atlantic Water, AW2 - lower Atlantic Water, UPDW - upper Polar Deep Water). The coloured arrows in the $\theta S$-diagram show the temperature minimum for each cast, the black arrow marks the temperature maxima. For the temperature profiles an approximate depth of the temperature minima is indicated with black arrow; the respective depth of the summer halocline, formed by the seasonal ice melt, is indicated for the salinity profiles. The salinities 33.1 and 34.2 indicate the mean salinities of the upper and lower haloclines, respectively.

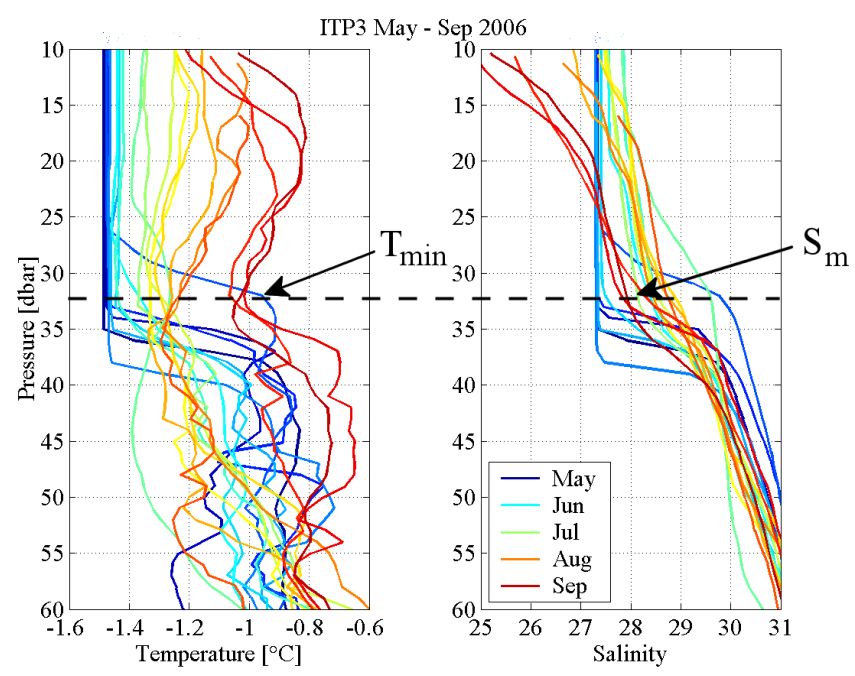

Fig. 4. Temperature and salinity evolution during the melt season. The data is recorded by ITP3 circulating in the Canada Basin from May (blue) until September (red) 2006. The dashed line indicates the estimated average depth of the winter convection from the casts recorded in May. In this case the temperature minimum $\left(T_{\min }\right)$ observed in September is found at the same depth although its temperature and salinity $\left(S_{\mathrm{m}}\right)$ have increased significantly during the summer.

like the oxygen isotope method, this method yields the local, seasonal, ice melt, and does not include meltwater, or brine, advected from the shelves.

To validate the method used to distinguish meltwater from the freshwater content in the Polar Mixed Layer, the meltwater content estimated from hydrographic data is compared to the heat input during melt season. The heat input is provided by NCEP-NCAR and ERA-Interim reanalyses
(Kalnay et al., 1996; Dee et al., 2011). The surface fluxes include the net short wave radiation $q_{\mathrm{sw}}$, the net longwave radiation $q_{1 \mathrm{w}}$ as well as the sensible $q_{\mathrm{s}}$ and latent $q_{1}$ heat fluxes (all quantities given in $\mathrm{W} \mathrm{m}^{-2}$ ). From the NCEP-NCAR Reanalysis project daily mean values of surface fluxes are used. From the ERA-Interim Reanalysis project cumulative fluxes at the air-sea interface with $12 \mathrm{~h}$ time step are used. Although the ERA-Interim is known to perform better especially in the high latitudes (Jakobson et al., 2012), the large errors involved with all reanalysed products should be kept in mind.

The cumulative heat flux $q$ is integrated (Eq. 3) from the end of May (150th calendar day) to late August (240th calendar day).

$q=\int_{150}^{240}\left(q_{\mathrm{sw}}+q_{\mathrm{lw}}+q_{\mathrm{s}}+q_{1}\right) \mathrm{d} t$

The start of the integration is chosen well after the beginning of the actual polar day in late March, since the ice is not initially at freezing point temperature and is required to warm up before the melt begins. The chosen date is still a couple of weeks in advance of that observed by Rigor et al. (2000) and Perovich et al. (2003) who reported that the surface melt did not begin until mid-June. The integration also terminates some weeks prior to the end of melt season. However, the early closing date for the integration is determined by the timing of the ship-based CTD surveys, generally conducted in late August or early September (Table 1).

Spatial integration of heat input is approximated within the area enclosing the hydrographic stations marked in Fig. 1. For each studied sub-domain the average heat input $\left(\mathrm{J} \mathrm{m}^{-2}\right)$ is computed over a constant area regardless of the interannual variability in the locations of ship-based CTD casts. This is not considered to cause critical error since the onset of melt 

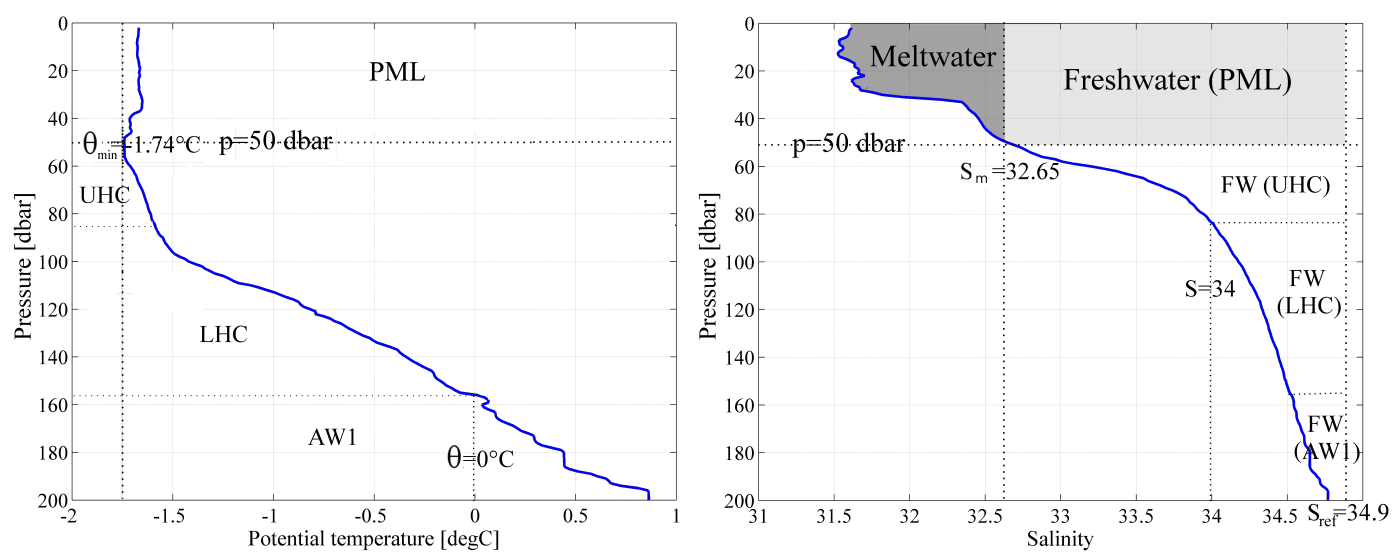

Fig. 5. The temperature and salinity profiles illustrating the integrated (Eq. 1) freshwater content in separate water masses. The meltwater content (dark grey) is distinguished from the freshwater content (light grey) in the Polar Mixed Layer (PML) by the salinity $S_{\mathrm{m}}$ at the depth of temperature minimum $\Theta_{\min }$.

and freeze-up occur simultaneously over large (hundreds of kilometres) length scales (Rigor et al., 2000).

Assuming that all the heat received between June and August is consumed in the melting process and no heat is needed to warm the ice or is transmitted through the ice into the upper ocean, the heat input $q$ computed in Eq. (3) is further converted into the maximum possible ice melt in metres, $M W C$, in a water column with horizontal cross section $1 \mathrm{~m}^{-2}$ by

$\mathrm{MWC}=\frac{q}{L_{\mathrm{ice}} \cdot \rho}$,

where $L_{\text {ice }}=333.15 \mathrm{~kJ} \mathrm{~kg}^{-1}$ is the latent heat of ice and $\rho$ is density of water. The density of water is used instead of the density of ice to give the height of a liquid water column which is comparable to the hydrographic meltwater estimate given by Eq. (1). This assumption does not take into account the possible oceanic heat flux. However, the presence of the temperature minimum at the base of the Polar Mixed Layer (Fig. 4) indicates that the heat flux from underlying layers is negligible during summer.

\subsection{Caveats in data analysis}

\subsubsection{Definition of temperature minimum}

Compared to the present-day well-calibrated instruments, the subjective choice of temperature minimum represents a considerably larger uncertainty than the measurement inaccuracies, typical errors for temperature and salinity being $0.001{ }^{\circ} \mathrm{C}$ and 0.002 , respectively. Already in Fig. 4 the ambiguity in defining the temperature minimum is encountered. Compared to the casts obtained in the central parts of the sub-basins, identification of the temperature minimum becomes even more complicated when approaching the rim of the Canada Basin. Close to the Chukchi Sea, Alaskan Coastal Water and Bering Sea Summer Water deliver warm water directly beneath the Polar Mixed Layer and may occasionally lift the temperature minimum from its original position closer to the surface.

Another local feature in the Canada Basin, particularly in the areas with strong seasonal ice melt such as the Chukchi Sea and Southern Beaufort Sea, is the near-surface temperature maximum resulting from radiative warming of surface waters during summer. Because of increased stability near the surface, the temperature minimum indicating the depth of winter convection is located between the near-surface temperature maximum, usually with salinity below 30 or 31 and located around depth 20-35 m (Shimada et al., 2001; Jackson et al., 2010) and the temperature maximum originating from the ACW $(S \sim 31.5)$ or BSSW $(S \sim 32.5)$ at the depth 40-70 m (Fig. 3).

The difficulties in unambiguously detecting the temperature minimum are also encountered in the climatological data. Although the vertical resolution of the climatology is at the highest in the upper ocean, it is not sufficient to resolve the details of the Polar Mixed Layer. Since the choice of temperature minimum influences the thickness of the Polar Mixed Layer and the upper halocline, anomalies in the properties of these two water masses can be under- or overestimated.

Based on examination of the year round data obtained by several ITPs (Ice-Tethered Profilers, Krishfield et al., 2008), the diffusion of heat from below appears to shift the temperature minimum upward. However, in the Canada Basin where most ITP measurements are obtained, the diffusion of heat is often overcome by the downwelling driven by Ekman convergence. In Fig. 4, the depth of temperature minimum found in the end of the melt season corresponds well to the depth of winter convection during previous winter in spite of the substantial warming.

Figure 4 also demonstrates that the diffusion of salt from below is considerable. Since the reference salinity for 
Thickness of the Polar Mixed Layer
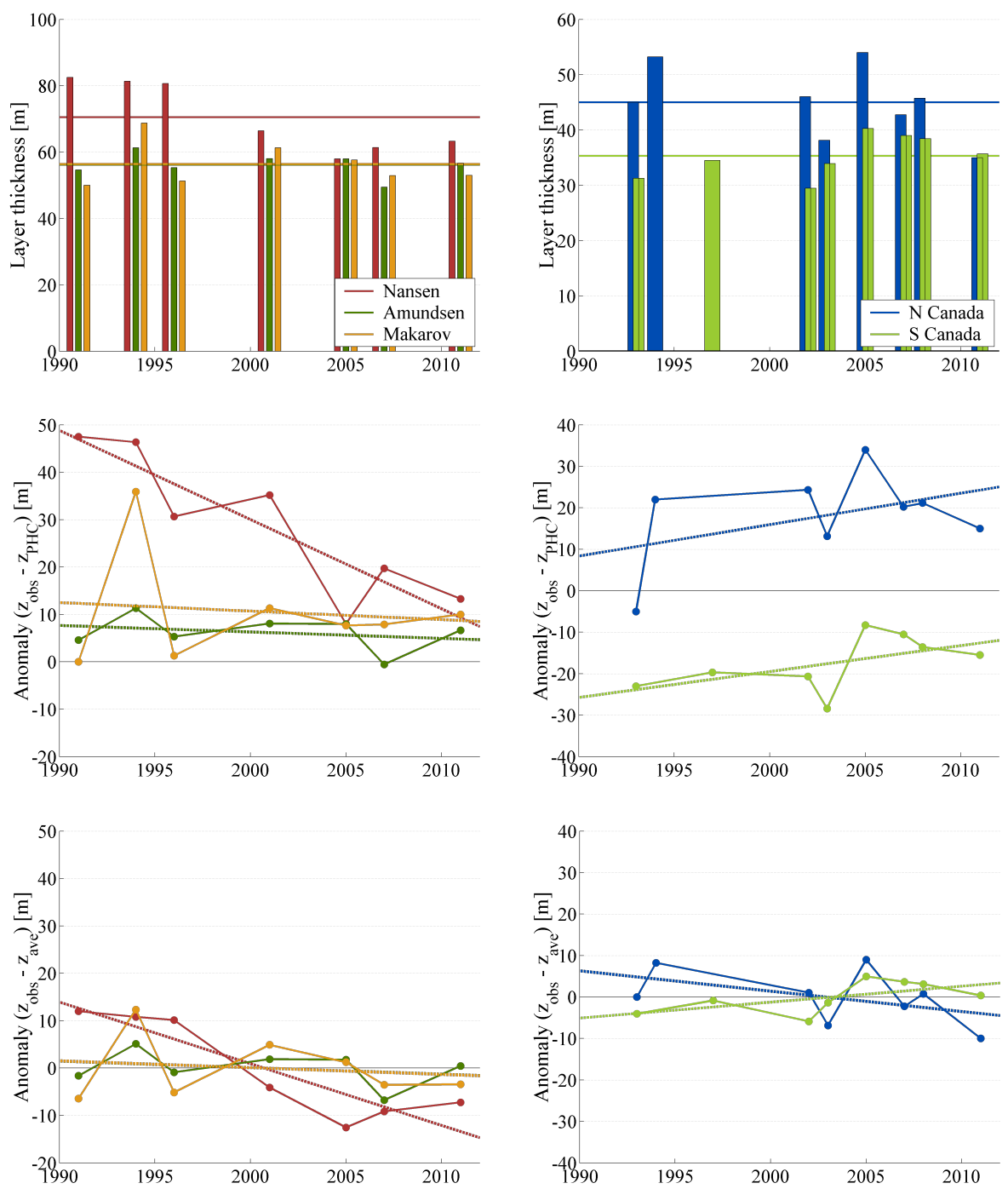

Fig. 6. The bars in the upper panel show the observed thickness of the Polar Mixed Layer (note different scales for the Eurasian and Canada basins). The horizontal lines denote the $20 \mathrm{yr}$ average obtained from the observations. The middle panel shows the anomalies of the observations from the PHC climatology. By computing the linear trend (dashed lines) from these anomalies, the offset resulting from spatial variability is removed. The quantified linear trends are found in Table 3. To enable better comparison between the observations (upper panel) and the anomalies from climatology (middle panel), the lower panel demonstrates anomalies of the observations from the average computed from the observations (both shown in the upper panel) with the same scale as the anomalies from climatology. The effect of the spatial variability within the basin (the offset) can be estimated by comparing the trends, or the shape of the curve, in the middle and lower panels.

meltwater $\left(S_{\mathrm{m}}\right)$ is defined as the salinity at the depth of temperature minimum, the increase in $S_{\mathrm{m}}$ increases the meltwater and decreases the freshwater content in the Polar Mixed Layer. Examination of the ITPs implied that an average increase in $S_{\mathrm{m}}$ was up to $1 \mathrm{ppt}$. This could add up to $30 \%$ to the meltwater estimates.

\subsubsection{Extrapolation of data}

Because the varying conventions regarding the upper limit of CTD casts, the uppermost observations are sometimes obtained as deep as 10 dbar. Thereby, for better comparison, salinity and temperature are extrapolated as constant up to the surface from the value at 10 dbar regardless of the data quality near the surface. Generally the upper 10-15 dbar are fairly well homogenised by mechanical mixing, possibly caused by ship thrusters, and the error resulting from the extrapolation is negligible. In the Nansen Basin, where the vertical salinity gradient is weak close to the surface (see e.g. Fig. 3), the typical underestimation amounts to $1-2 \mathrm{~cm}$ of meltwater. This is generally the case also in the less saline 
Thickness of the upper halocline
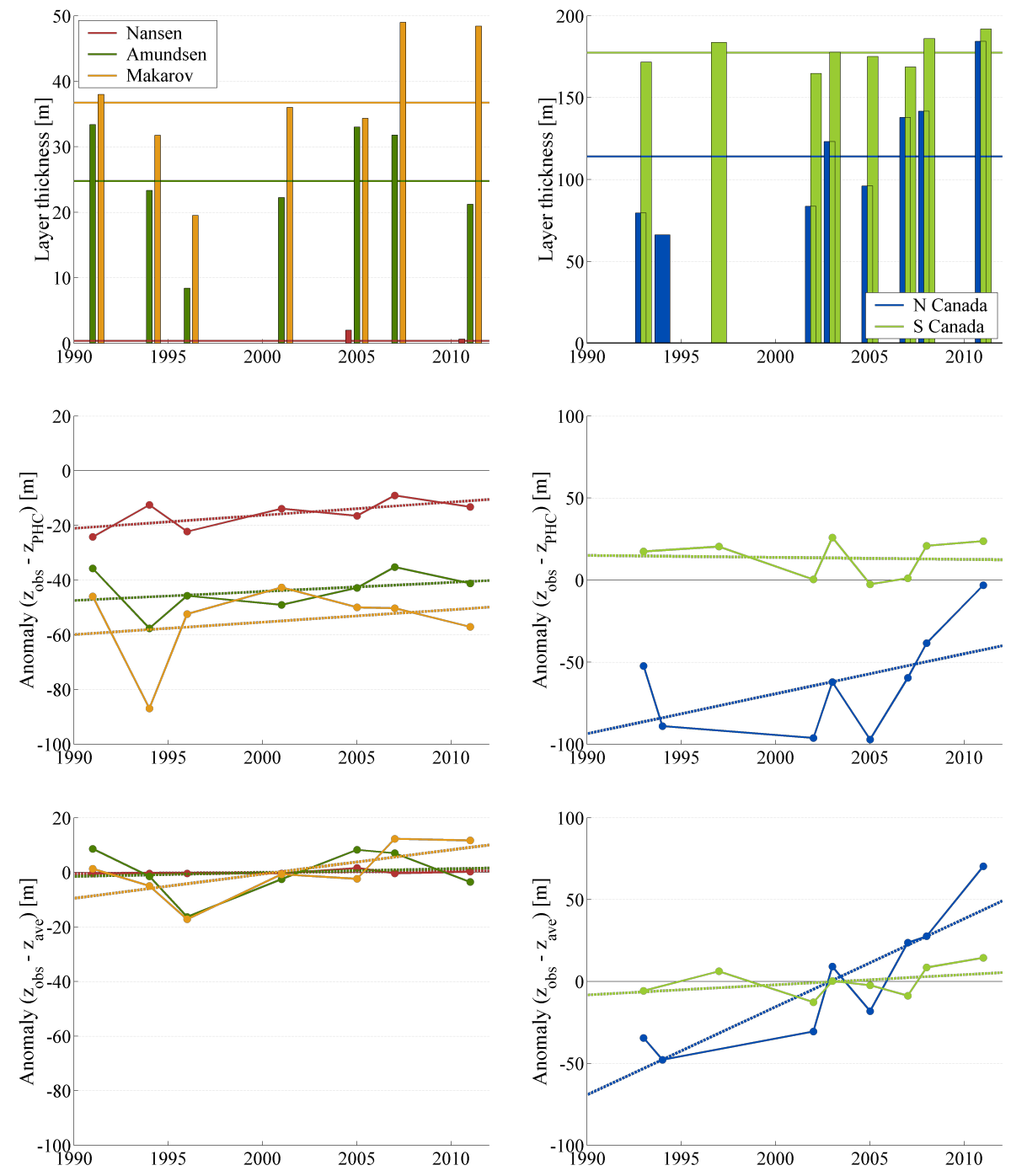

Fig. 7. The same as Fig. 6 but for the upper halocline.

Canada Basin. However, the findings of this study suggest that the recent freshening and warming add to the surface stability and no clear summer mixed layer is necessarily present at the time of observations: during 2008 on average $10-20 \mathrm{~cm}$ of meltwater is not included in the estimate due to the extrapolation.

\subsubsection{Temporal and spatial restrictions of hydrographic observations}

The oceanographic observations obtained by icebreakers are biased towards waters with low ambient ice concentration, possibly implying higher than average ice melt. On the other hand, part of the meltwater is out of reach of the oceanographic observations because of basal melting beneath the thicker ice floes and the large melt ponds on top of the sea ice.

When the melt season is close to its end, the melt water on top of the ice floes has a high probability to be released to the ocean and hence increase, perhaps dramatically, the meltwater content in a short time. Thus, although all the icebreaker expeditions are conducted towards the end of the melt season, July-September, a two month difference between observations can have a significant effect on the estimated seasonal ice melt.

\section{Results}

\subsection{Water mass analysis}

Because the freshwater and heat contents as well as the water masses are defined with salinity and temperature, the freshwater and heat contents are prone to reflect the shift in the 
Thickness of the lower halocline
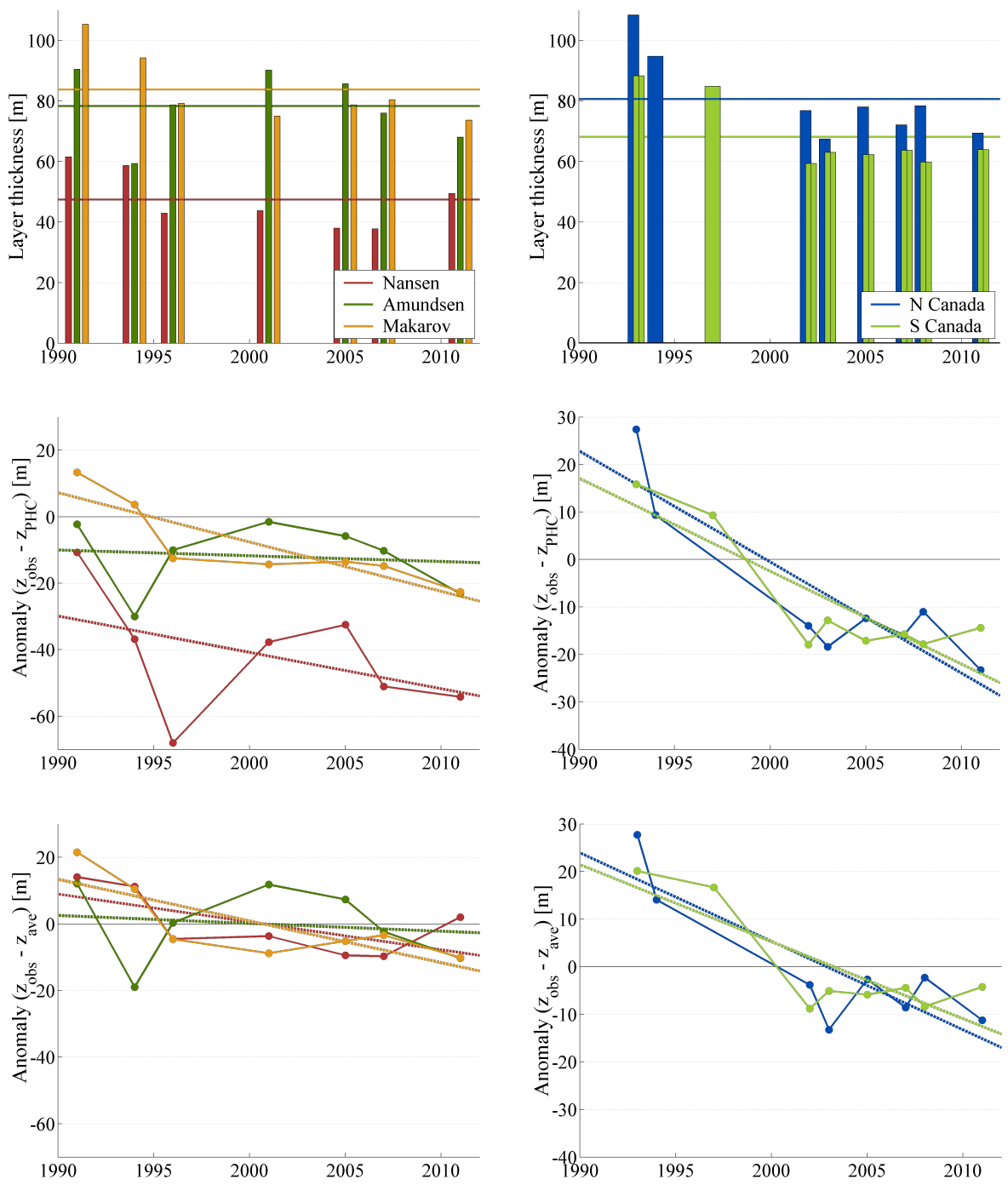

Fig. 8. The same as Fig. 6 but for the lower halocline.

depth of isolines. Therefore, it is essential first to address how the volumes of the different water masses vary in time and space.

The changes in thickness, freshwater and heat content for the different basins and the different water masses are shown in Figs. 6 to 30. These figures provide the main results of this study. Each variable is presented in three parts. The upper part presents both the mean and the variations in thickness, salinity/freshwater content and temperature/heat content of the water mass. The middle part gives the anomalies between the icebreaker observations (shown in the upper part) and the climatology. The middle part also shows trends based on the anomalies. These linear approximations are quantified with uncertainty estimates in Tables 3 to 5. In order to compare the temporal variability shown in the upper and middle panels, the lower panel presents the anomalies from the upper panel with the same scale as the middle panel. The anomalies in the lower panel are simply the deviation of the observational mean from the 20-year-average in the basin (both shown in the upper panel). Thus, from the middle and lower panels, it is possible to judge how well the changes in the entire basin conform to those given by the anomalies. Furthermore, comparing the middle and lower panels, it is possible to assess the offset resulting from the random locations of the hydrographic casts since the offset is removed from the middle panel and still present in the lower panel.

\subsubsection{The Polar Mixed Layer}

The Polar Mixed Layer is generally thickest in the Nansen Basin, $80 \mathrm{~m}$ in the 1990s (Fig. 6, upper panel). However, the Polar Mixed Layer has been thinning at the rate of 
Thickness of the upper Atlantic Water
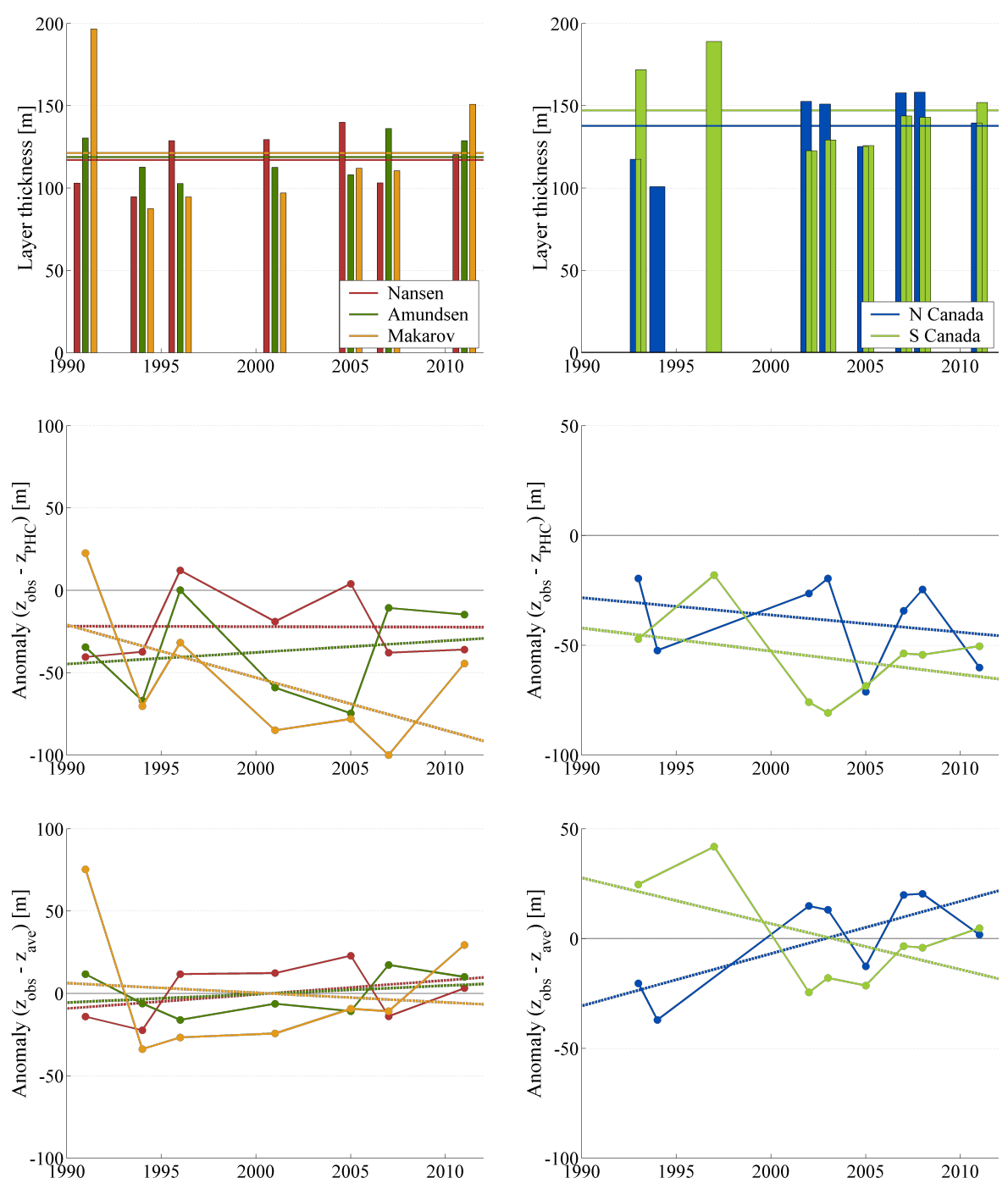

Fig. 9. The same as Fig. 6 but for the upper Atlantic Water.

nearly $20 \mathrm{~m} \mathrm{decade}^{-1}$ (Table 3 ) and its thickness has decreased close to $60 \mathrm{~m}$. In the Amundsen and Makarov basins, the average winter convection fluctuates around $55 \mathrm{~m}$. In the Canada Basin, the large freshwater input adds to the buoyancy and limits the average depth of winter convection to $45 \mathrm{~m}$ in the northern and to $35 \mathrm{~m}$ in the southern part.

It should be noted here that the coarse vertical resolution in the climatology causes large error in estimating the depth of the temperature minimum. According to climatology, the average depth of the temperature minimum in the Nansen Basin is located between 40 and $50 \mathrm{~m}$ whereas in the Southern Canada Basin the climatology indicates deeper temperature minimum, between 50 and $60 \mathrm{~m}$. In both cases the difference to the observations is $20-30 \mathrm{~m}$. Corresponding error is seen in the thickness of the upper halocline. For example, the shallower temperature minimum in the Nansen Basin results in a 20 m-thick upper halocline, although the upper halocline is known to be generally absent in the Nansen Basin (Figs. 6 and 7, middle panels). Consequently, the anomalies in thickness will influence the freshwater and heat content anomalies discussed later.

\subsubsection{The halocline waters}

The most substantial geographic disparities of water masses in the Arctic Ocean derive from the different properties of the inflowing Atlantic and Pacific waters. This is especially evident for the upper halocline. Because the upper halocline largely derives from the Pacific waters, its thickness in the Southern Canada Basin reaches $180 \mathrm{~m}$ (Fig. 7, upper panel). Even in the Northern Canada Basin the average thickness of the upper halocline is close to $120 \mathrm{~m}$. In the Makarov Basin, 
Thickness of the lower Atlantic Water
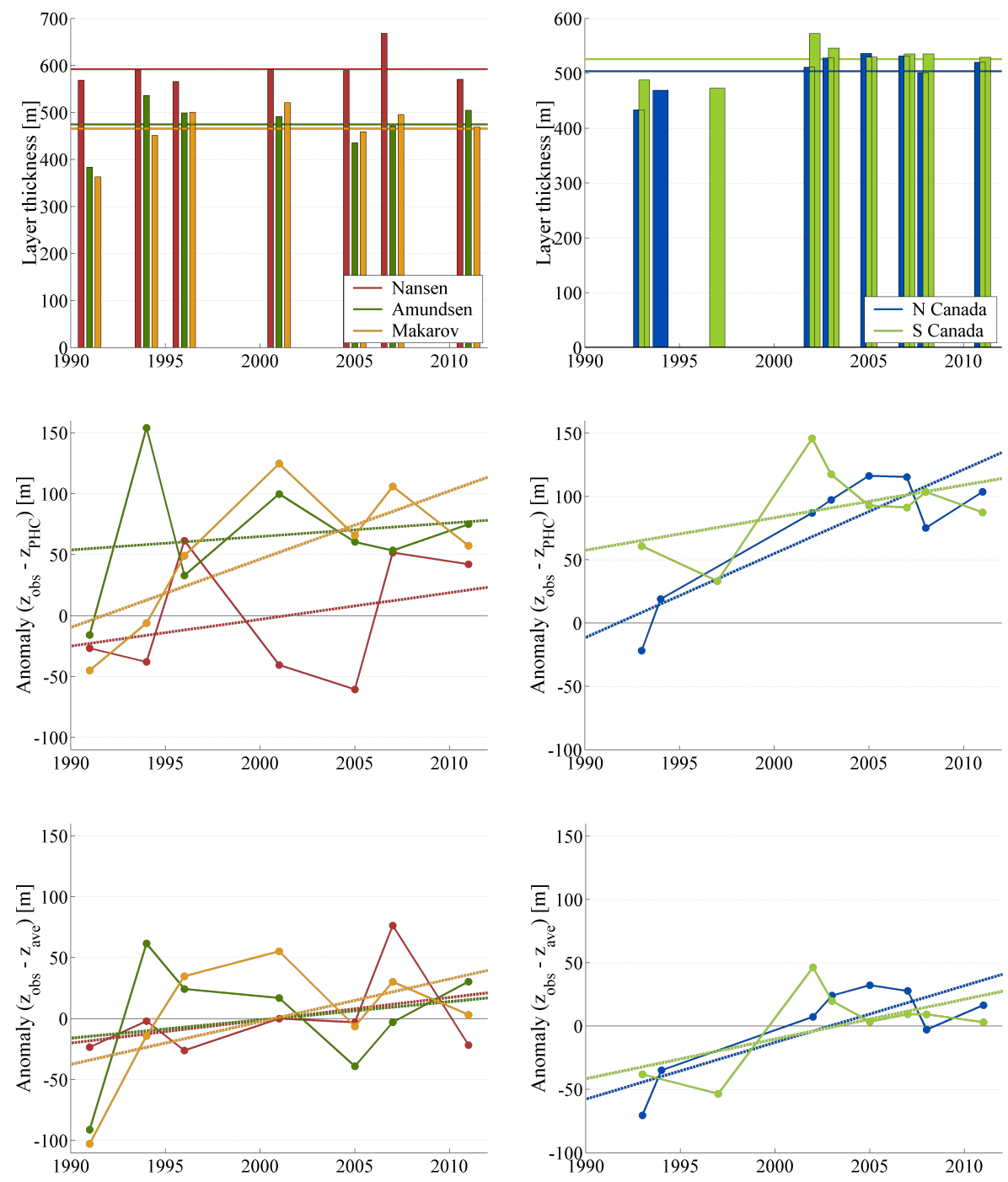

Fig. 10. The same as Fig. 6 but for the lower Atlantic Water.

where the upper halocline waters mainly derive from the Siberian shelves, the thickness reduces below $40 \mathrm{~m}$ and in the Amundsen Basin to less than $30 \mathrm{~m}$. In the Nansen Basin the upper halocline is generally absent. Also the lower halocline is at the thinnest, below $50 \mathrm{~m}$, in the Nansen Basin (Fig. 8). The thickness of the lower halocline is largest in the Amundsen, Makarov and Northern Canada basins where it occupies $80 \mathrm{~m}$ of the water column. In the southern Canada Basin the LHC thickness decreases close to $60 \mathrm{~m}$.

During the first half of the 1990s, both the upper and lower haloclines weakened considerably in the Amundsen and Makarov basins. The thickness was reduced by roughly $20 \mathrm{~m}$ in both layers, which amounts approximately to half of the upper and 1/5 of the lower halocline volume. However, the data from 1996 and 2001 have quite poor coverage in the Makarov Basin (Table 1) being concentrated close to the Lomonosov Ridge (Fig. 1) and thus the magnitude of the reduction may not be representative for the entire basin. By 2007, the upper halocline in both the Amundsen and Makarov basins had rebounded to its state in the early 1990s.

A more substantial thickening of the upper halocline is occurring in the northern parts of the Canada Basin (Fig. 7, middle panel). Although the sparse data sets from the 1990s do not provide a reliable baseline, merely the increase during the 2000s is remarkable. The thickness of the upper halocline increases from roughly $100 \mathrm{~m}$ in the early 2000 s to more than $180 \mathrm{~m}$ in 2011. It should be noted here that while the increase in the upper halocline thickness occurs during the 2000s, the reduction in the thickness of the lower halocline takes place between the 1990s and 2000s and remains constant during the 2000s (Fig. 8, middle panel). Thus, the thinning of the lower halocline does not coincide with the thickening of the 
Salinity / freshwater content of the upper halocline
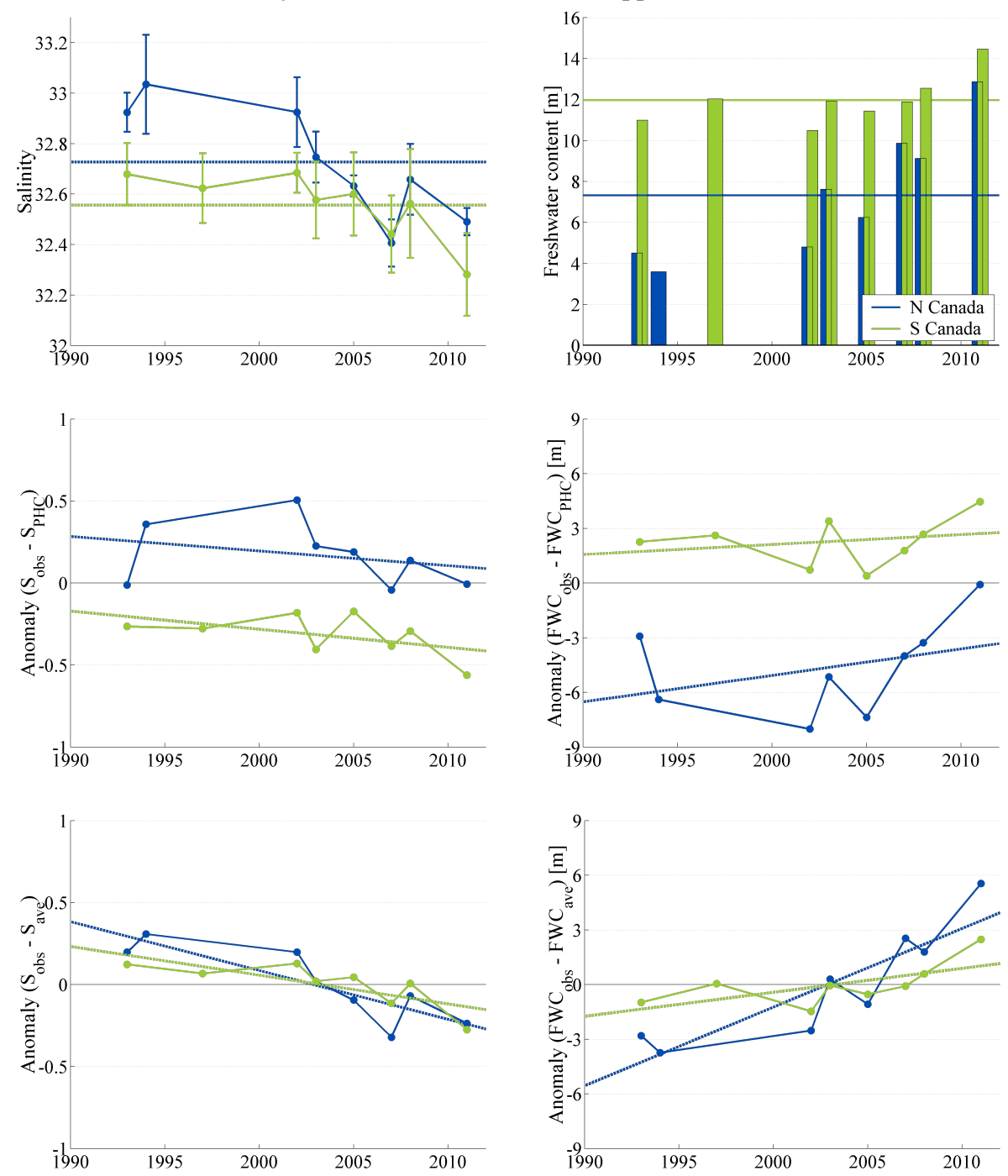

Fig. 11. The bars in the upper panel show the observed mean salinity with standard deviation (left) and freshwater content (right) of the upper halocline in the Canada Basin. The horizontal lines denote the $20 \mathrm{yr}$ average obtained from the observations. The middle panel shows the anomalies of the observations from the PHC climatology. By computing the linear trend (dashed lines) from these anomalies, the offset resulting from spatial variability is removed. The quantified linear trends are found in Table 4. To enable better comparison between the observations (upper panel) and the anomalies from climatology (middle panel), the lower panel demonstrates anomalies of the observations from the average computed from the observations (both shown in the upper panel) with the same scale as the anomalies from climatology. The effect of the spatial variability within the basin (the offset) can be estimated by comparing the trends, or the shape of the curve, in the middle and lower panels.

upper halocline. Moreover, the magnitude and significance of the reduction of the lower halocline thickness presented in Table 3 should be considered together with the disparities in the location of hydrographic stations between the two decades.

\subsubsection{The Atlantic Water}

The Atlantic layer is thickest in the Nansen Basin, where it covers $700 \mathrm{~m}$ of the water column (upper panels in Figs. 9 and 10). The temperature maximum divides the Atlantic Water into the 130 m-thick upper Atlantic Water (AW1) and the 600 m-thick lower Atlantic Water (AW2). In the Amundsen and Makarov basins, the thickness of the lower layer is reduced by $150 \mathrm{~m}$ whereas the upper layer maintains its thickness. The reduction in AW2 beyond the Gakkel Ridge is compensated by the colder upper Polar Deep Water, which extends higher in the water column and thus displaces the lower zero-isotherm upward. 
Salinity / freshwater content of the upper halocline
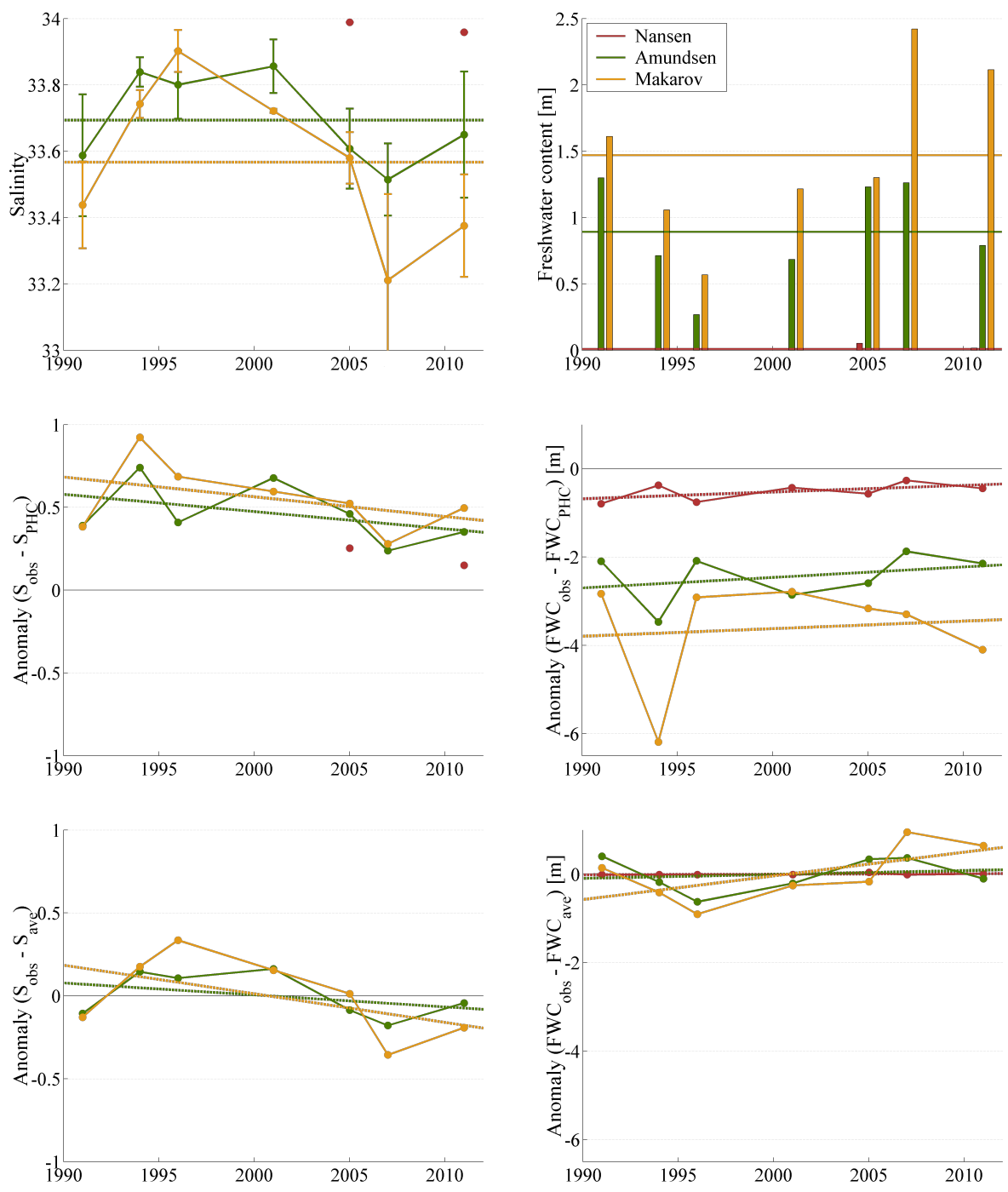

Fig. 12. The same as Fig. 11 but for the upper halocline in the Eurasian Basin.

In the Canada Basin, the Atlantic layer is submerged below the Pacific waters and the lower zero-isotherm is sometimes located deeper than $1000 \mathrm{~m}$. Nonetheless, the total thickness of the Atlantic layer is nearly the same as in the Nansen Basin. While the thickness of AW1 increases to 140$150 \mathrm{~m}, \mathrm{AW} 2$ is thinner, $500 \mathrm{~m}$, than in the Nansen Basin. The increase in AW1 thickness, and the corresponding thinning of AW2, is likely to result from a weakening and downward displacement of the temperature maximum. The cooling of the temperature maximum could be due to the incorporation of colder shelf waters (e.g. Rudels, 1986).

Overall, time variability in the thickness of the Atlantic Water is related primarily to the vertical displacement of the temperature maximum dividing the Atlantic Water into upper and lower layers. This is best seen in the Makarov Basin where the thinning of the upper Atlantic layer by $90 \mathrm{~m}$ be- tween 1991 and 2001 is accompanied by $170 \mathrm{~m}$ thickening of the lower Atlantic layer (middle panels in Figs. 9 and 10). After 2001 the trend reverses and the thickness is slightly increasing in the upper and decreasing in the lower Atlantic layer. Similar but weaker trends are observed in the Amundsen Basin. In the Nansen Basin trends appear opposite to those in the Makarov and Amundsen basins: the maximum thickness of AW1 and minimum of AW2 are reached in the early 2000s.

\subsection{Freshwater content}

\subsubsection{Space variability}

One of the most prominent features in the Arctic Ocean is the presence of a strong horizontal salinity gradient between the Eurasian and Amerasian basins (Aagaard and Carmack, 
Salinity / freshwater content of the Polar Mixed Layer
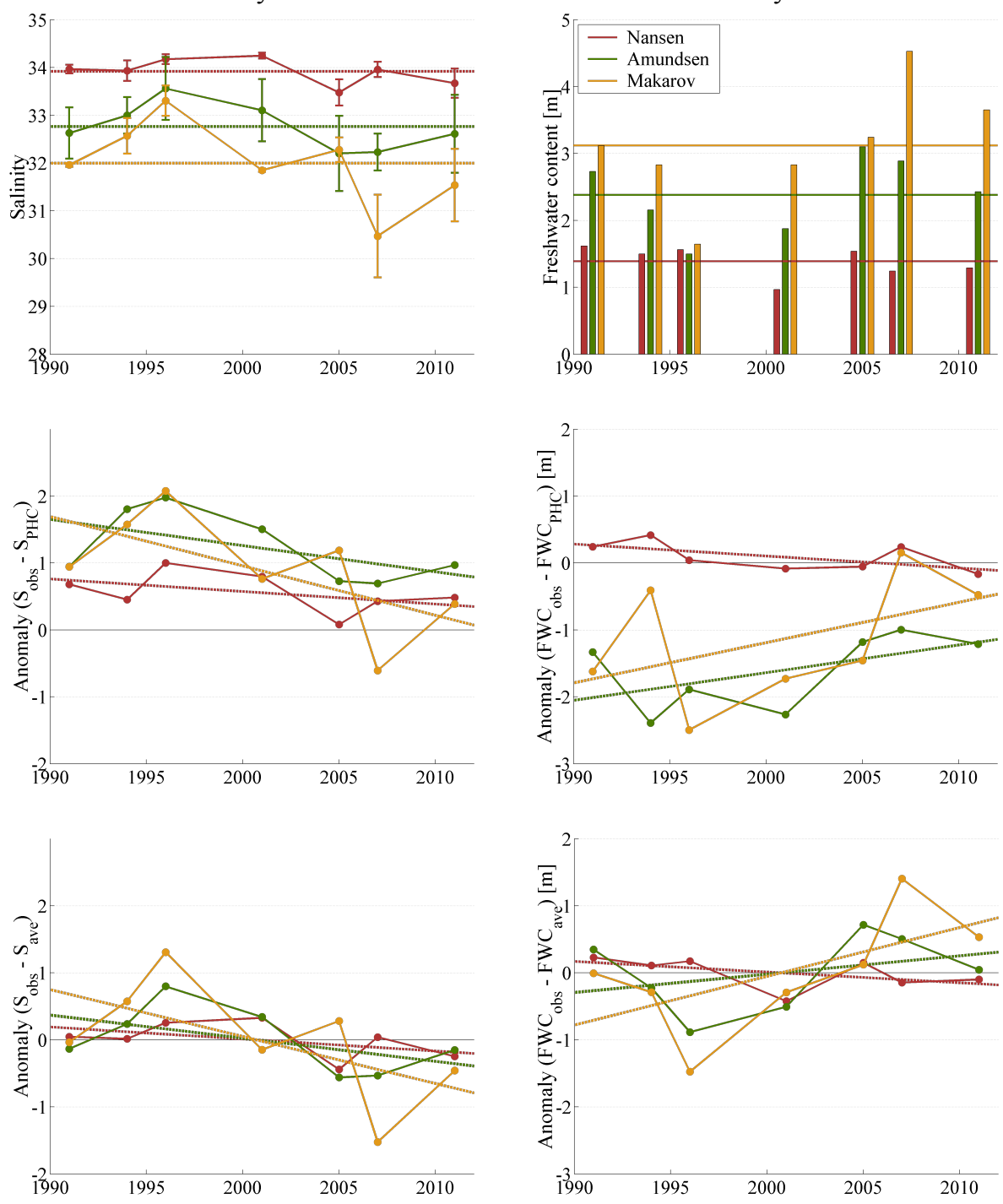

Fig. 13. The same as Fig. 11 but for the Polar Mixed Layer in the Eurasian Basin.

1989). The unequally distributed freshwater results mainly from the different properties of inflowing Atlantic and Pacific waters (Jones et al., 2008). The salinity variability is, by definition, reflected in the freshwater content. The total freshwater content (relative to salinity 34.9 ) varies from roughly $3 \mathrm{~m}$ in the Nansen Basin to $20 \mathrm{~m}$ in the Southern Canada Basin (Fig. 31). The most substantial increase occurs between the Makarov Basin and the Northern Canada Basin.

The horizontal variability is strongest in the upper halocline where freshwater content decreases rapidly with increasing distance from the Bering Strait (upper panels in Figs. 11 and 12). In the Canada Basin, the upper halocline stands out as the largest freshwater reservoir, containing plausibly more than half of the local freshwater content, $12 \mathrm{~m}$ in the southern and 7-8 $\mathrm{m}$ in the Northern Canada Basin. In the Makarov Basin, the upper halocline freshwater content is only 1-2 m (Fig. 12) and the Polar Mixed Layer becomes the main storage for freshwater with $3 \mathrm{~m}$ of freshwater (Fig. 13). However, regardless of the thickening of the Polar Mixed Layer, the freshwater content in the PML decreases from $5 \mathrm{~m}$ in the Canada Basin (Fig. 14) to $1.5 \mathrm{~m}$ in the Nansen Basin (Fig. 13) due to the increasing surface salinity. In the lower halocline the horizontal variability of salinity is small and the freshwater content reflects primarily changes in layer thickness. The lower halocline is the thickest in the Makarov Basin (Fig. 8) and thus its freshwater content largest (upper panels in Figs. 15 and 16). The freshwater content decreases with thickness and is lowest in the Nansen and Southern Canada basins.

In the deeper, Atlantic, layers, the largest difference is between the Nansen Basin and the other basins. Despite the large volume of the Atlantic Water, its freshwater content 
Salinity / freshwater content of the Polar Mixed Layer
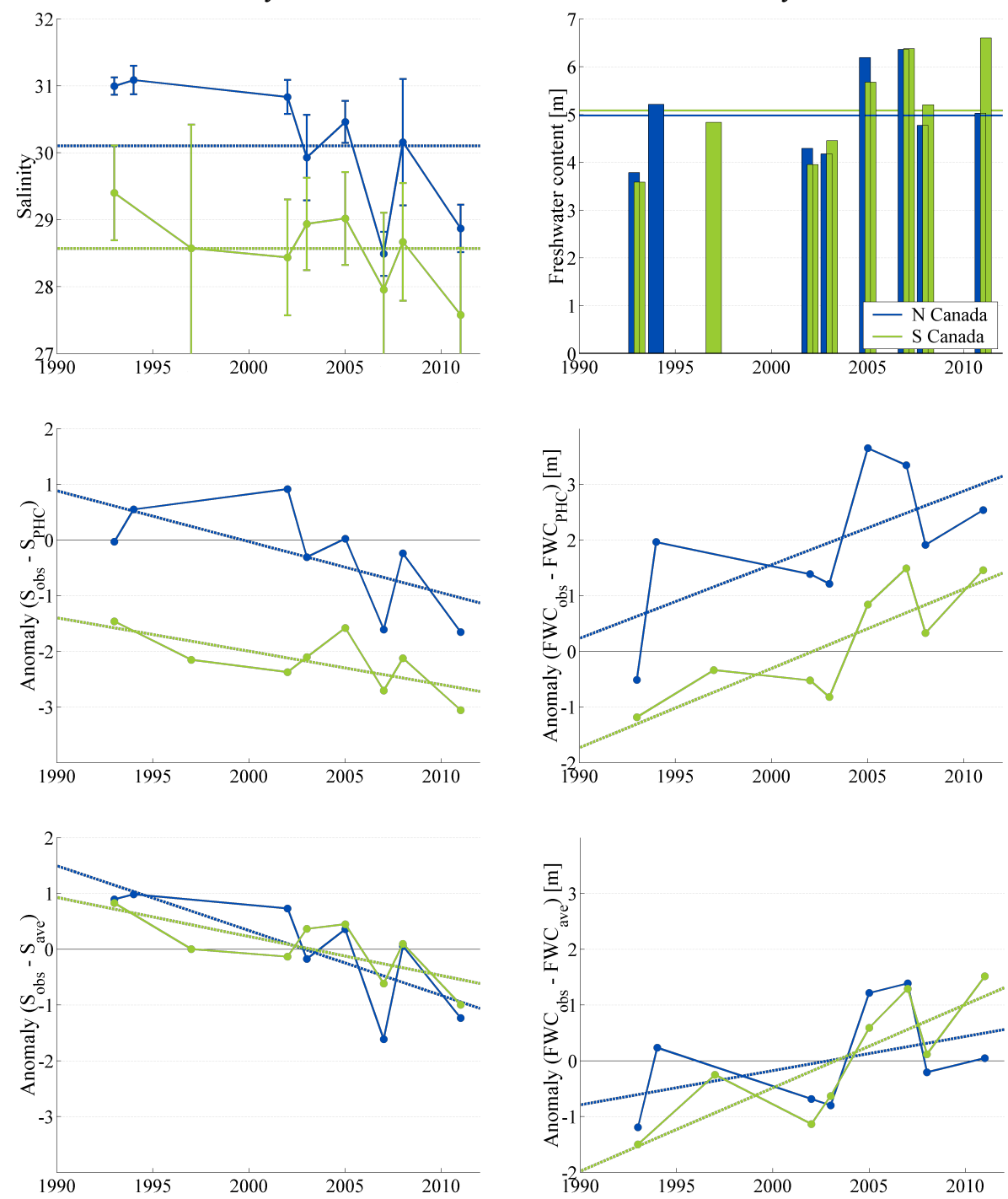

Fig. 14. The same as Fig. 11 but for the Polar Mixed Layer in the Canada Basin.

remains low due to the high salinities. However, especially in the deep Atlantic layer, AW2, the freshwater content shows a remarkable variability between the basins. The most striking feature is the clearly negative freshwater content, on average $-0.3 \mathrm{~m}$, in the Nansen Basin (Fig. 17). In the Amundsen Basin, decrease in salinity by $0.04 \mathrm{ppt}$ increases the freshwater content to $0.3 \mathrm{~m}$ in spite of the concurrent decrease in the layer thickness. In the Canada Basin, the freshwater content in AW2 further increases to $0.6 \mathrm{~m}$ (Fig. 18). In AW1 the horizontal differences are not as large and the initial salinity decrease between the Nansen and Amundsen basins is only 0.02 ppt. Nevertheless, even the modest salinity decrease and the deepening of temperature maximum, resulting in increasing layer thickness, nearly double the freshwater content from the $0.35 \mathrm{~m}$ in the Nansen Basin (Fig. 19) to $0.6 \mathrm{~m}$ in the Canada Basin (Fig. 20).

\subsubsection{Time variability}

The strongest time variability of the freshwater content occurs in the two uppermost water masses. The first half of the 1990s is characterized by increasing salinity in the Nansen, Amundsen and Makarov basins. Between 1991 and 1996, the freshwater inventory in the Polar Mixed Layer of the Amundsen and Makarov basins reduces by nearly $1 \mathrm{~m}$ corresponding to the $1 \mathrm{ppt}$ increase in salinity (Fig. 13, middle panel). In the upper halocline, the maximum salinity anomaly is reached in 1994, although the observations suggest that salinification continued until 1996 when salinity increased from 33.6 to 33.8 in the Amundsen and from 33.4 to 33.9 in the Makarov basin (Fig. 12, middle panel). Both the salinification and the thinning of the upper halocline contributed to the decrease in freshwater content. 
Salinity / freshwater content of the lower halocline
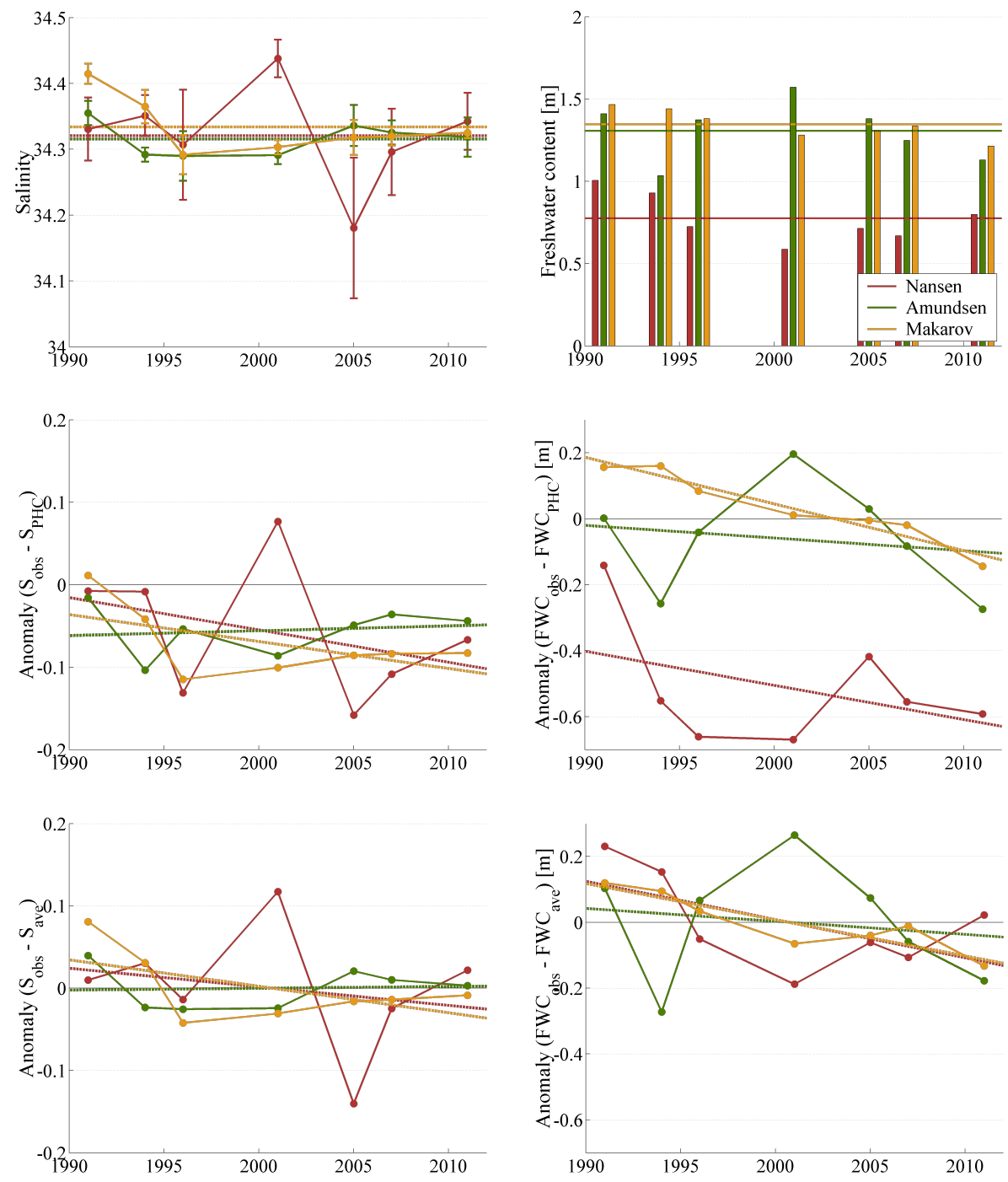

Fig. 15. The same as Fig. 11 but for the lower halocline in the Eurasian Basin.

After the rapid salinification during the first half of the 1990s, a slow freshening takes place. In the Amundsen and Makarov basins, the minimum salinities and the lowest salinity anomalies in the Polar Mixed Layer and in the upper halocline are reached in 2007. In the Nansen Basin, the decrease is more modest. However, a thin upper halocline appears in the Nansen Basin in 2005 and 2011, indicating possible freshening of the upper layers. Also the reduced depth of the winter convection, resulting in decrease in the Polar Mixed Layer thickness (Fig. 6), is likely to result from the decreased surface salinity and consequently increased stratification. The most substantial freshening occurs in the Northern Canada Basin where the freshwater content in the upper halocline roughly doubles during the 2000s (Fig. 11, middle panel). The additional $8 \mathrm{~m}$ of freshwater derives from both the $\sim 100 \mathrm{~m}$ thickening of the upper halocline and the $0.5 \mathrm{ppt}$ decline in salinity. The increase in the upper halocline thickness accounts for over $6 \mathrm{~m}$ of the increase in the freshwater content whereas the concurrent decrease in salinity adds roughly $2 \mathrm{~m}$ to the freshwater content.

In the Southern Canada Basin, the isohalines display a rather modest downwelling and the upper halocline appears to thicken by only $15 \mathrm{~m}$ between 2002 and 2011 . This corresponds to $1 \mathrm{~m}$ increase in the freshwater content whereas $2 \mathrm{~m}$ of the additional freshwater content is associated with the 0.2-0.3 ppt decrease in salinity. In the Polar Mixed Layer, the lowest salinities, nearly 2 ppt below the climatological average, are observed in 2007 and 2011. Between 2002 and 2011 roughly $3 \mathrm{~m}$ of freshwater is added to the Polar Mixed Layer mainly due to the $0.7 \mathrm{ppt}$ decline in salinity.

Interestingly, despite the freshening in the upper layers, the Nansen Basin emerges as the only domain where the total 
Salinity / freshwater content of the lower halocline
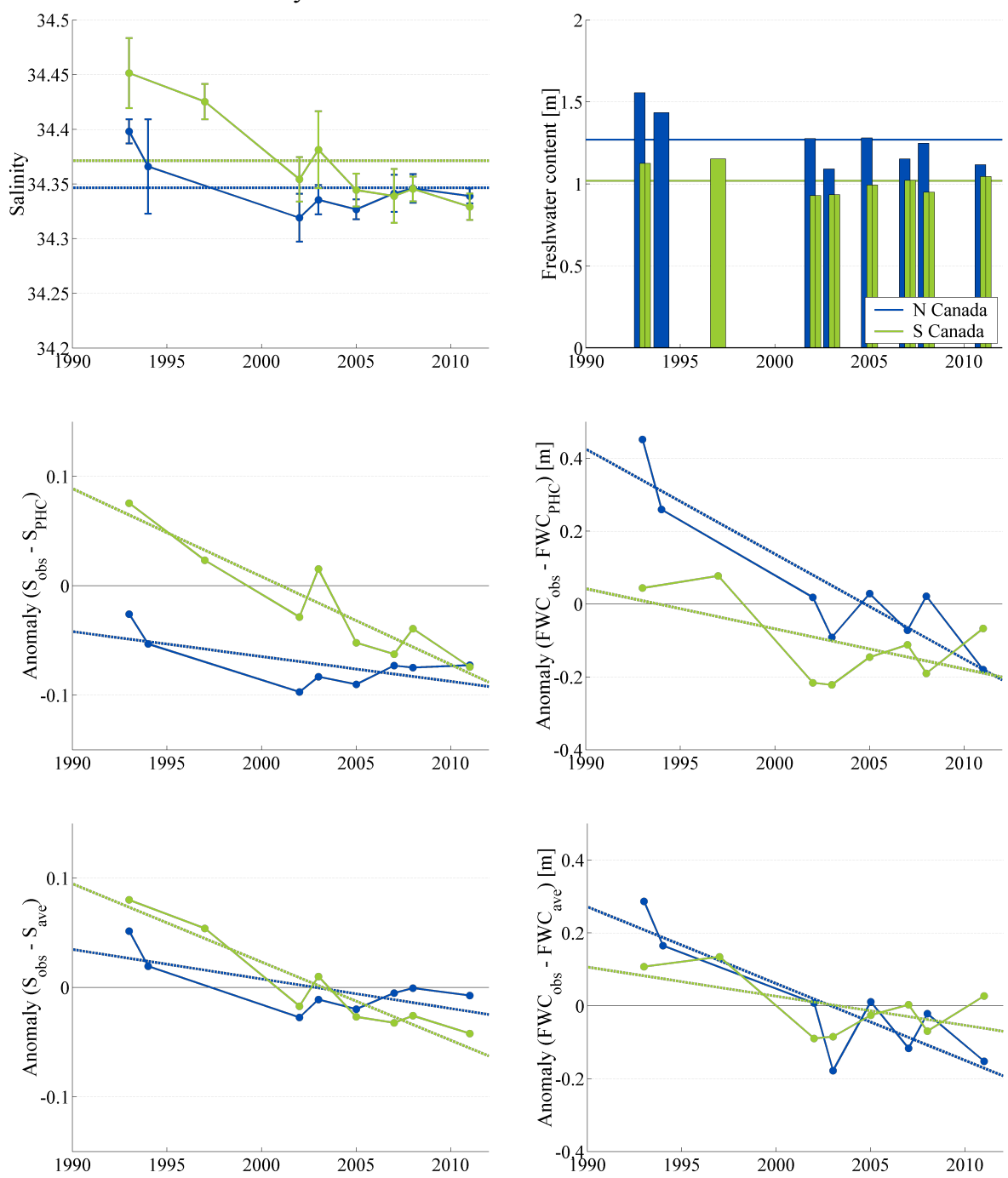

Fig. 16. The same as Fig. 11 but for the lower halocline in the Canada Basin.

freshwater content rather declines than increases (Fig. 31). Although the salinity of the Polar Mixed Layer is slightly decreasing, the resulting stability and reduction in depth of winter convection decreases its freshwater content (upper panel in Fig. 13). Furthermore, besides the less saline upper ocean, the stratification in the Nansen Basin is strengthened by the increasing salinity in the upper Atlantic Water (Fig. 19, Table 4). AW1 reaches its maximum salinity in 2001, after which a slow decrease takes place. Opposite trends are observed in the Amundsen and Makarov basins with the minimum salinities occurring in 2001. However, the concurrent thinning of AW1 overrides the freshening during the 1990s and no significant change is observed in the freshwater content before the late 2000s when the gain in thickness adds to the freshwater content in spite of the slightly increasing salinities.
Two separate salinification events arise in the lower Atlantic layer (Fig. 17). The first is recorded in 1996 with salinity anomaly of 0.04 in the Nansen and nearly 0.02 in the Amundsen Basin. The second event is seen in the Nansen Basin with salinities 0.01-0.02 above the climatological average. In the Nansen Basin, the high salinities coincide with large AW2 volume and thus the freshwater content becomes increasingly more negative. In the Amundsen Basin, the salinity and thickness variability seem independent. Although the salinities observed in the Amundsen Basin in 2007 and 2011 are somewhat higher than in 2005, they are close to the long time average. Neither of these saline events is observed in the Makarov Basin, where the lower Atlantic layer salinity is almost continuously decreasing. 
Salinity / freshwater content of the lower Atlantic Water
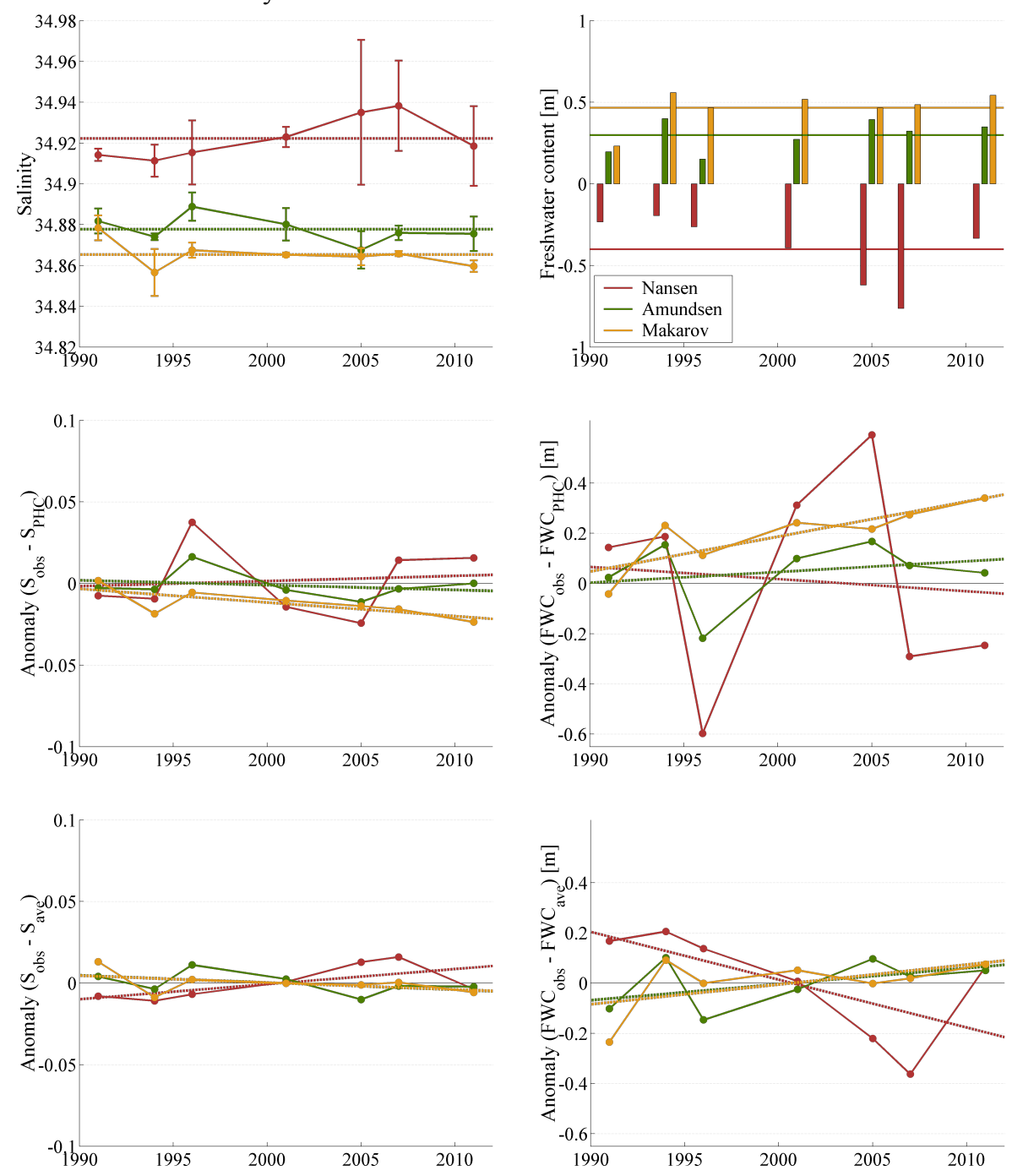

Fig. 17. The same as Fig. 11 but for the lower Atlantic Water in the Eurasian Basin.

\subsection{Heat content}

\subsubsection{Atlantic Water}

The largest amount of the heat residing in the Arctic Ocean is stored in the Atlantic layer. Horizontal variability of the heat content reflects changes in both thickness and temperature. Between the Nansen and Amundsen basins, both the temperature and thickness of the Atlantic Water are reduced, which is seen as a considerable decrease in the heat content (Figs. 21 and 22). In the Nansen Basin, the Atlantic Water has an average potential temperature of $1.6^{\circ} \mathrm{C}$ in the upper (AW1) and $1.1^{\circ} \mathrm{C}$ in the lower (AW2) layer. In the Amundsen Basin, the temperature of AW1 drops to roughly $1^{\circ} \mathrm{C}$ and the temperature of $\mathrm{AW} 2$ to $0.6{ }^{\circ} \mathrm{C}$. The temperature in $\mathrm{AW} 1$ decreases faster than in AW2 and the difference between the two layers is reduced further away from the area of Atlantic inflow. In the Makarov Basin, the temperatures are $0.6^{\circ} \mathrm{C}$ and $0.4{ }^{\circ} \mathrm{C}$ for AW1 and AW2, respectively; in the Canada Basin, both Atlantic layers maintain an average temperature slightly below $0.5^{\circ} \mathrm{C}$ (Figs. 23 and 24).

Similar to the salinity variability, two warming events emerge in the Nansen Basin (Figs. 21 and 22). The first warming event occurs in 1996 when the average temperature increases by $1{ }^{\circ} \mathrm{C}$ in the upper and by $0.5^{\circ} \mathrm{C}$ in the lower Atlantic layer. The first event is also observed in the Amundsen and Makarov basins, where the warming amounts to half of that observed in the Nansen Basin. Anomalously high temperatures in 1996 coincide with increase in layer thickness, which further enhances the heat content.

Between 2001 and 2007, the warming of Atlantic Water is limited to the Nansen Basin. In 2007, the temperature anomaly in $\mathrm{AW} 1$ is $1.2^{\circ} \mathrm{C}$, equivalent to that in 1996 , while the anomaly in AW2 exceeds the previous warming event by 

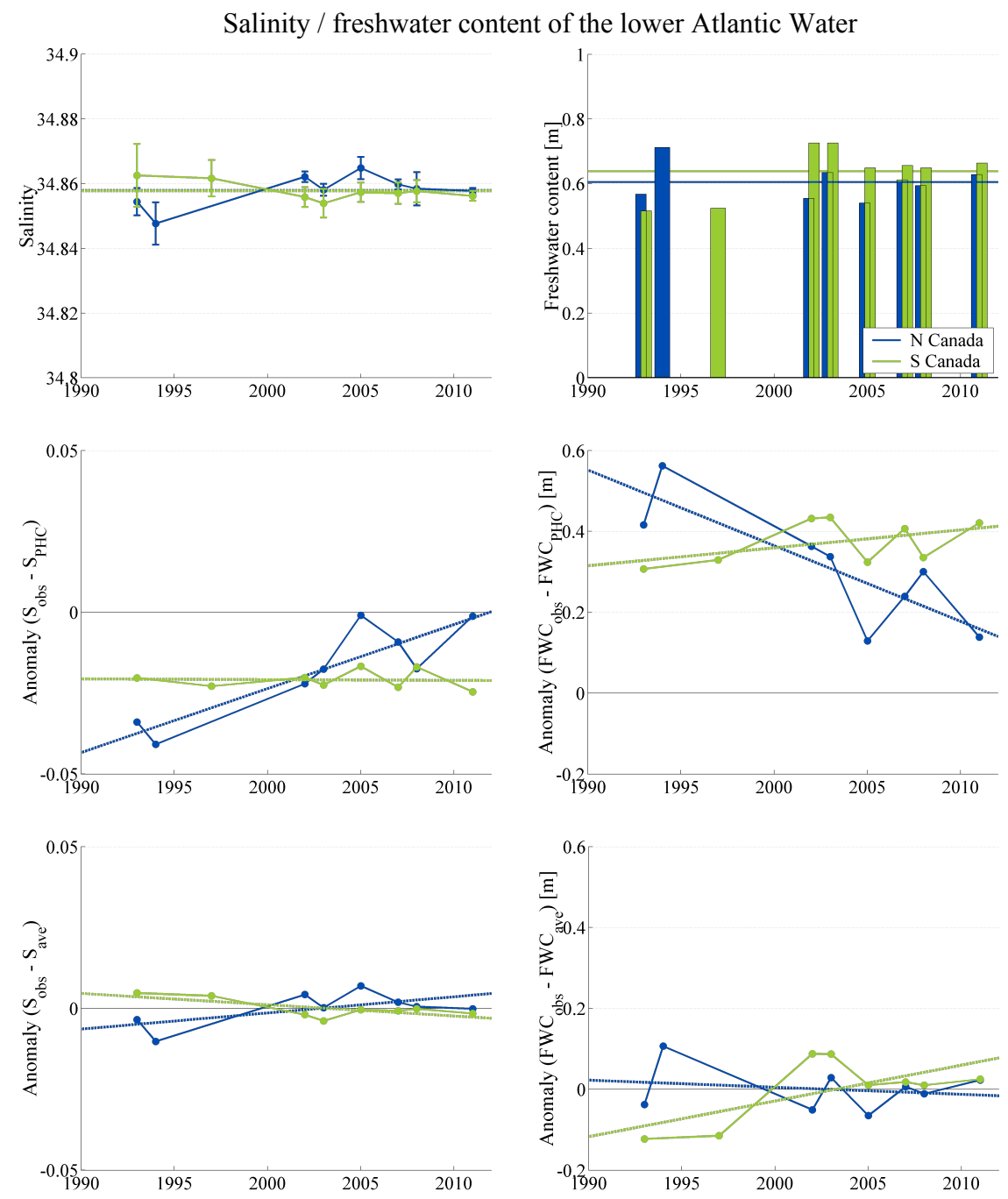

Fig. 18. The same as Fig. 11 but for the lower Atlantic Water in the Canada Basin.

$0.1^{\circ} \mathrm{C}$. Also in 2007 the warming is accompanied by anomalously thick AW2 layer. In the Amundsen Basin both Atlantic layers appear to cool slightly, although the simultaneous increase in thickness of AW1 leads to a heat content comparable to that in 1996. In the Makarov Basin both Atlantic layers are slowly warming and by 2011 the temperature of the lower layer reaches the anomaly observed in 1996 . The temperature of AW1 still remains below the maximum of 1996.

Lack of observations from the 1990s makes it difficult to detect any trends in the Canada Basin. The significant warming presented in Table 5 derives from the high temperatures in the 2000s. However, in the Northern Canada Basin, maximum temperature in both Atlantic layers is reached already in 2002 and 2003, after which a possible cooling takes place. In the Southern Canada Basin, the mean temperatures in both layers remain constant during the latter decade.

\subsubsection{The upper layers of the Eurasian and Makarov basins}

Concurrently with the warming of the Atlantic layer, between 1991 and 1996, the temperature of the lower halocline is decreasing (Fig. 25, middle panel). Temperature decreases by $0.3{ }^{\circ} \mathrm{C}$ in the Amundsen Basin and by $0.2^{\circ} \mathrm{C}$ in the Makarov Basin. In addition, the temperature of the upper halocline has a minimum in 1994 in both of these basins (Fig. 26). The cooling of the halocline waters may indicate that the weakened stability enabled winter convection to extend below the upper halocline. Consequently, the halocline waters were replaced, or diluted, with surface waters with temperature close to the freezing point. By 2005, the temperature of the lower halocline has returned to the values observed in 1991. 
Salinity / freshwater content of the upper Atlantic Water
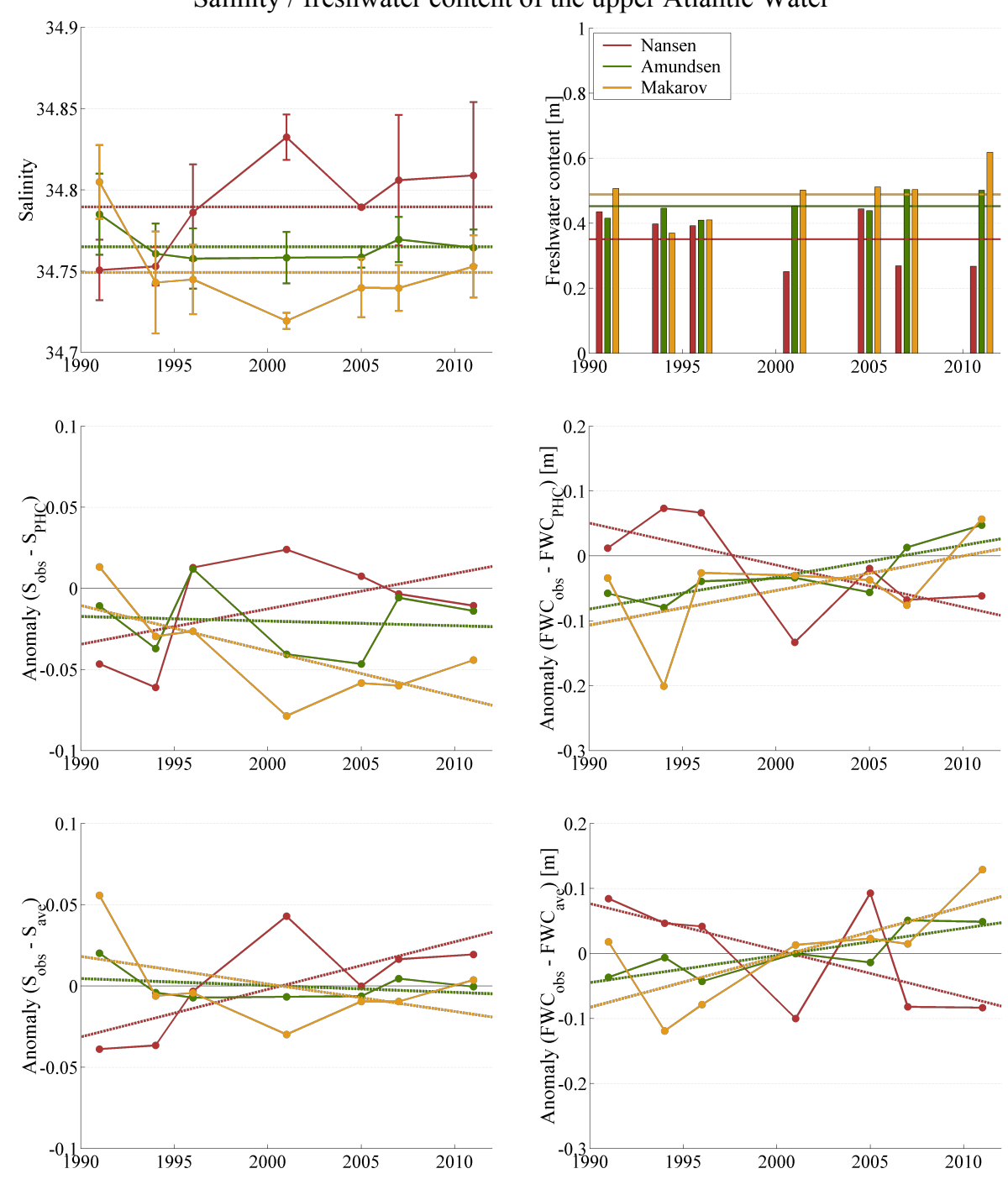

Fig. 19. The same as Fig. 11 but for the upper Atlantic Water in the Eurasian Basin.

\subsubsection{The upper layers of the Canada Basin}

As seen by comparing Figs. 27 and 28, the Polar Mixed Layer is warmest in the Southern Canada Basin. However, it is important to emphasize that the apparent horizontal variability in the heat content of the two uppermost layers possibly results from the use of constant reference temperature. The chosen reference temperature, $-1.9^{\circ} \mathrm{C}$, is close to the freezing point temperature in the Nansen Basin, generally yielding a negligible heat content for the Polar Mixed Layer. On the other hand, for the relatively low salinity surface waters in the Canada Basin, the chosen reference temperature is considerably lower than the local freezing point temperature, $-1.6^{\circ} \mathrm{C}$ corresponding to the mean salinity 29 in the Polar Mixed Layer. Thus the space variability in the Polar Mixed Layer heat content is exaggerated.
In addition to the warm Polar Mixed Layer, the high horizontal variability, represented by the large standard deviation, within the Southern Canada Basin is notable. For example, in 1993, 1997 and 2003 the standard deviation is almost $1.5^{\circ} \mathrm{C}$. Both the relatively high temperature and large standard deviation are attributed to the southern location of the basin. The southern location increases the amount of incoming solar radiation and consequently reduces ice concentration. The low ice concentration further increases the absorption of short wave radiation, which emphasizes horizontal temperature differences between ice-free and ice-covered areas.

Between 2002 and 2011, the average temperature of the Polar Mixed Layer increases by $0.3^{\circ} \mathrm{C}$ in the Southern and $0.4^{\circ} \mathrm{C}$ in the Northern Canada Basin. Warming of the upper halocline is negligible in the Southern Canada Basin, whereas in the northern part it reaches $0.2^{\circ} \mathrm{C}$ (Fig. 29, middle 

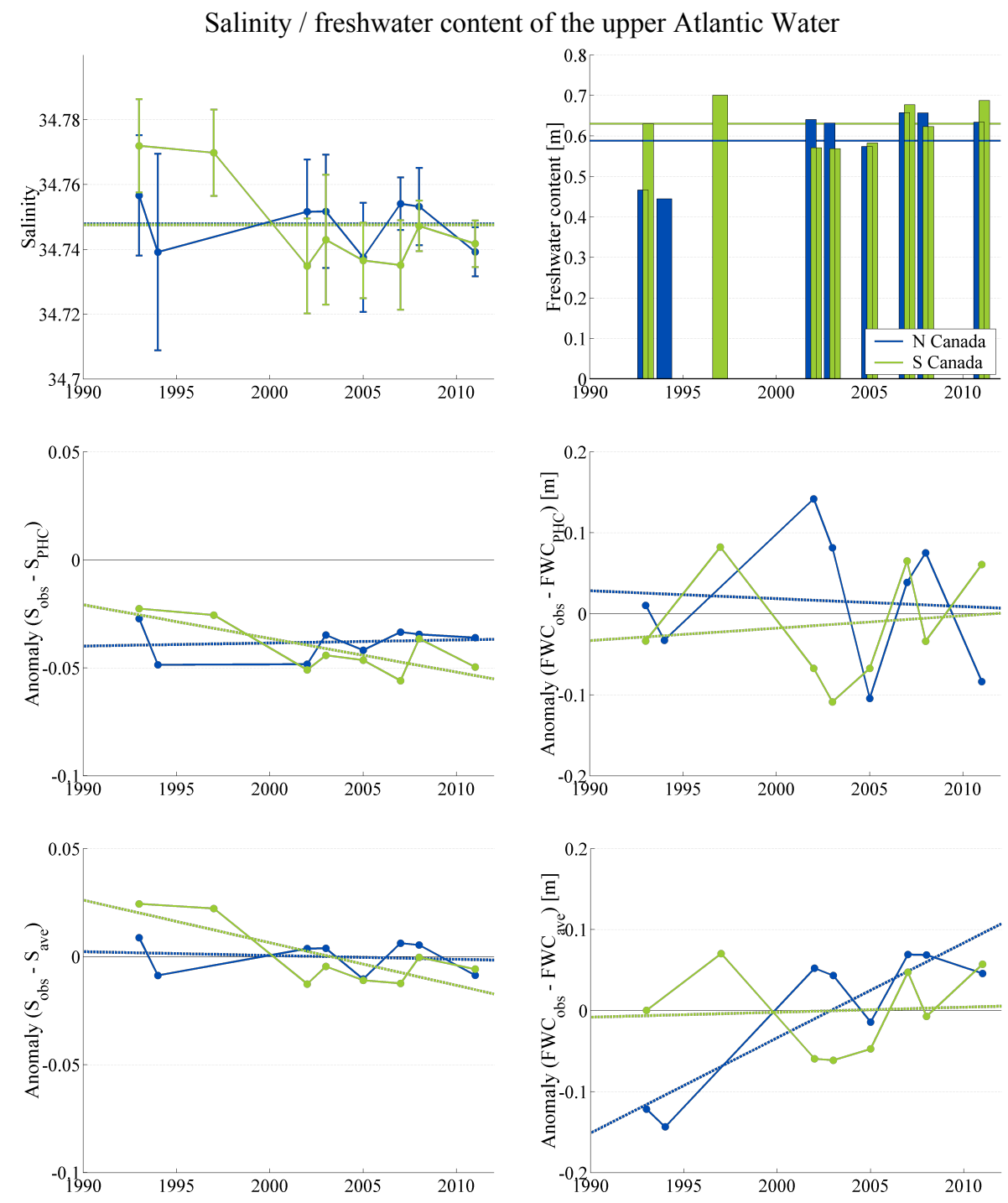

Fig. 20. The same as Fig. 11 but for the upper Atlantic Water in the Canada Basin.

panel). The warming in the Northern Canada Basin enhances the increase in heat content, which is mainly driven by the thickening of the upper halocline. An equivalent warming is observed in the lower halocline (Fig. 30). Note that the trends for the upper halocline, presented in Table 5 and Fig. 29, are computed for the period 1991-2011 and thus they do not capture the more robust increase during the later decade.

\subsection{Meltwater}

Following the results obtained by e.g. Maykut and McPhee (1995) the seasonal ice melt is here approached with the assumption that solar insolation is the primary source of energy for melting. In Fig. 33 the potential seasonal ice melt induced by the atmospheric heat input (derived from the products provided by NCEP and ERA-Interim reanalyses) is compared to the hydrographic melt estimate. The hydrographic estimate is the direct result from the method described in Sect. 2.5.

\subsubsection{Space variability}

Both methods for estimating the meltwater content, the hydrographic data and the heat input from reanalyses, suggest that the average annual melt amounts to $1-2 \mathrm{~m}$. Compared to the hydrographic melt estimate, the cumulative heat input predicts considerably less interannual and horizontal variability. The large variability may partly result from the limited horizontal coverage of the hydrographic surveys, which are thus prone to emphasize local details.

Based on the hydrographic estimate the smallest seasonal ice melt occurs in the Nansen Basin, where on average $0.6 \mathrm{~m}$ of meltwater is added to the surface layer during the melt season (Fig. 33). The meltwater content is doubled in the 
Temperature / heat content of the upper Atlantic Water
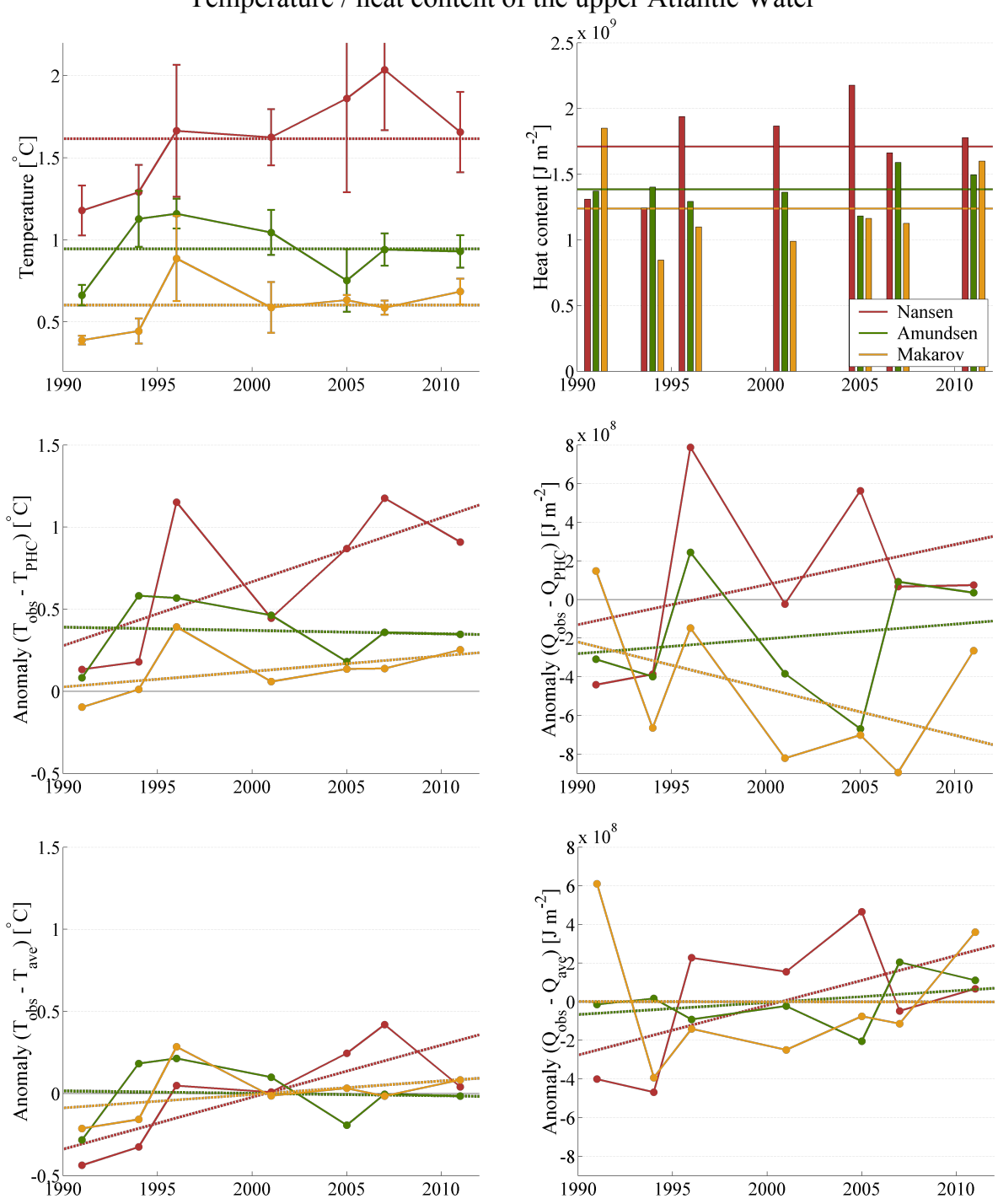

Fig. 21. The bars in the upper panel show the observed mean temperature with standard deviation (left) and heat content (right) of the upper Atlantic Water in the Eurasian Basin. The horizontal lines denote the $20 \mathrm{yr}$ average obtained from the observations. The middle panel shows the anomalies of the observations from the PHC climatology. By computing the linear trend (dashed lines) from these anomalies, the offset resulting from spatial variability is removed. The quantified linear trends are found in Table 5. To enable better comparison between the observations (upper panel) and the anomalies from climatology (middle panel), the lower panel demonstrates anomalies of the observations from the average computed from the observations (both shown in the upper panel) with the same scale as the anomalies from climatology. The effect of the spatial variability within the basin (the offset) can be estimated by comparing the trends, or the shape of the curve, in the middle and lower panels.

Amundsen Basin and in the Makarov Basin the average annual ice melt amounts to $1.8 \mathrm{~m}$. In the Southern Canada Basin, the hydrographic melt estimate yields on average $2 \mathrm{~m}$ of meltwater.

The highest correspondence between the hydrographic melt estimate and the melt predicted by the atmospheric heat input is reached in the Canada Basin. In the Canada Basin also the two heat input estimates, from NCEP and ERAInterim reanalyses, are consistent. Elsewhere in the Arctic
Ocean, ERA-Interim predicts $0.2-0.5 \mathrm{~m}$ less melt than the NCEP Reanalysis. In the Amundsen and Makarov basins the hydrographic estimate generally falls between the two heat input estimates. In the Nansen Basin, the correspondence between the hydrographic and heat input estimates is much weaker as both reanalysed surface fluxes indicate twice as much sea ice melt than estimated from the hydrographic data. 
Temperature / heat content of the lower Atlantic Water
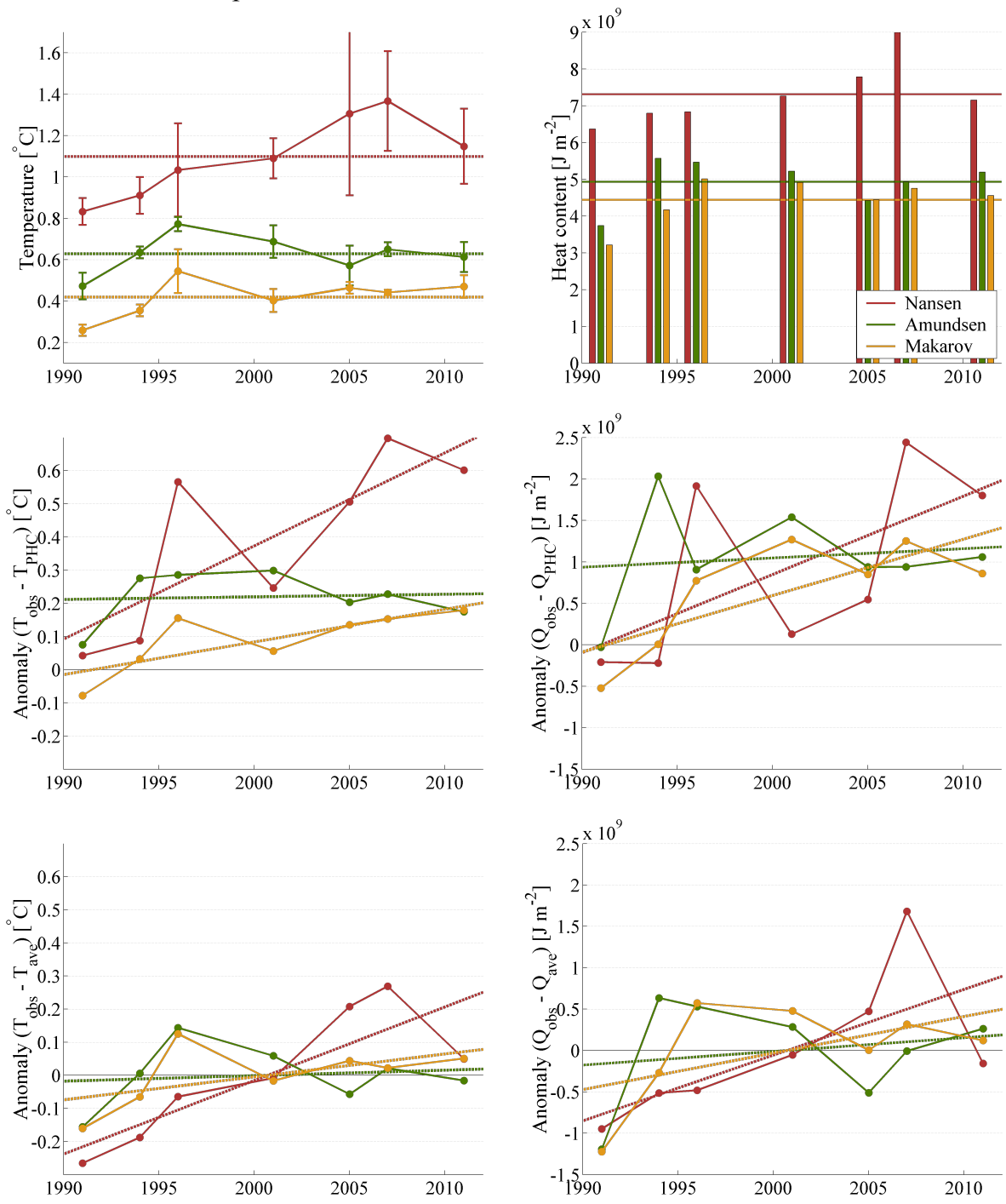

Fig. 22. The same as Fig. 21 but for the lower Atlantic Water in the Eurasian Basin.

\subsubsection{Time variability}

Regardless of the difference in the two methods to determine seasonal ice melt, the hydrographic estimate appears to reflect relatively well the interannual variability in atmospheric heat fluxes even in the Nansen Basin (Fig. 33). Among the large interannual variability an almost persistently decreasing trend from 1991 to 1996 can be identified in large parts of the Arctic Ocean. A wide-spread meltwater minimum is reached in 1996 in the Eurasian and Makarov basins. In the Amundsen and Makarov basins, this reduction in hydrographic meltwater estimate is quite consistent with the simultaneously diminishing net atmospheric heat input. However, while the heat fluxes indicate rather modest decrease in the Nansen Basin, the hydrography displays an abrupt drop in meltwater content. In 1996 seasonal ice melt amounts only to $0.1 \mathrm{~m}$. In 2001, the meltwater content is still considerably lower, $0.3 \mathrm{~m}$, than the 20-year-average $0.6 \mathrm{~m}$.

After 2001, the atmospheric heat input increases everywhere in the Arctic Ocean according to the two reanalyses used here. The hydrographic estimate represented in Fig. 33 implies that in the Eurasian and Makarov basins the average seasonal ice melt increases by roughly $0.2-0.5 \mathrm{~m}$ between the 1990s and 2000s. In the Canada Basin both estimates reach their maximum in 2007 and 2008. During 2007 and 2008 the meltwater content is $0.5 \mathrm{~m}$ higher compared to other years, $2.5 \mathrm{~m}$ in the southern and $2 \mathrm{~m}$ in the northern part of the Canada Basin. On the contrary, the maxima that emerge in 2001 and 2007 in the hydrographic melt estimates for the Makarov Basin are not supported by the atmospheric heat input. 
Temperature / heat content of the upper Atlantic Water
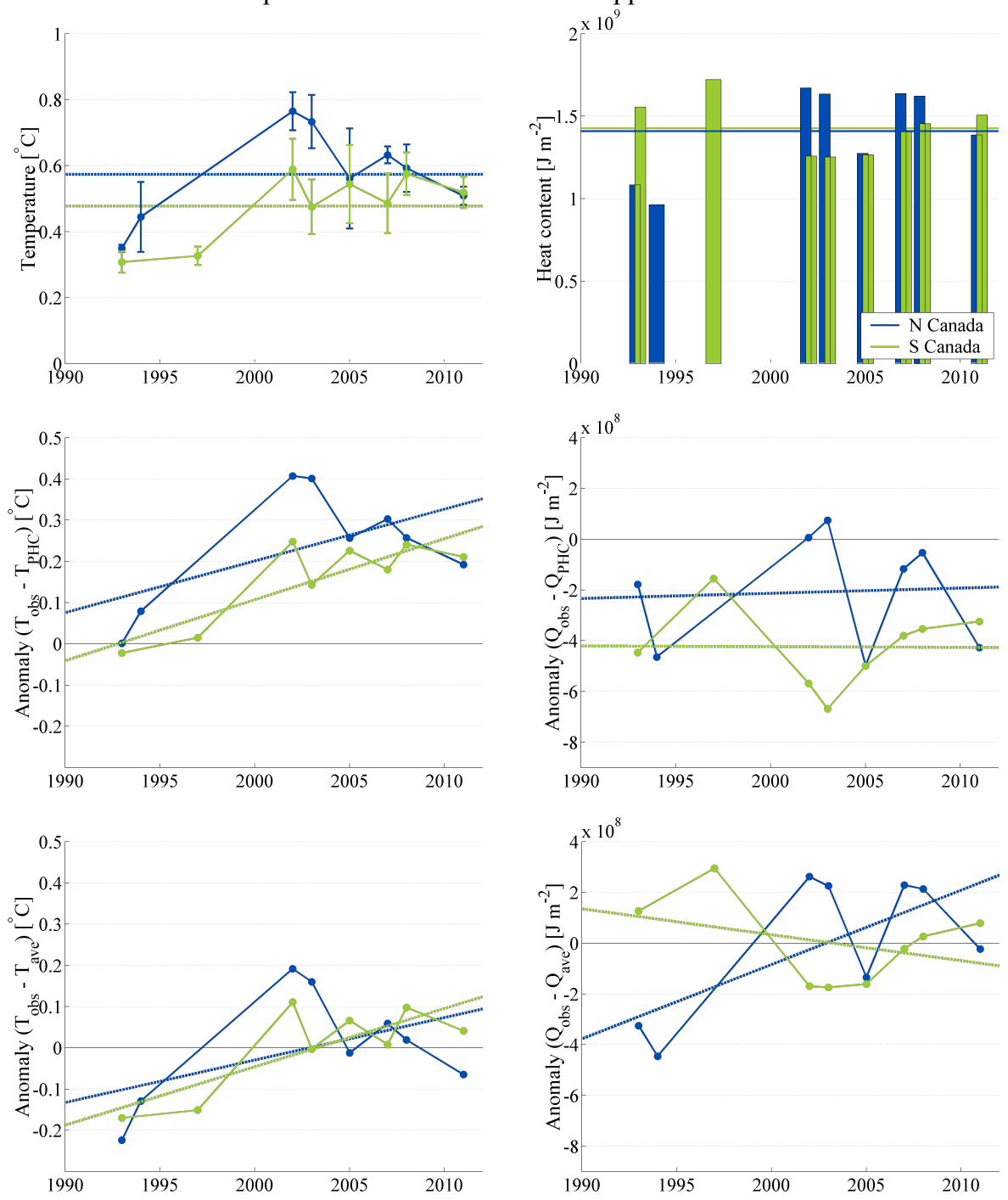

Fig. 23. The same as Fig. 21 but for the upper Atlantic Water in the Canada Basin.

\section{Discussion}

\subsection{The upper layers in the Eurasian Basin}

\subsubsection{The 1990s}

A key contributor to the observed changes in the Eurasian Basin upper layers is the so-called retreat of the Arctic halocline, which is well discussed in literature (e.g. Morison et al., 1998; Steele and Boyd, 1998). The retreat of the Arctic halocline, here called the upper halocline, was associated with the eastward advection of Siberian river runoff during the early 1990s. As a result, the upper halocline contracted in volume (Fig. 7) and the reduced freshwater input increased salinities in both the upper halocline and the Polar Mixed Layer (Figs. 12 and 13). The salinification of the Polar Mixed Layer was further enhanced by the intensified export of liquid freshwater (Karcher et al., 2005) and sea ice (Vinje, 2001) through the Fram Strait. Moreover, the divergence of the ice cover created numerous leads and consequently increased heat loss from the ocean to the atmosphere (Rigor et al., 2002). Subsequent rapid ice formation rejected brine to the surface layer increasing its salinity. Johnson and Polyakov (2001) tracked the salinification to originate in the Laptev Sea where salinity increased by almost $1.5 \mathrm{ppt}$ by 1995. Later this anomaly was transported into the Makarov and Amundsen basins (Polyakov et al., 2008). Although the origins of salinification has been debated (Swift et al., 2005), extent and magnitude of the salinification presented by Johnson and Polyakov compare favourably with salinity increase of 1-1.5 ppt in the Amundsen and Makarov basins.

Along with the salinification, the upper ocean stability weakened. Because the winter homogenization was able to 
Temperature / heat content of the lower Atlantic Water
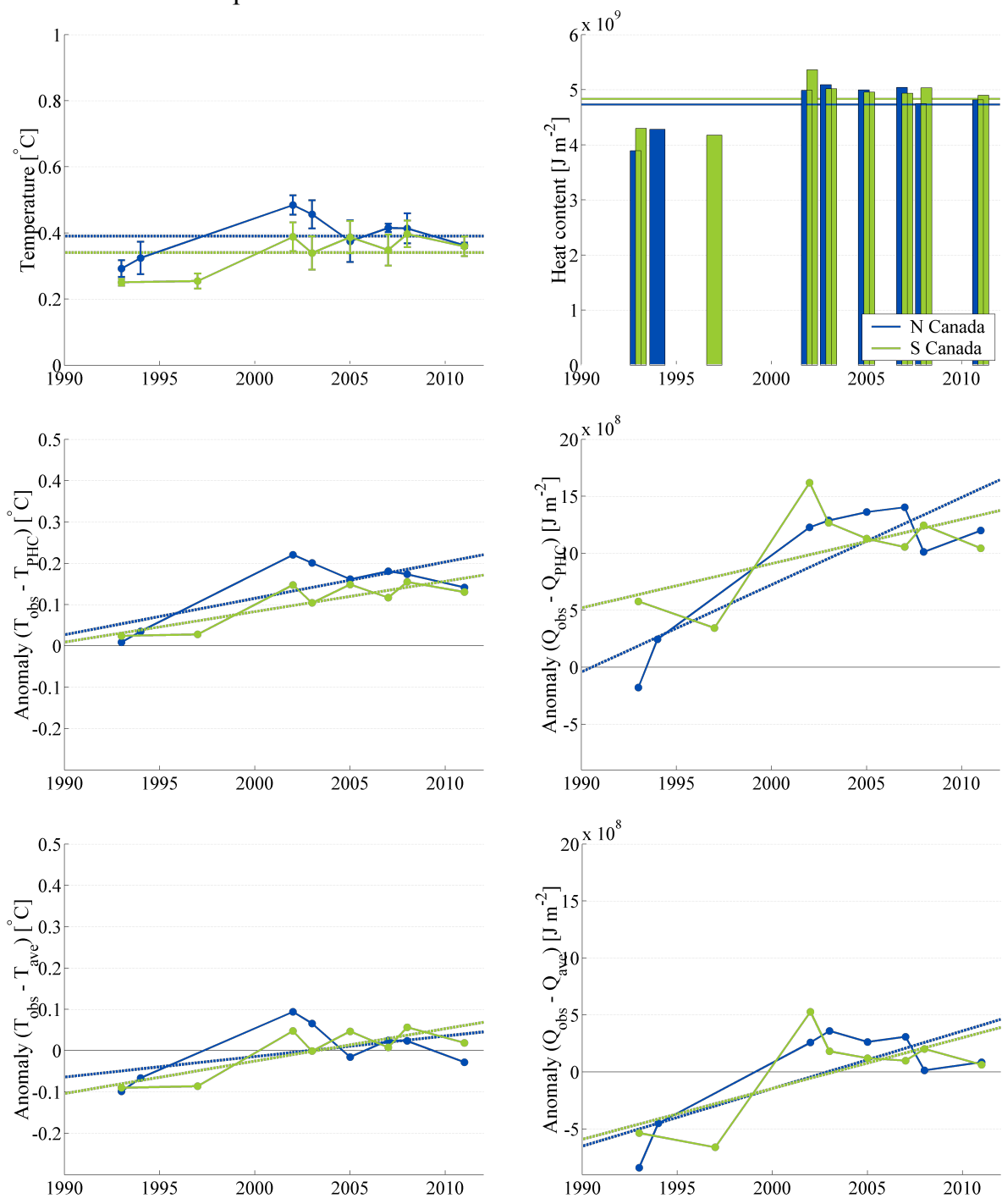

Fig. 24. The same as Fig. 21 but for the lower Atlantic Water in the Canada Basin.

reach into the underlying water masses, the thickness of the Polar Mixed Layer is roughly maintained during the 1990s (Fig. 6) despite the reduced freshwater input. Thus it is likely that winter haline convection transformed, or reformed, part of the waters in the upper and lower halocline range into the Polar surface waters. The concurrent freshening and cooling of the lower halocline, seen in Figs. 15 and 25, further imply that halocline waters are replaced with less saline surface water that is cooled close to the freezing point temperature. As earlier discussed by Kikuchi et al. (2004) and Rudels et al. (2004), the significance of local convection in forming especially the lower halocline waters was strengthened due to the absence of advection from the continental shelves during the 1990s.

In spite of the winter convection reaching down to the thermocline, no warming of the Polar Mixed Layer is ob- served. Moreover, although the retreating upper halocline was expected to enhance the oceanic heat flux to the sea ice (Steele and Boyd, 1998; Martinson and Steele, 2001; Björk et al., 2002), the seasonal ice melt is in fact decreasing in the Eurasian and Makarov basins (Fig. 33). The decrease in ice melt concurs with the salinification of the Polar Mixed Layer (Fig. 13). The increased surface salinity implies that ice melt was not sufficient to compensate for the reduced freshwater input from the shelves. On the contrary, brine rejection from newly formed ice was a probable contributor to the increased salinity. Due to the ice divergence, discussed by Johnson and Polyakov (2001) and Rigor et al. (2002), thermodynamic growth of sea ice was possibly enhanced during winter. Thus, it seems likely that the heat deriving from the halocline is lost directly to atmosphere. The increased longwave radiation would further influence the surface heat 
Temperature / heat content of the lower halocline
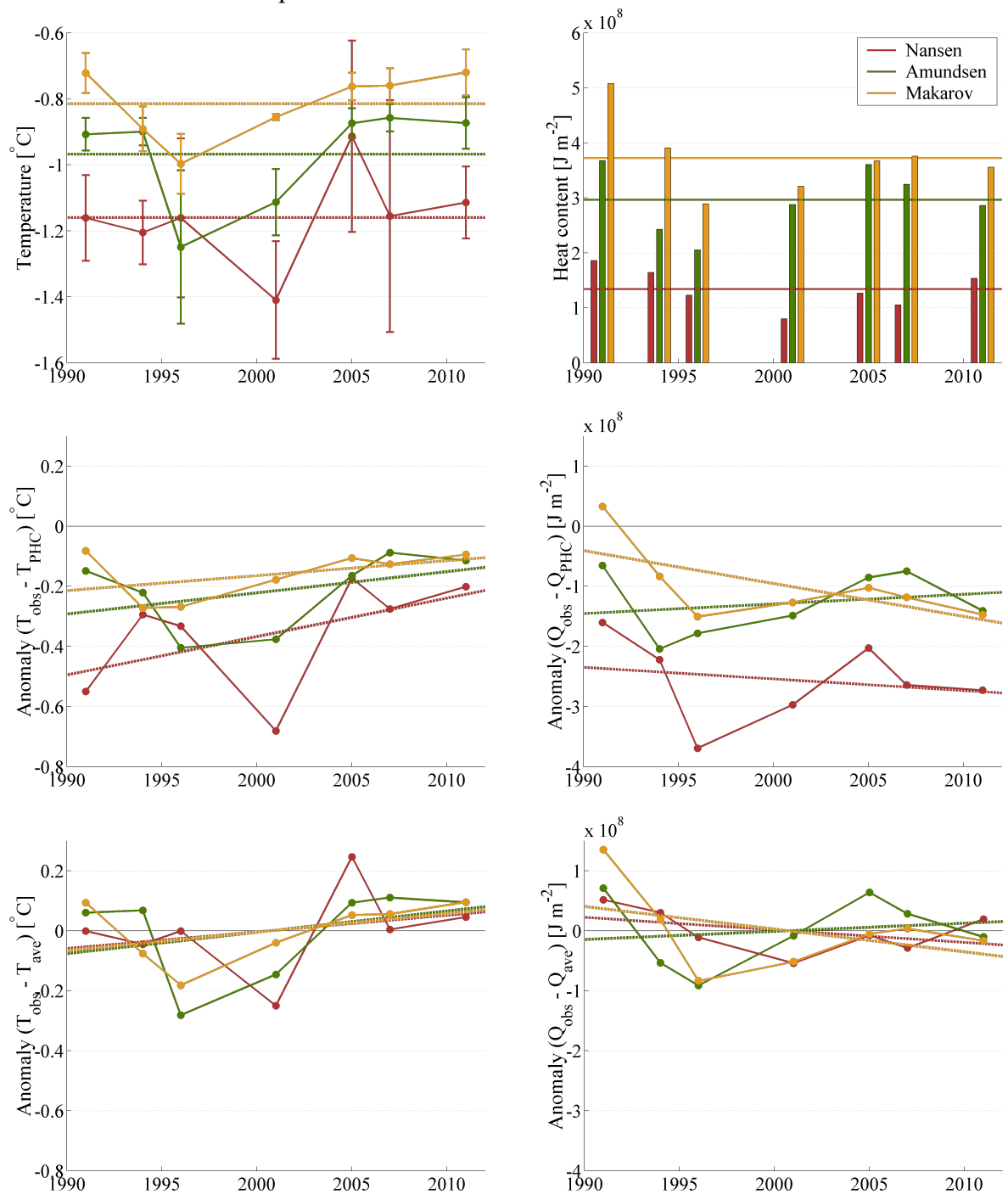

Fig. 25. The same as Fig. 21 but for the lower halocline in the Eurasian Basin.

budget, which could partly account for the coincidently decreasing downward heat fluxes seen in Fig. 33.

\subsubsection{The 2000s}

According to Boyd et al. (2002), the surface salinity in the Nansen, Amundsen and Makarov basins continued to increase until 1998. Although this year is not represented in the data sets used in this study, the observations from 1996 and 2001 suggest that the salinification ceases in the late 1990s. By 2005, the salinities in the upper halocline and the Polar Mixed Layer have rebounded back to the values in the early 1990s (Figs. 12 and 13). The maximum freshwater contents observed in these two uppermost water masses, in 2005 in the Amundsen and in 2007 in the Makarov Basin, compare well with the reported large river water fraction in the upper $50 \mathrm{~m}$ (Jones et al., 2008; Bauch et al., 2011). A slight decrease in the freshwater content by 2011 suggests that no substantial freshening is occurring in the central Arctic Ocean and the salinity has merely rebounded towards the state in 1991.

Also in the Nansen Basin, the salinity of the Polar Mixed Layer has been decreasing after 2001. Concurrently, temperature of the inflowing Atlantic Water is increasing (Figs. 21 and 22). The salinity decrease could indicate that higher temperatures of the underlying water lead to a larger fraction of the heat flux from the Atlantic layer going to ice melt and less to the atmosphere (see e.g. Rudels, 2010). However, Fig. 33 shows that the modest increase in the seasonal ice melt corresponds to the increase in surface heat fluxes and does not seem to respond to the increased Atlantic Water temperatures. Furthermore, the simultaneous reduction of the mixed layer depth (Fig. 6) suggests that the increased stability limits the vertical mixing from reaching the Atlantic heat storage. 
Temperature / heat content of the upper halocline
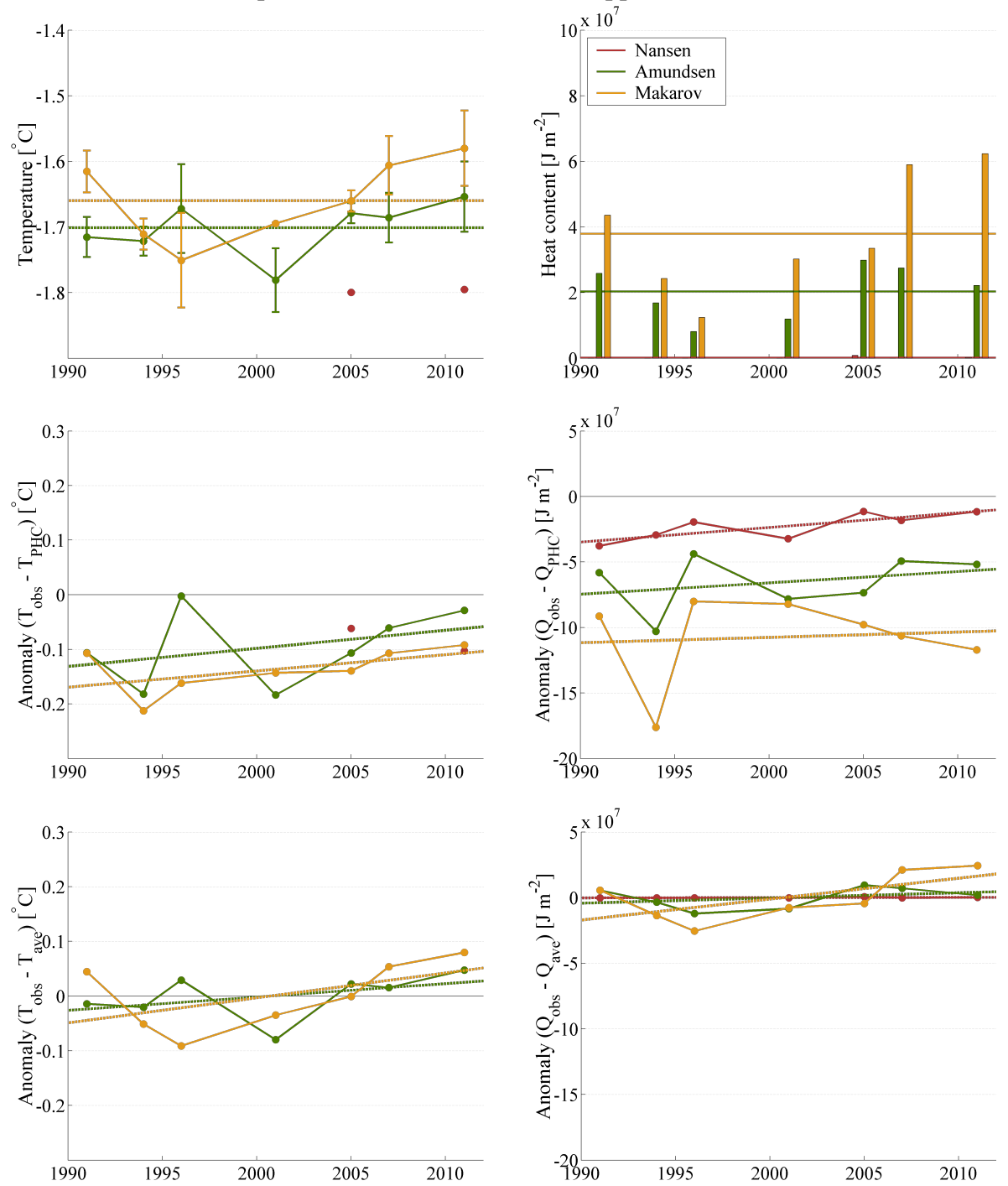

Fig. 26. The same as Fig. 21 but for the upper halocline in the Eurasian Basin.

That the upper ocean stability is restored and the cold surface waters no longer mixed down to the thermocline are also seen as the warming of lower halocline. This description, however, mainly holds for the interior of the deep basins, which is the main concern in this work. In the boundary current at the slope, where other mixing processes might be present, Polyakov et al. (2010) found that the cooling of the Atlantic Water and the temperature increase of the halocline water did not balance. Only $7 \%$ of the Atlantic Water heat loss was accounted for as the warming of the halocline. They concluded that some of the missing heat likely entered the upper layer and possibly contributed to the ice melt.

\subsection{The upper layers in the Canada Basin}

\subsubsection{The 1990s}

Inadequate temporal data coverage precludes any firm conclusions of the hydrographic conditions in the Canada Basin during the 1990s. Moreover, the disparities in the locations of hydrographic surveys make it difficult to present a reliable comparison between the two decades. During the 1990s the high ice concentration forced the icebreakers to operate mainly near the shelf break. Therefore never, or very seldom, were hydrographic casts obtained from the deep Canada Basin. The casts located near the shelf break are likely to emphasize the properties of shelf waters, which are freshened by runoff and ice melt. In addition, the low ice concentration enhances absorption of solar radiation and heating of 
Temperature / heat content of the Polar Mixed Layer
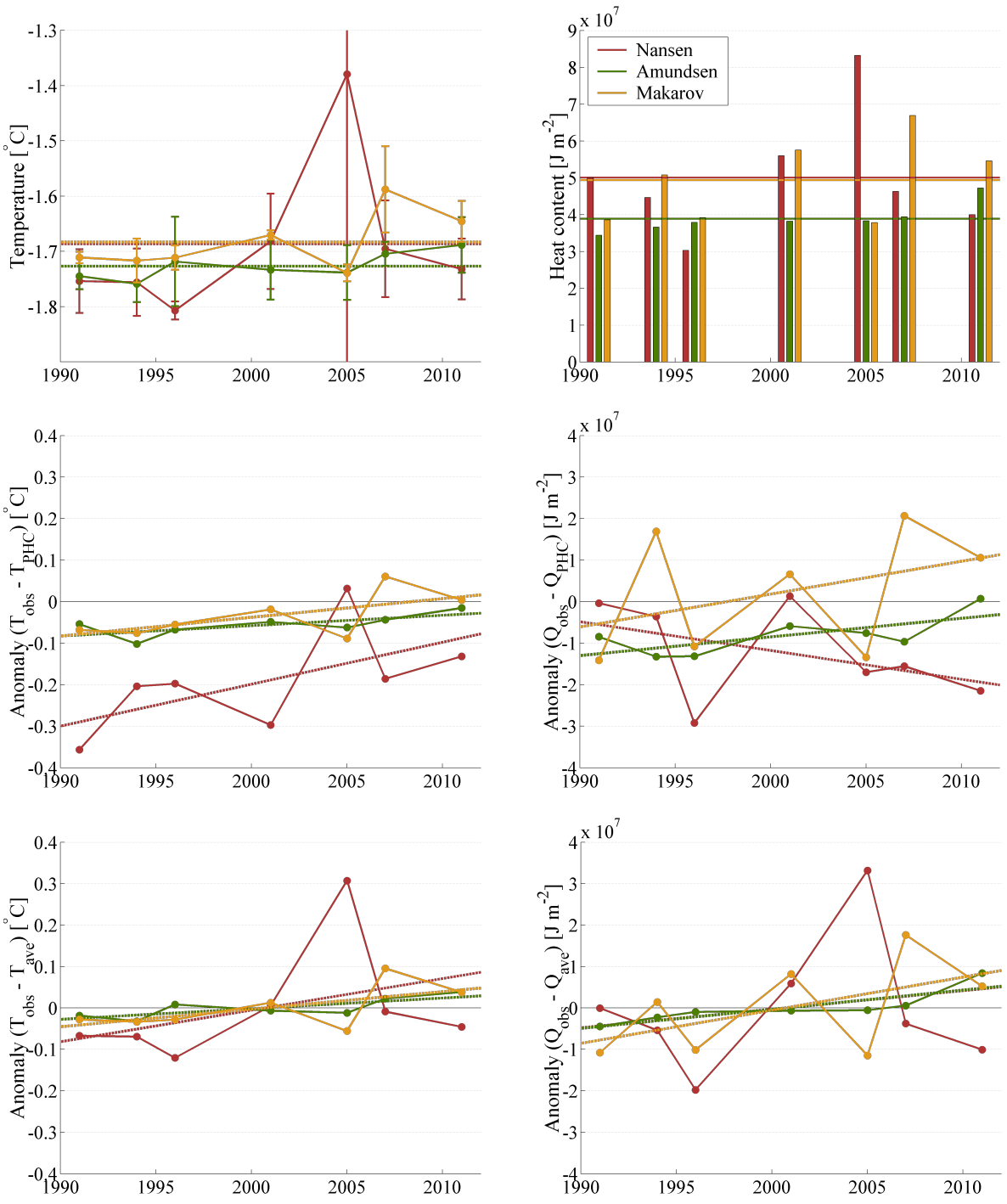

Fig. 27. The same as Fig. 21 but for the Polar Mixed Layer in the Eurasian Basin.

surface waters. Especially in the Southern Canada Basin the upper ocean is expected to be distorted due to the presence of shelf waters modified by runoff and solar heating. The high standard deviation of both salinity (Fig. 14) and temperature (Fig. 28) is interpreted to result from this bias.

Besides the fact that the data were limited to the area close to the North American continental slope, earlier research implies that the Southern Canada Basin may be presented here by two exceptional years in the 1990s. For example, Guay and Falkner (1997) concluded, based on the dissolved barium concentration, that large amount of river discharge was present near the North American continental slope in 1993. Several studies (McPhee et al., 1998; Macdonald et al., 1999; Kadko and Swart, 2004) conducted at the SHEBA observation site in 1997 reported anomalously low salinities. The freshening in 1997 was traced to partly originate in the
Mackenzie discharge, which likely contributes also to the elevated freshwater (Fig. 14) and meltwater (Fig. 33) contents.

The high temperatures in 1993 and 1997 have also been discussed previously. The hydrographic survey obtained from the southernmost Beaufort Sea during the Henry Larsen 1993 expedition captures a core of anomalously warm $\left(>5^{\circ} \mathrm{C}\right)$ water close to the surface (maximum temperature around $22-24 \mathrm{~m}$ ). This pool of warm water, suggested by Carmack et al. (1995) to be related to the low ice concentration in the Bering and Chuckhi seas during that summer, increases the average potential temperature and the heat content considerably. On the contrary, according to Kadko and Swart (2004), in 1997 the surface waters were locally heated through thin ice and leads in the ice cover. 

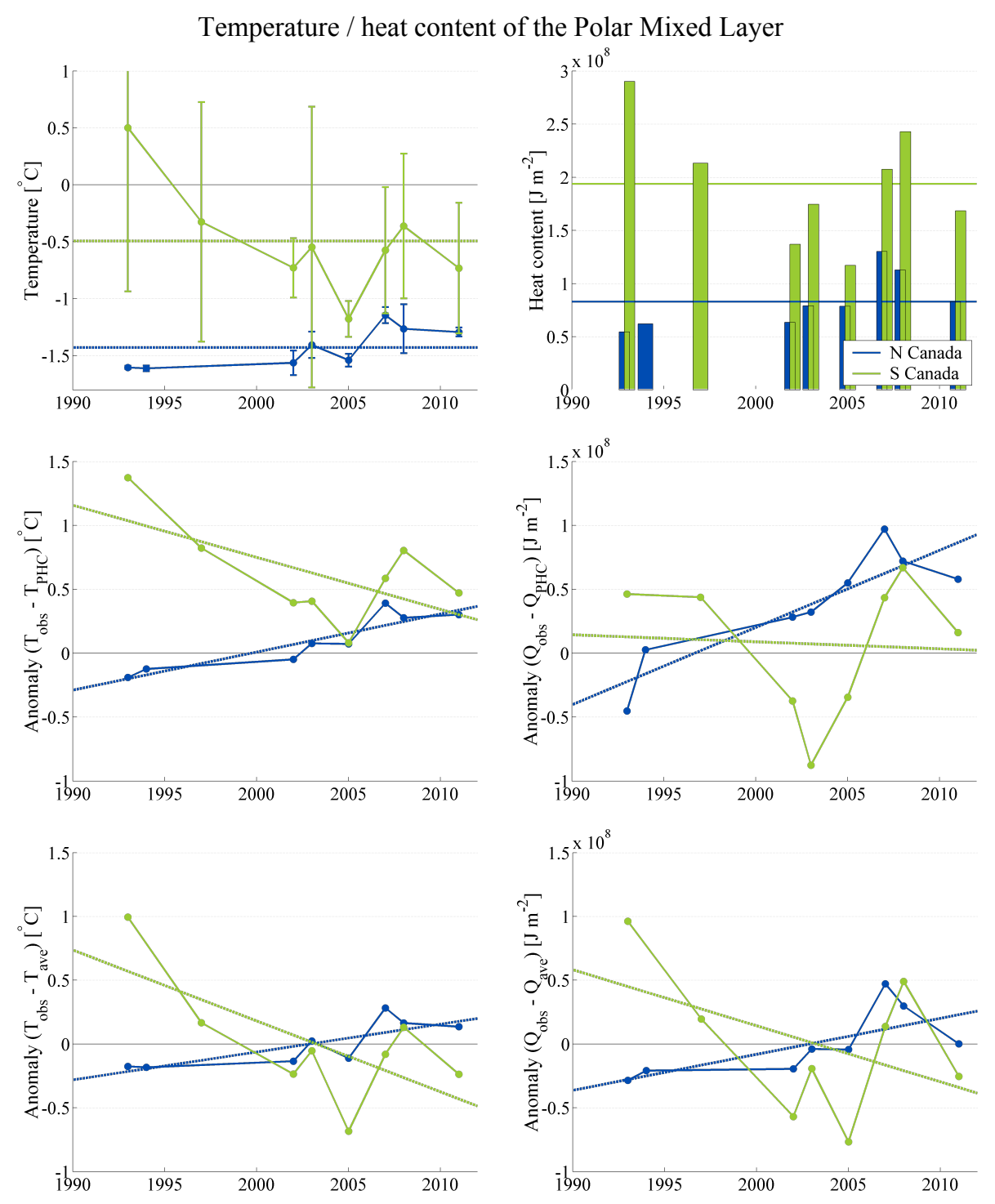

Fig. 28. The same as Fig. 21 but for the Polar Mixed Layer in the Canada Basin.

\subsubsection{Freshening in the 2000s}

Rapid thickening of the upper halocline characterizes the changes in the Northern Canada Basin. Between 2002 and 2011, the thickness of the upper halocline increases by $100 \mathrm{~m}$. The thickening is primarily associated with the downwelling of the isohalines and increase in the sea surface height, driven by the wind-induced Ekman pumping (Proshutinsky et al., 2009; Rabe et al., 2011; Giles et al., 2012). Compared to the Southern Canada Basin, the more robust freshening in the Northern Canada Basin could be due to the relocation of the center of the Beaufort Gyre (Proshutinsky et al., 2009). The enlarged gyre enables the relatively fresh Pacific waters to be distributed northward. However, Morison et al. (2012) suggested that between 2003 and 2008 the amount of Pacific water might be slightly re- duced in the Canada Basin. Instead, they observed additional $3.6 \mathrm{~m}$ of Eurasian river runoff to be present mainly in the 50$115 \mathrm{~m}$ depth range, thus residing within the upper halocline. The signal from Eurasian shelf would first be detected in the Northern Canada Basin in 2007 and 2008. By 2011, it is possibly propagating into the Southern Canada Basin, observed as increased thickness and freshwater content of the upper halocline (Figs. 7 and 11).

The thickness of the Polar Mixed Layer fluctuates around the average of $35 \mathrm{~m}$ in the southern and $45 \mathrm{~m}$ in the northern part of the Canada Basin. While there is no trend in the thickness, the salinity of the Polar Mixed Layer decreases by $\sim 1 \mathrm{ppt}$ in the entire Canada Basin. The minimum salinities are reached in 2011, when they decrease 1.5 and 3 ppt below the climatological average of the Northern and Southern Canada basins, respectively. The decrease in salinity 
Temperature / heat content of the upper halocline
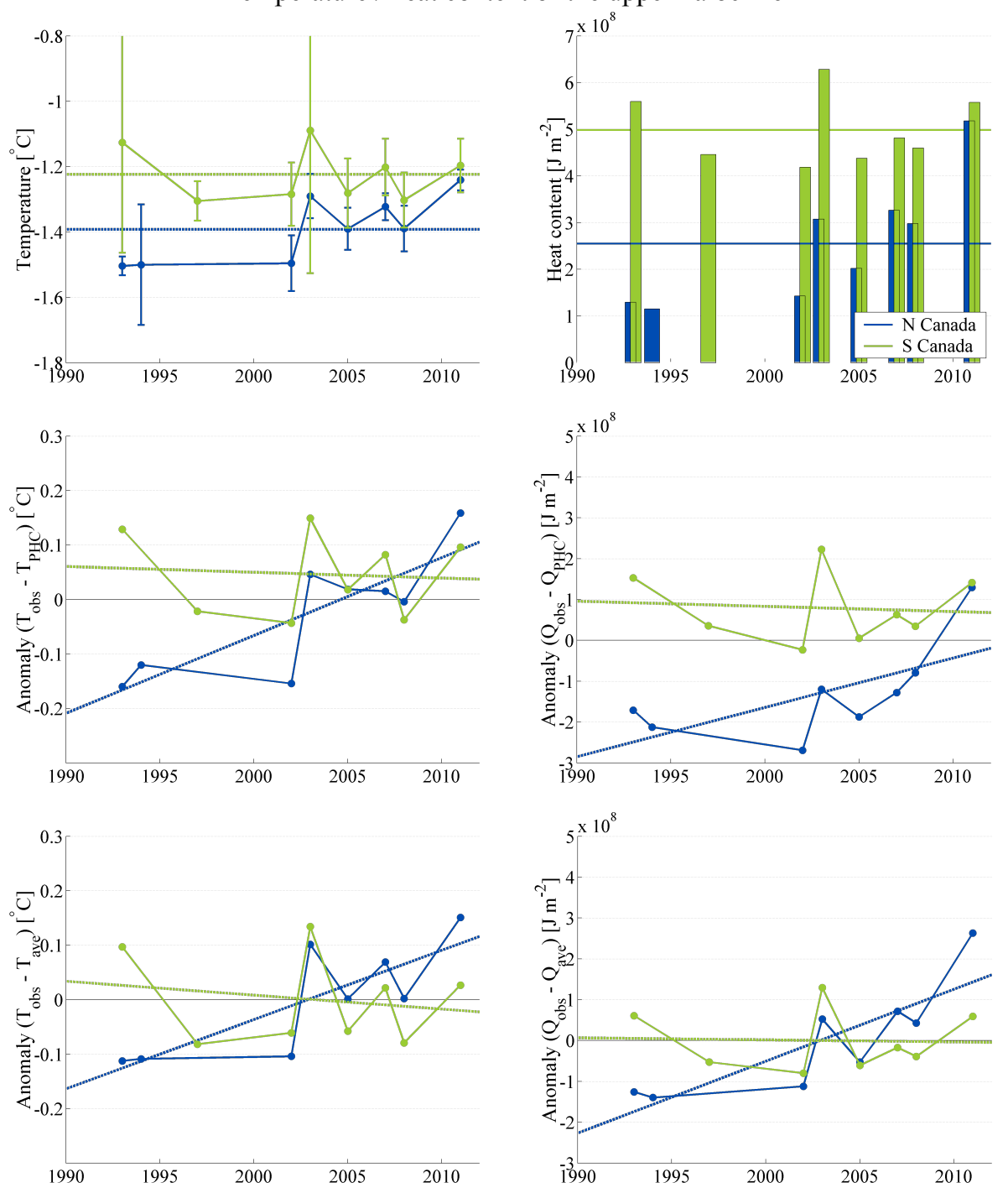

Fig. 29. The same as Fig. 21 but for the upper halocline in the Canada Basin.

corresponds to the roughly $1 \mathrm{~m}$ increase in freshwater content seen in Fig. 14. As the concurrent increase in meltwater content exceeds $0.5 \mathrm{~m}$ (Fig. 33), part of the freshening is suggested to reflect the accelerating sea ice melt. This increase in meltwater content compares well with the results of Morison et al. (2012), who distinguished $0.6 \mathrm{~m}$ of the freshwater added to the water column between 2003 and 2008 to derive from ice melt. In addition to ice melt, also river runoff and Ekman convergence are likely to contribute low salinity water near the surface.

Overall, the $5 \mathrm{~m}$ increase in the total freshwater content presented in Fig. 31 corresponds well with other studies conducted in the Beaufort Gyre. For example, Proshutinsky et al. (2009) report on an increase of $4 \mathrm{~m}$ between 2003 and 2007 whereas the increase of $10000 \mathrm{~km}^{3}$ given by Giles et al. (2012) corresponds to roughly $5 \mathrm{~m}$ of freshwater added to the Canada Basin during the 2000s.

\subsubsection{Warming during the 2000s}

In the Canada Basin, the increasing heat content is largely influenced by the thickening upper halocline (Fig. 7). Furthermore, particularly in the Northern Canada Basin, the increasing temperature is contributing to the heat content (Fig. 29, middle panel). In the Southern Canada Basin no clear trend in the upper halocline temperature can be distinguished. The possible warming of Pacific derived waters, suggested by Shimada et al. (2006) and Woodgate et al. (2010), is likely to be disturbed by the large variability in the properties of the Bering Strait inflow. Moreover, because the Pacific waters contributing to the upper halocline (ACW, 
Temperature / heat content of the lower halocline
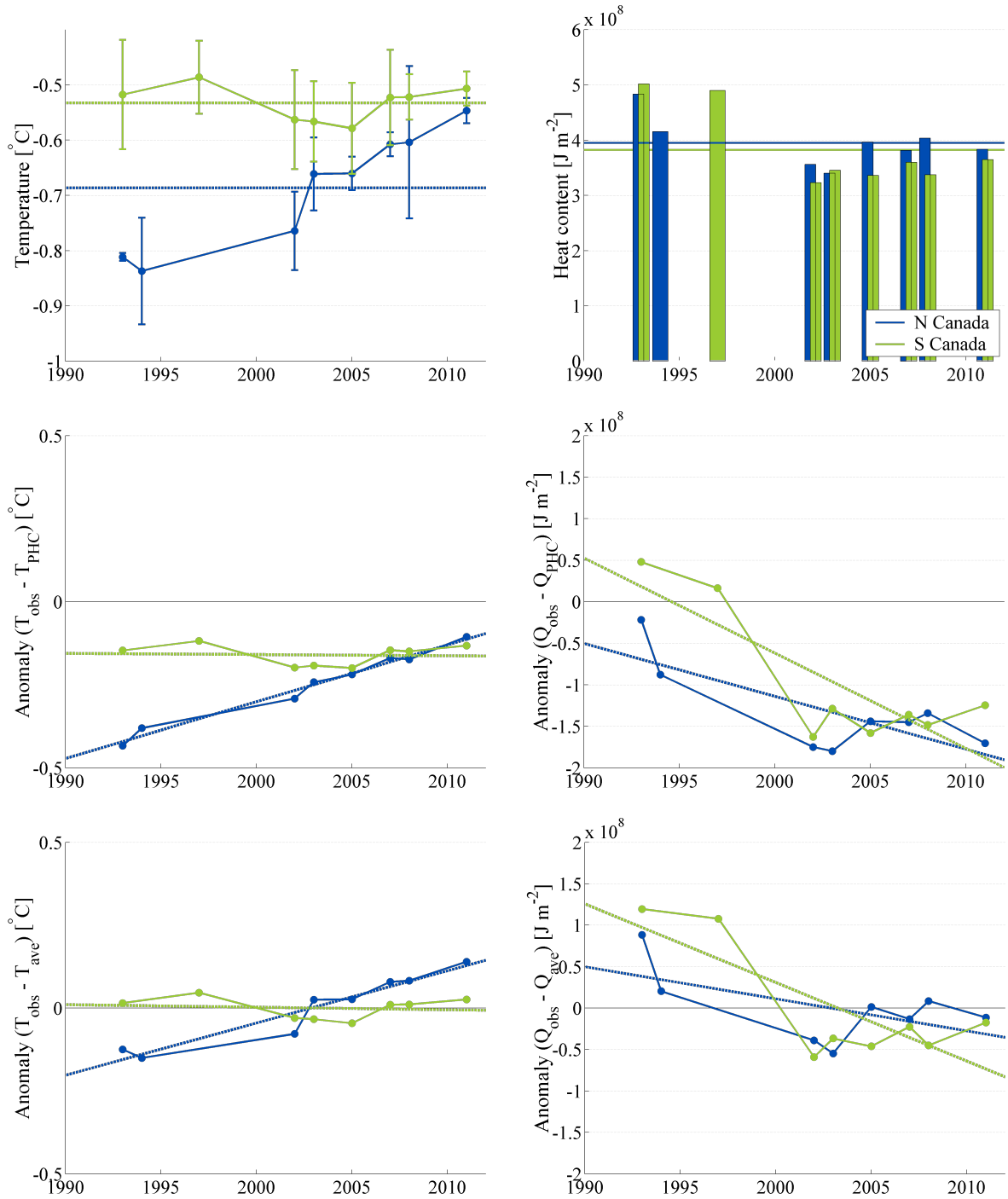

Fig. 30. The same as Fig. 21 but for the lower halocline in the Canada Basin.

BSSW, BSWW) are combined, possible variability of the warm (ACW, BSSW) halocline waters is likely overshadowed by presence of the cold Bering Sea Winter Water. It is also possible that the additional heat imported through the Bering Strait has been consumed by ice melt, or lost to the atmosphere, already over the shallow Chukchi Sea.

Also the warming of the Polar Mixed Layer is more evident in the Northern than in the Southern Canada Basin (Fig. 28, middle panel). Nonetheless, the warming should be considered together with the freshening presented in Fig. 14. Because the freezing point temperature depends on the local salinity, the decreasing salinity is reflected in the minimum temperature reached during previous winter. For example, in the Northern Canada Basin the decrease in salinity, from 31 to 29 , corresponds to an increase in freezing point temperature from -1.7 to $-1.6^{\circ} \mathrm{C}$. Consequently, the temperature in the beginning of the summer is initially higher, likely yielding higher temperatures at the end of the melt season. Therefore, only half of the observed warming, $0.2-0.3^{\circ} \mathrm{C}$, can be attributed to the increased absorption of solar radiation.

\subsection{Atlantic Water}

An obvious warming characterizes the Atlantic layer during the 1990s (Figs. 21 and 22), which is reflected to the total heat content presented in Fig. 32. The warming of the boundary current along the Eurasian continental slope was first detected in 1990 (Quadfasel et al., 1991). Along the boundary current, the Atlantic core temperature was observed to increase by $1{ }^{\circ} \mathrm{C}$ during the first half of the 1990s (Grotefendt et al., 1998). The $1^{\circ} \mathrm{C}$ increase in the upper Atlantic Water of the Nansen Basin in 1996 (Fig. 21) compares well with 
the estimate of Grotefendt et al. (1998). Both the temperature anomalies and hydrographic observations suggest that the warming spread from the Nansen Basin to the Amundsen and Makarov basins. The warming is accompanied by increased volume of the Atlantic Water. Particularly the heat content in the lower, more slowly warming, Atlantic layer increases due to its increasing thickness. In the Canada Basin, the observations from the 1990s are insufficient to detect the timing and magnitude of a possible warming. However, in 2002 and 2003, the temperature anomaly is remarkably high in the Northern Canada Basin (Figs. 23 and 24). Overall, these results are considered consistent with the propagation and magnitude of the 1990s warming reported in several studies (e.g. Swift et al., 1997; Morison et al., 1998; McLaughlin et al., 2009).

Then why is the temperature in the upper Atlantic layer increasing more strongly than in the lower layer? Does not the concurrent salinification, associated with changes in ocean advection and rapid ice formation (Steele and Boyd, 1998; Rigor et al., 2002), weaken the upper ocean stratification, enabling more heat to be transferred to the upper ocean and eventually to the sea ice and the atmosphere? Indeed, the winter convection appears to be able to reach deeper, down to the thermocline within the lower halocline, but not down to the Atlantic layer. Whereas the temperature of the upper Atlantic layer is increasing and the heat likely conserved, the cooling of the lower halocline (Fig. 25) is interpreted to indicate that winter convection replaces the warmer waters with colder surface waters. Besides decreasing temperatures, deeper vertical mixing also results in decreasing salinities within the lower halocline (Fig. 15). However, not enough oceanic heat is derived from the thermocline to decrease the salinity of the Polar Mixed Layer through increased ice melt (Fig. 13). On the contrary, the salinity of the Polar Mixed Layer is increasing and the seasonal ice melt decreasing.

Another anomalously warm inflow event was detected to enter the Arctic Ocean through the Fram Strait in the late 1990s (Schauer et al., 2004). In 2004, the increased temperatures in the boundary current along the Eurasian continental slope indicated that the warm signal was propagating further into the Arctic Ocean (Polyakov et al., 2005; Polyakov et al., 2011). However, based on the data analysed here, this warm signal is not distinguished beyond the Nansen Basin. On the contrary, in the Amundsen and Makarov basins the warming of the 1990s is followed by slight decrease in temperature. This cooling is consistent with the results of Polyakov et al. (2012), although, as shown in their Fig. 4, large variability within the Amundsen and Makarov basins is evident.

The heat content and the warming of the Atlantic layer have been extensively discussed, but the variations and distribution of salinity and freshwater content of the Atlantic Water have received much less attention. Especially in the lower Atlantic layer, the warm pulses are accompanied by strong salinification. In 1996, coincidentally with the warm pulse, an increase in salinity is observed in the Nansen and Amund- sen basins. In the 2000s, together with the warming, also the salinification appears to be confined in the Nansen Basin. In the Amundsen Basin, the salinities of both layers are elevated in 2007 and 2011. However, both layers are slightly cooling. In the Makarov Basin, a modest warming of both layers is not accompanied by salinification, but an decrease in the salinity of the lower Atlantic layer. A minor upward trend is seen in the salinity of the upper Atlantic layer. However, since the salinities remain well below the climatological average, and also below the salinities observed in the 1990s, it is unclear whether the warming in the Makarov Basin is related to the warm and saline pulse from the Fram Strait observed in the Nansen Basin. The absence of unambiguous trends in the Amundsen Basin suggests that the pulse has not penetrated beyond the Nansen Basin.

The salinification during the 2000s enhances the already remarkable difference in the freshwater content and salinity between the Nansen Basin and the other basins. It should be noted here that if a substantial fraction of heat is transported upwards by double-diffusive convection through diffusive interfaces (Lenn et al., 2009; Polyakov at al., 2011; Polyakov et al., 2012), the temperature would be reduced between the Nansen and Amundsen basins but result in a marginal change in salinity. Thus, the warming and salinification of the Nansen Basin may imply that the warmer and more saline Atlantic inflow, supplied by the Fram Strait branch (Schauer et al., 1997), mainly circulates in the Nansen Basin. In that case, the less saline and colder Barents Sea branch would be the major contributor to the Atlantic layer elsewhere in the Arctic Ocean. It has already been suggested by the model results of Karcher et al. (2003) that only under favourable conditions, such as strong cyclonic circulation prevailing from the late 1980s to the mid-1990s, is a substantial amount of Fram Strait branch water able to bypass the Lomonosov Ridge. However, to explain the difference in AW properties between the Nansen and Amundsen basins, the Fram Strait branch should be deflected from the continental slope already north of the Laptev Sea and return toward the Fram Strait along the Gakkel Ridge.

This interpretation, that most of the water in the Atlantic layer in the Amundsen Basin derives from the Barents Sea branch, is examined by comparing the average properties of AW1 and AW2 in the Nansen and Amundsen basins. Through this comparison, it is possible to determine a mixing line to the unknown mixing partner. To get the relative contributions from the two components, information about the properties of the Barents Sea branch is required. Using observations from the Kara Sea shelf and slope in 2007 (Fig. 34, reproduction of Fig. 4 in Rudels et al., 2013) we find the ratio between the two waters to be about $1: 1$ in AW1 and $1: 2$ in AW2, the shelf input being the largest. If the difference in thickness is taken as evidence that the transports in the Atlantic layers diminish between the Nansen and the Amundsen Basin then the supply to the AW1 layer in the Amundsen Basin is about equal to the supply to the Nansen Basin. For 

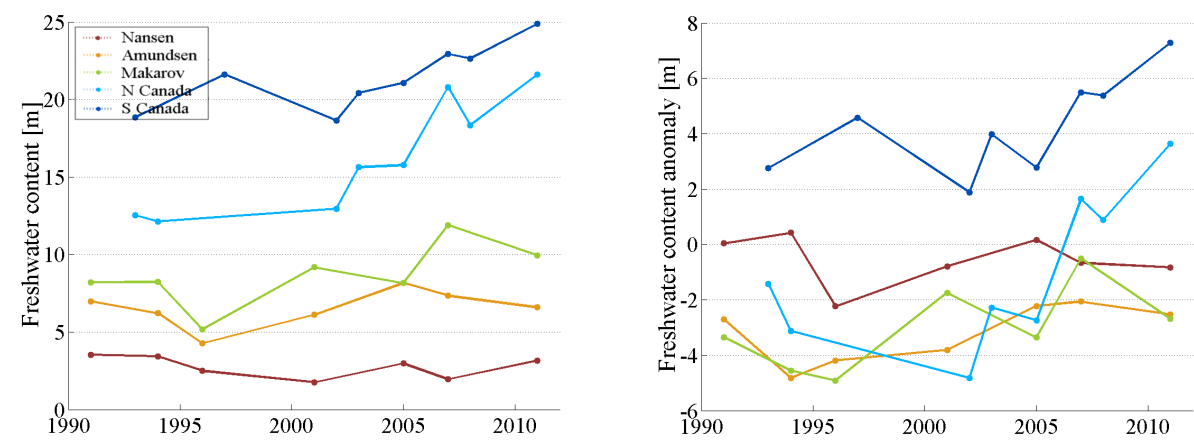

Fig. 31. Total freshwater content, including seasonal ice melt, in each discussed basin. The hydrographic estimate for freshwater content with reference salinity 34.9 is on the left and the anomalies from climatology on the right.
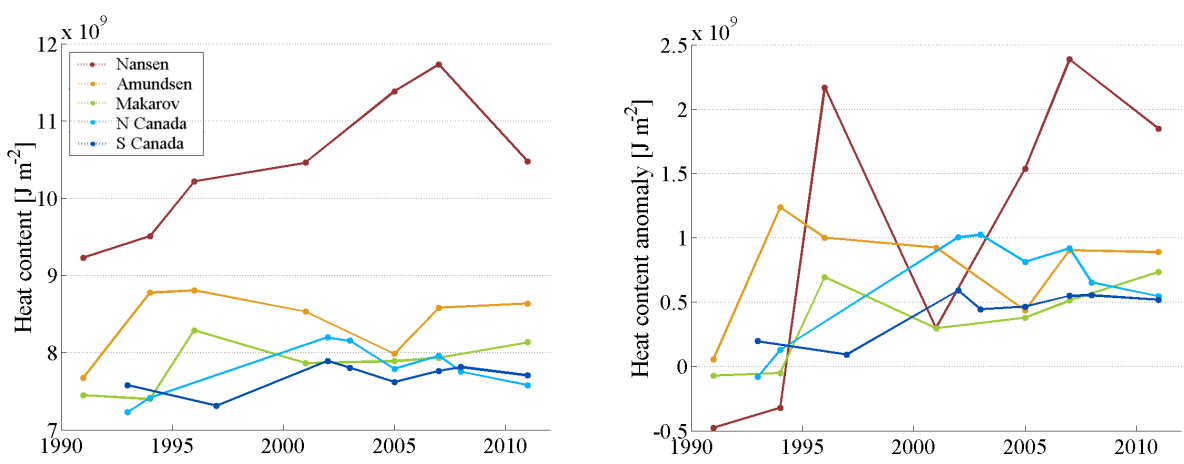

Fig. 32. Total heat content in each discussed basin. The hydrographic estimate for heat content with reference temperature $-1.8^{\circ} \mathrm{C}$ is on the left and the anomalies from climatology on the right.

AW2 the corresponding ratio is $4 / 5$ between the Amundsen Basin and the Nansen Basin. Up to $50 \%$ of the AW1 layer in the Amunden Basin is then supplied by the shelf input from the Barents and Kara seas. In the AW2 layer, the Barents Sea inflow branch supplies $2 / 3$ of the water. This indicates that about half of the inflow to the upper Atlantic layer and 3/5 of the lower Atlantic layer return towards Fram Strait within the Nansen Basin. This is less than the almost total return flow suggested by Rudels et al. (2013) but it is still substantial.

Another alternative to increase the freshwater content would be to melt sea ice, using the heat stored in the Atlantic Water, and mix it down to the Atlantic layer. However, this would result in a less dense water mass, even if not all heat lost by the Atlantic Water goes to ice melt (Rudels et al., 2004). This major interaction occurs already north of Svalbard as the Atlantic Water passes through Fram Strait into the Nansen Basin and leads to the formation of the Polar Mixed Layer there.

\subsection{Seasonal ice melt}

\subsubsection{The Nansen Basin}

The largest difference between the potential ice melt derived from the reanalysed heat fluxes and the melt estimate based on hydrographic observations emerges in the Nansen Basin. Although the heat input obtained from the ERAInterim products is somewhat smaller compared to that given by NCEP Reanalysis, also the ERA-Interim predicts the seasonal ice melt to be twice the melt estimated from the hydrography. Despite large uncertainties associated with both estimates, the difference between the estimates is remarkable since, in addition to the atmospheric heat, the Polar Mixed Layer in the Nansen Basin is presumed to receive oceanic heat from the underlying Atlantic Water. Intuitively, this would imply larger melt than the estimate based solely on the atmosphere-ocean surface fluxes.

A close inspection of the temperature and salinity profiles (not shown) reveals that the possible warming of the Polar Mixed Layer from below and the consequent upward displacement of the temperature minimum does not significantly influence the hydrographic melt estimate. Particularly in the Nansen Basin, the summer halocline is found notably closer to the surface than the identified temperature minima. Because the salinity gradient below the summer halocline is weak, most of the meltwater is located above the summer halocline and the possible vertical displacement of temperature minimum is considered negligible.

Regardless, according to other studies, the apparently low average hydrographic melt, $0.7 \mathrm{~m}$, is considered 

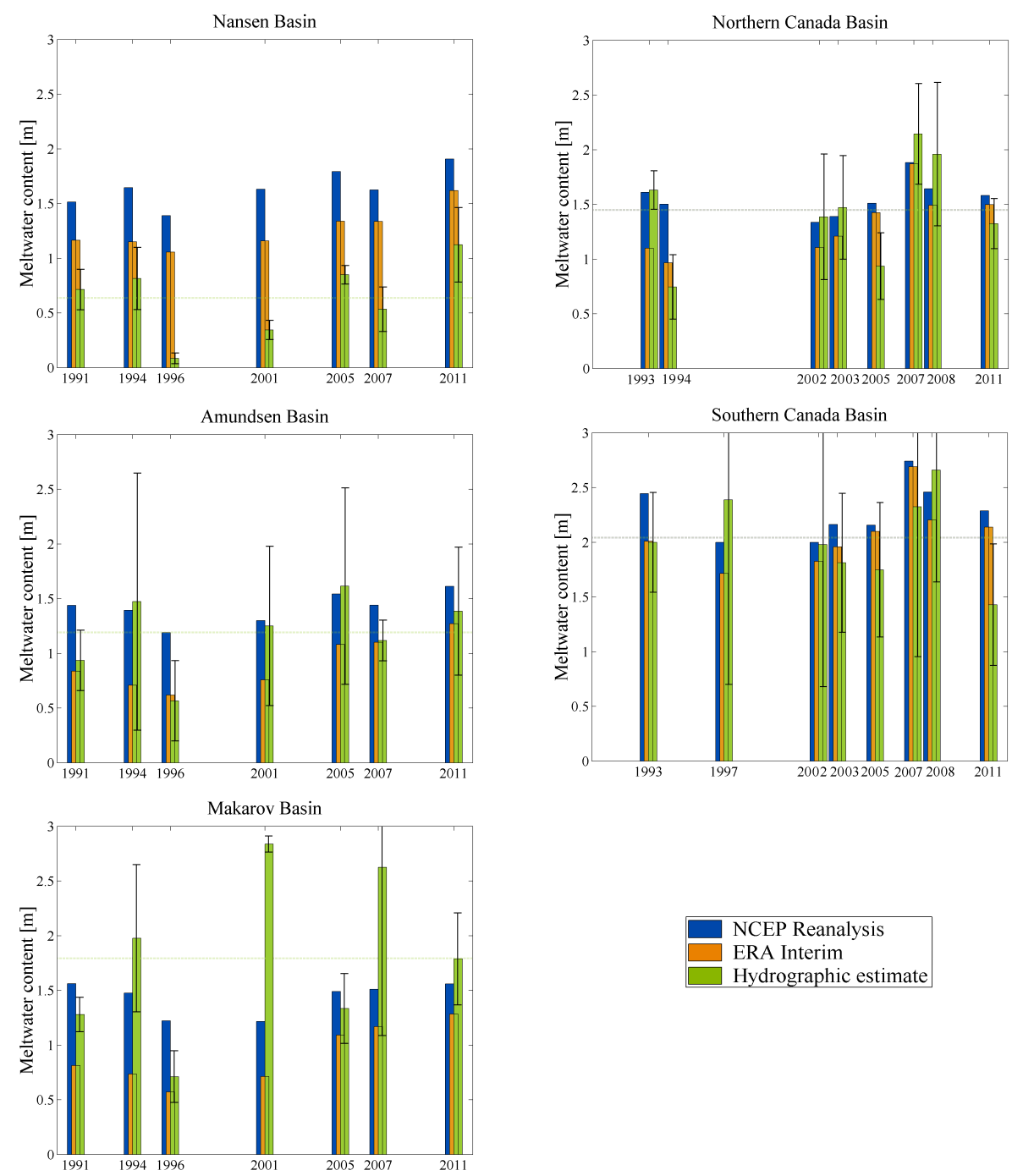

Fig. 33. The meltwater content estimated from the hydrographic data (green) compared to the estimated potential ice melt induced by the atmospheric surface fluxes (NCEP-blue, ERA-Interim-orange). The brackets indicate standard deviation for the hydrographic estimate.

characteristic to the Nansen Basin. For example Perovich et al. (2008), using an Ice Mass Balance buoy located approximately over the Gakkel Ridge, defined the average seasonal melt to be $0.5 \mathrm{~m}$. Therefore, the hydrographic melt estimate is interpreted to be realistic and the reanalysed heat fluxes possibly exaggerated. The low seasonal ice melt in the Nansen Basin could further support the impression that even weak stratification may inhibit mixing of Atlantic heat content close to the sea ice, rendering the sea ice better insulated than generally assumed.

\subsubsection{The Amundsen and Makarov basins}

Overall, in the Amundsen and Makarov basins the hydrographic melt estimate compares well with the seasonal ice melt based on the heat fluxes. During the 1990s the meltwater content decreases along with the net heat input. The de- crease could imply that, as the ice export (Vinje, 2001) and divergence (Rigor et al., 2002) reduce ice concentration, heat loss from exposed ocean surface exceeds the absorption of incoming solar radiation. The consequent rapid ice formation could then be observed as the increasing salinity of the Polar Mixed Layer seen in Fig. 13.

After the late 1990s, increasing heat input is reflected to the seasonal ice melt. However, the ice melt maxima arising in the hydrographic melt estimate for the Makarov Basin in 2001 and 2007 have no correspondence in the heat input estimates. Therefore, those individual melt maxima are suggested to be exceptional local features emphasized by the restricted spatial extent of hydrographic observations.

In addition to the relatively low surface salinity observed in the Makarov Basin in 2001, the hydrographic melt estimate is enhanced by the relatively high salinity (33.3) at the base of the Polar Mixed Layer. When this high salinity is 


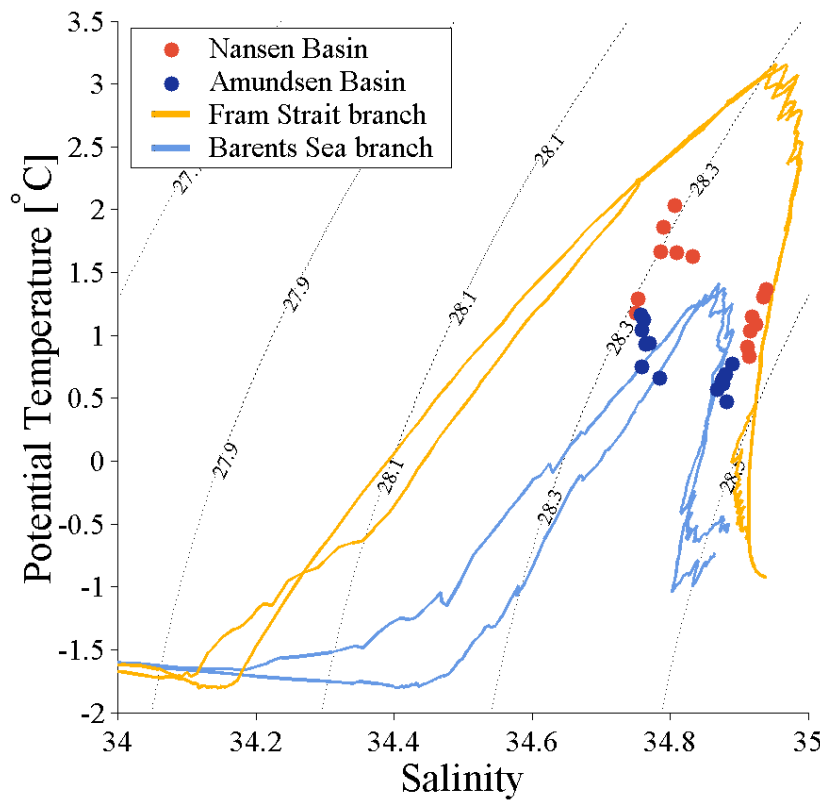

Fig. 34. $\theta S$-diagrams from the Kara Sea slope in 2007 demonstrating the different properties between the two Atlantic inflow branches, through the Fram Strait and the Barents Sea. The average properties of Atlantic Water in the Nansen and Amundsen basins between 1991 and 2007 are marked.

used as reference salinity, it yields much larger meltwater content than the more typical reference salinities of 32 . The high reference salinity is possibly a remnant from the salinification of the Polar Mixed Layer in the 1990s.

Another striking melt event occurred in the Makarov Basin in 2007. In addition to the large meltwater content, the low surface salinities are increasing the freshwater content in the Polar Mixed Layer (Fig. 13). As salinity decreases also in the upper halocline (Fig. 12), the freshening appears to cover the entire upper part of the water column. Comiso et al. (2008) suggested that persisting southerly winds pushed the anomaly in sea ice concentration northward. According to Wang et al. (2009) these winds also enhanced the inflow of warm Pacific waters between 2004 and 2007 and intensified the Transpolar Drift Stream. Thus, the anomalously high melt and freshwater estimate in 2007 is interpreted to result from advection.

\subsubsection{The Canada Basin}

According to several studies (McPhee et al., 1998; Perovich et al., 2003; Perovich et al., 2008), the average seasonal melt in the Beaufort Sea amounted to roughly $1 \mathrm{~m}$ during the 1990s. Compared to this average, the melt estimates throughout the observational period are high, and, at least in the 1990s, likely to be exaggerated by the input from river runoff. For 1997, the presence of river runoff has been confirmed: based on oxygen isotope ratio at the SHEBA site, Kadko and
Swart (2004) detected that only $1.2 \mathrm{~m}$ of freshwater derived from sea ice melt and that river runoff accounted for $0.8 \mathrm{~m}$ of additional freshwater to the Polar Mixed Layer. Since the SHEBA observation site was located at $\sim 75^{\circ} \mathrm{N}$, farther north from the Mackenzie delta than most of the casts used in this study, the presence of fresh shelf waters is likely to be more pronounced in the data analysed here. Thus the $2.4 \mathrm{~m}$ of meltwater, together with elevated freshwater content, appear reasonable.

Melt estimates for the 2000s compare relatively well with literature. During the period 1998-2004, Perovich et al. (2007b) estimated the annual heat input in the Canada Basin to vary between $8.5 \cdot 10^{8} \mathrm{~J} \mathrm{~m}^{-2}$ and $11 \cdot 10^{8} \mathrm{~J} \mathrm{~m}^{-2}$. This heat estimate corresponds to $2.6-3.3 \mathrm{~m}$ of meltwater, if all available heat is used to melt ice. However, some of the annual heat input given in Perovich et al. is used to warm the sea ice before melting whereas here only the June-August cumulative heat input is used to produce the average meltwater content of $2 \mathrm{~m}$.

The maximum meltwater content reached in 2007 and 2008 is consistent with previous observations of rapid, or catastrophic, sea ice melt occurring during these two years (Perovich et al., 2008; Kwok and Cunnigham, 2010). In 2007, the hydrographic estimate of $2.3 \mathrm{~m}$ in the Southern Canada Basin is close to the ice melt of $2.8 \mathrm{~m}$ measured by an Ice Mass Balance buoy in the Beaufort Sea (Perovich et al., 2008). Although also the renalysed surface fluxes indicate a maximum in the amount of available heat in 2007 and 2008, the maximum is more pronounced in the hydrographic meltwater estimate. Particularly in the Northern Canada Basin, the hydrographic estimate seems to exceed the potential ice melt derived from the heat fluxes. This may imply that heat stored in the upper ocean is needed to contribute in the seasonal ice melt.

As discussed in Sect. 4.2.3, the temperature of the Polar Mixed Layer has been increasing in the Northern Canada Basin during the past decade. Although no evident warming is observed in the Southern Canada Basin, the temperatures in 2007 and 2008 are elevated. Some of this heat, still present at the end of the melt season, may be stored in the Polar Mixed Layer and reduce ice formation the following winter. Furthermore, the reduced ice formation could lead to lower salinity of the temperature minimum and thus to a smaller ice melt estimate the following year.

\section{Conclusions}

Hydrographic data from various icebreakers have been used to detect variability in the freshwater content, heat content and seasonal ice melt between 1991 and 2011. Admittedly, the greatest uncertainty in our analysis is related to the sparse hydrographic sampling in both time and space. Nonetheless, a reasonably consistent picture emerges and, based on 
comparison with climatology and previous studies, the results are inferred to be quantitatively plausible.

The general downward trend in the Eurasian Basin freshwater content during the 1990s and the accumulation of freshwater in the Canada Basin during the 2000s are identified. Distinction between the upper halocline and the Polar Mixed Layer reveals that the recent freshening of the two layers is driven by different processes. Particularly in the Northern Canada Basin, where the most substantial increase in freshwater content has occurred, the upper halocline gains freshwater primarily through the increasing layer thickness. Salinity decrease of the Polar Mixed Layer in the Canada Basin is likely influenced by the accelerated ice melt. In the Eurasian Basin, the advective processes, including melting in the marginal seas, are assumed to regulate the freshwater balance in both the upper halocline and the Polar Mixed Layer.

Analysis of the salinity changes in the Atlantic layer reveals that the freshwater content deeper in the water column in the Nansen Basin is decreasing. Whereas the saline and warm pulse of Atlantic Water in the 1990s was observed simultaneously in the Nansen, Amundsen and Makarov basins, during the 2000s the pulse of water with similar salinity and temperature anomalies is not evident beyond the Nansen Basin. This indicates that most of the Fram Strait inflow is confined to the Nansen Basin and the colder and less saline Barents Sea inflow is the main contributor to the Atlantic layer beyond the Gakkel Ridge. However, even in the Nansen Basin, where the Atlantic Water is the warmest and the upper halocline is generally absent, the seasonal ice melt appears independent from the increasing Atlantic heat content. During the 2000s, freshening of the upper ocean is decreasing the depth of winter convection and the established stratification restricts, at least during summer, the upward mixing of Atlantic heat. Comparison of the hydrographic melt estimate to the potential ice melt obtained from reanalysed heat fluxes indicates that the seasonal ice melt rather reflects the variability in atmospheric heat fluxes than changes in the deep ocean heat content.

Acknowledgements. The research leading to these results has received funding from the Väisälä foundation (MK) and from the European Union's 6th Framework Programme under grant agreement No. 018509 DAMOCLES (MK,BR\&MM) and the 7th Framework Programme (FP7 2007-2013) under grant agreements No. 212643 THOR (MK\&BR) and No. 308299 NACLIM (MK\&BR). We value the time and effort of all scientists and staff involved in the data collection and precessing and thank the anonymous reviewers for their beneficial comments and suggestions. Reiner Schlitzer's Ocean Data View (http://odv.awi.de, 2012) was found useful in preparing the maps.

Edited by: K. J. Heywood

\section{References}

Aagaard, K. and Coachman, L. K.: Toward an ice-free Arctic ocean, Eos Trans. AGU, 56, 484-486, 1975.

Aagaard, K. and Carmack, E. C.: The role of sea ice and other fresh water in the Arctic circulation, J. Geophys. Res., 94, 14 485-14 498, 1989.

Aagaard, K., Coachman, L. K., and Carmack, E. C.: On the halocline of the Arctic Ocean, Deep-Sea Res., 28, 529-545, 1981.

Anderson, L. G., Björk, G., Holby, O., Jones, E. P., Kattner, G., Koltermann, K.-P., Liljeblad, B., Lindegren, R., Rudels, B., and Swift, J. H.: Water masses and circulation in the Eurasian Basin: results from the Oden 91 expedition, J. Geophys. Res., 99, 32733283, 1994.

Bauch, D., van der Loeff, M. R., Andersen, N., Torres-Valdes, S., Bakker, K., and Abrahamsen, E. P.: Origin of freshwater and polynya water in the Arctic Ocean halocline in summer 2007, Prog. Oceanogr., 91, 482-495, 2011.

Björk, G., Söderkvist, J., Winsor, P., Nikolopoulos, A., and Steele, M.: Return of the cold halocline layer to the Amundsen Basin of the Arctic Ocean: implications for the sea ice mass balance, Geophys. Res. Lett., 29, 1513-1516, 2002.

Björk, G., Jakobsson, M., Rudels, B., Swift, J. H., Anderson, L., Darby, D. A., Backman, J., Coakley, B., Winsor, P., Polyak, L., and Edwards, M.: Bathymetry and deep-water exchange across the Central Lomonosov Ridge at $88-89^{\circ}$ N, Deep-Sea Res., 54, 1197-1208, 2007.

Bourgain, P., Gascard, J. C., Shi, J., and Zhao, J.: Large-scale temperature and salinity changes in the upper Canadian Basin of the Arctic Ocean at a time of a drastic Arctic Oscillation inversion, Ocean Sci., 9, 447-460, doi:10.5194/os-9-447-2013, 2013.

Boyd, T. J., Steele, M., Muench, R. D., and Gunn, J. T.: Partial recovery of the Arctic Ocean halocline, Geophys. Res. Lett., 29, 1657-1660, 2002.

Carmack, E. C., Macdonald, R. W., Perkin, R. G., McLaughlin, F. A., and Pearson, R. J.: Evidence for warming of Atlantic Water in the Southern Canadian Basin of the Arctic Ocean: results from the Larsen-93 expedition, Geophys. Res. Lett., 22, 1061-1064, 1995.

Cavalieri, D. J. and Parkinson, C. L.: Arctic sea ice variability and trends, 1979-2010, The Cryosphere, 6, 881-889, 2012, http://www.the-cryosphere-discuss.net/6/881/2012/.

Coachman, L. K. and Barnes, C. A.: The contribution of Bering Sea water to the Arctic Ocean, Arctic, 14, 147-161, 1961.

Comiso, J. C., Parkinson, C. L., Gersten, R., and Stock, L.: Accelerated decline in the Arctic sea ice cover, Geophys. Res. Lett., 35, L01703, doi:10.1029/2007GL031972, 2008.

Comiso, J. C.: Large Decadal Decline of the Arctic Multiyear Ice Cover, J. Clim, 25, 1176-1193, 2011.

Curry, R., Dickson, B., and Yashayaev, I.: A change in the freshwater balance of the Atlantic Ocean over the past four decades, Nature, 426, 826-829, 2003.

Curry, R. and Mauritzen, C.: Dilution of the Northern North Atlantic Ocean in Recent Decades, Science, 308, 1772-1774, 2005.

Dee, D. P., Uppala, S. M., Simmons, A. J., Berrisford, P., Poli, P., Kobayashi, S., Andrae, U., Balmaseda, M. A., Balsamo, G., Bauer, P., Bechtold, P., Beljaars, A. C. M., van de Berg, L., Bidlot, J., Bormann, N., Delsol, C., Dragani, R., Fuentes, M., Geer, A. J., Haimberger, L., Healy, S. B., Hersbach, H., Hólm, E. V., Isaksen, L., Kållberg, P., Köhler, M., Matricardi, M., 
McNally, A. P., Monge-Sanz, B. M., Morcrette, J.-J., Park, B.-K., Peubey, C., de Rosnay, P., Tavolato, C., Thépaut, J.-N., Vitart, F..: The ERA-Interim reanalysis: configuration and performance of the data assimilation system, Q. J. R. Meteorol. Soc., 137, 553597, 2011.

Dickson, B., Yashayaev, I., Meincke, J., Turrell, B., Dye, S., and Holfort, J.: Rapid freshening of the deep North Atlantic Ocean over the past four decades, Nature, 416, 832-837, 2002.

Dickson, R. R., Rudels, B., Dye, S., Karcher, M., Meincke, J., and Yashayaev, I.: Current estimates of freshwater flux through arctic and subarctic seas, Prog. Oceanogr., 73, 210-230, 2007.

Giles, K. A., Laxon, S. W., Ridout, A. L., Wingham, D. J., and Bacon, S.: Western Arctic Ocean freshwater storage increased by wind-driven spin-up of the Beaufort Gyre, Nature Geosci., 5, 194-197, 2012.

Grotefendt, K., Logemann, K., Quadfasel, D., and Ronski, S.: Is the Arctic Ocean warming?, J. Geophys. Res., 103, 27679, doi:10.1029/98JC02097, 1998.

Guay, C. K. and Falkner, K.: Barium as a tracer of Arctic halocline and river waters, Deep-Sea Res., 44, 1543-1569, 1997.

Jackson, J. M., Carmack, E. C., McLaughlin, F. A., Allen, S. E., and Ingram, R. G.: Identification, characterization, and change of the near-surface temperature maximum in the Canada Basin, 1993-2008, J. Geophys. Res., 115, C05021, doi:10.1029/2009JC005265, 2010.

Jakobson, E., Vihma, T., Palo, T., Jakobson, L., Keernik, H., and Jaagus, J.: Validation of atmospheric reanalyses over the central Arctic Ocean, Geophys. Res. Lett., 39, L10802, doi:10.1029/2012GL051591, 2012.

Johnson, M. and Polyakov, I. V.: The Laptev Sea as a source for recent Arctic Ocean salinity changes, Geophys. Res. Lett., 28, 2017-2020, 2001.

Jones, E. P., Anderson, L. G., Jutterström, S., Mintrop, L., and Swift, J. H.: Pacific freshwater, river water and sea ice meltwater across Arctic Ocean basins: results from the 2005 Beringia expedition, J. Geophys. Res., 113, C128012, doi:10.1029/2007JC004124, 2008.

Kadko, D. and Swart, P.: The source of the high heat and freshwater content of the upper ocean at the SHEBA site in the Beaufort Sea in 1997, J. Geophys. Res., 109, C01022, doi:10.1029/2002JC001734, 2004

Kalnay, E., Kanamitsu, M., Kistler, R., Collins, W., Deaven, D., Gandin, L., Iredell, M., Saha, S., White, G., Woollen, J., Zhu, Y., Cheillab, M., Ebsuzaki, W., Higgins, W., Janowiak, J., Mo, K. C., Ropelewski, C., Wang, J., Leetma, A., Reynolds, R., Jenne, R., and Joseph, D.: The NCEP/NCAR 40-yr reanalysis project, Bull. Amer. Meteor. Soc., 77, 437-470, 1996.

Karcher, M. J., Gerdes, R., Kauker, F., and Köberle, C.: Arctic warming-evolution and spreading of the 1990s warm event in the Nordic Seas and the Arctic Ocean, J. Geophys. Res., 108, C23034, doi:10.1029/2001JC001265, 2003.

Karcher, M. J., Gerdes, R., Kauker, F., Köberle, C., and Yashayaev, I.: Arctic Ocean change heralds North Atlantic freshening, Geophys. Res. Lett., 32, L21606, doi:10.1029/2005GL023861, 2005.

Kikuchi, T., Hatakeyama, K., and Morison, J. H.: Distribution of convective lower halocline water in the Eastern Arctic Ocean, J. Geophys. Res., 109, C12030, doi:10.1029/2003JC002223, 2004.
Krishfield, R. A., Toole, J. M., Proshutinsky, A., and Timmermans, M. L.: Automated Ice-Tethered Profilers for seawater observations under pack ice in all seasons, J. Atmos. Ocean. Technol., 25, 2091-2105, 2008.

Kwok, R. and Cunningham, G. F.: Contribution of melt in the Beaufort Sea to the decline in Arctic multiyear sea ice coverage: 1993-2009, Geophys. Res. Lett., 37, L20501, doi:10.1029/2010GL044678, 2010.

Kwok, R. and Morison, J.: Dynamic topography of the ice-covered Arctic Ocean from ICESat, Geophys. Res. Lett., 38, L02501, doi:10.1029/2010GL046063, 2011.

Lenn, Y. D., Wiles, P. J., Torres-Valdes, S., Abrahamsen, E. P., Rippeth, T. P., Simpson, J. H., Bacon, S., Laxon, S. W., Polyakov, I., Ivanov, V., and Kirillov, S.: Vertical mixing at intermediate depths in the Arctic boundary current, Geophys. Res. Lett., 36, L05601, doi:10.1029/2008GL036792, 2009.

Macdonald, R. W., Paton, D. W., and Carmack, E. C.: The freshwater budget and under-ice spreading of Mackenzie River water in the Canadian Beaufort Sea based on salinity and ${ }^{18} \mathrm{O} /{ }^{16} \mathrm{O}$ measurements in water and ice, J. Geophys. Res., 100, 895-919, 1995.

Macdonald, R. W., Carmack, E. C., McLaughlin, F. A., Falkner, K. K., and Swift, J. H.: Connections among ice, runoff and atmospheric forcing in the Beaufort Gyre, Geophys. Res. Lett., 26, 2223-2226, doi:10.1029/1999GL900508, 1999.

Martinson, D. G. and Steele, M.: Future of the Arctic sea ice cover: implications of an Antarctic analog, Geophys. Res. Lett., 28, 307-310, 2001.

Maslanik, J., Serreze, M., and Barry, R.: Recent changes in Arctic summer ice cover and linkages to atmospheric circulation anomalies, Geophys. Res. Lett., 23, 1677-1680, 1996.

Maykut, G. A. and McPhee, M. G.: Solar heating of the Arctic mixed layer, J. Geophys. Res., 100, 24691-24704, 1995.

McLaughlin, F. A., Carmack, E. C., Macdonald, R. W., Melling, H., Swift, J. H., Wheeler, P. A., Sherr, B. F., and Sherr, E. B.: The joint roles of Pacific and Atlantic-origin waters in the Canada Basin, 1997-1998, Deep-Sea Res., 51, 107-128, 2004.

McLaughlin, F. A., Carmack, E. C., Williams, W. J., Zimmermann, S., Shimada, K., and Itoh, M.: Joint effects of boundary currents and thermohaline intrusions on the warming of Atlantic Water in the Canada Basin, 1993-2007, J. Geophys. Res., 114, C00A12, doi:10.1029/2008JC005001, 2009.

McPhee, M. G., Stanton, T. P., Morison, J. H., and Martinson, D. G.: Freshening of the upper ocean in the Arctic: is perennial sea ice disappearing?, Geophys. Res. Lett., 25, 1729-1732, 1998.

Morison, J. H., Steele, M., and Andersen, R.: Hydrography of the upper Arctic Ocean measured from the nuclear submarine U.S.S Pargo, Deep-Sea Res. I, 45, 15-38, 1998.

Morison, J. H., Kwok, R., Peralta-Ferriz, C., Alkire, M., Rigor, I., Andersen, R., and Steele, M.: Changing Arctic Ocean freshwater pathways, Nature, 481, 66-70, 2012.

Perovich, D. K., Grenfell, T. C., Richter-Menge, J. A. Light, B., Tucker, W. B., and Eicken, H.: Thin and thinner: sea ice mass balance measurements during SHEBA, J. Geophys. Res., 108, 8050-8070, doi:10.1029/2001JC001079, 2003.

Perovich, D. K., Light, B., Eicken, H., Jones, K. F., Runciman, K., and Nghiem, S. V.: Increasing solar heating of the Arctic Ocean and adjacent seas, 1979-2005: attribution and role 
in the ice-albedo feedback, Geophys. Res. Lett., 34, L19505, doi:10.1029/2007GL031480, 2007a.

Perovich, D. K., Nghiem, S. V., Markus, T., and Schweiger, A.: Seasonal evolution and interannual variability of the local solar energy absorbed by the Arctic sea ice-ocean system, J. Geophys. Res., 112, C03005, doi:10.1029/2006JC003558, $2007 \mathrm{~b}$.

Perovich, D. K., Richter-Menge, J. A., Jones, K. F., and Light, B.: Sunlight, water, and ice: extreme Arctic sea ice melt during the summer of 2007, Geophys. Res. Lett., 35, L11501, doi:10.1029/2008GL034007, 2008.

Polyakov, I. V., Beszczynska, A., Carmack, E. C., Dmitrenko, I. A., Fahrbach, E., Frolov, I. E., Gerdes, R., Hansen, E., Holfort, J., Ivanov, V. V., Johnson, M. A., Karcher, M., Kauker, M., Morison, J. H., Orvik, K. A., Schauer, U., Simmons, H. L., Skagseth, Ø., Sokolov, V. T., Steele, M., Timokhov, L. A., Wals, D., and Walsh, J. E.: One more step toward a warmer Arctic, Geophys. Res. Lett., 32, 17605, doi:10.1029/2005GL023740, 2005.

Polyakov, I. V., Alexeev, V. A., Belchansky, G. I., Dmitrenko, I. A., Ivanov, V. V., Kirillov, S. A., Korablev, A. A., Steele, M., Timokhov, L. A., and Yashayaev, I.: Arctic Ocean Freshwater Changes over the Past 100 Years and Their Causes, J. Clim, 21, 364-384, 2008.

Polyakov, I. V., Timokhov, L. A., Alexeev, V. A., Bacon, S., Dmitrenko, I. A., Fortier, L., Frolov, I. E., Gascard, J.-C., Hansen, E., Ivanov, V. V., Laxon, S., Mauritzen, C., Perovich, D., Shimada, K., Simmons, H. L., Sokolov, V. T., Steele, M., and Toole, J.: Arctic Ocean warming contributes to reduced polar ice cap, J. Phys. Oceanogr., 40, 2743-2756, 2010.

Polyakov, I. V., Alexeev, V. A., Ashik, I. M., Bacon, S., Beszczynska-Möller, A., Carmack, E. C., Dmitrenko, I. A., Fortier, L., Gascard, J.-C., Hansen, E., Hölemann, J., Ivanov, V. V., Kikuchi, T., Kirillov, S., Lenn, Y.-D., McLaughlin, F. A., Piechura, J., Repina, I., Timokhov, L. A., Walczowski, W., and Woodgate, R.: Fate of Early 2000s Arctic Warm Water Pulse, Bull. Am. Meteorol. Soc., 92, 561-566, 2011.

Polyakov, I. V., Pnyushkov, A. V., and Timokhov, L. A.: Warming of the Intermediate Atlantic Water of the Arctic Ocean in the 2000s, J. Clim, 25, 8362-8370, 2012.

Proshutinsky, A. Y. and Johnson, M. A.: Two circulation regimes of the wind-driven Arctic Ocean, J. Geophys. Res., 102, 1249312514, 1997.

Proshutinsky, A., Krishfield, R., Timmermans, M.-L., Toole, J. M., Carmack, E. C., McLaughlin, F. A., Williams, W. J., Zimmermann, S., Itoh, M., and Shimada, K.: Beaufort Gyre freshwater reservoir: state and variability from observations, J. Geophys. Res., 114, C00A10, doi:10.1029/2008JC005104, 2009.

Quadfasel, D., Sy, A., Wells, D., and Tunik, A.: Warming in the Arctic, Nature, 350, p. 385, doi:10.1038/350385a0, 1991.

Rabe, B., Karcher, M., Schauer, U., Toole, J. M., Krishfield, R. A., Pisarev, S., Kauker, F., Gerdes, R., and Kikuchi, T.: An assessment of Arctic Ocean freshwater content changes from the 1990s to the 2006-2008 period, Deep-Sea Res. I, 58, 173-185, 2011.

Rigor, I. G., Colony, R. L., and Seelye, M.: Variations in surface air temperature observations in the Artic, 1979-97, J. Clim, 13, 896-914, 2000.

Rigor, I. G., Wallace, J. M., and Colony, R. L.: Response of sea ice to the Arctic oscillation, J. Clim., 15, 2648-2663, 2002.
Roach, A. T., Aagaard, K., Pease, C. H., Salo, S. A., Weingartner, T., Pavlov, V., and Kulakov, M.: Direct measurements of transports and water properties through the Bering Strait, J. Geophys. Res., 100, 18433-18457, 1995.

Rudels, B.: The theta-S relations in the northern seas: Implications for the deep circulation, Polar Res., 4, 133-159, 1986.

Rudels, B., Jones, E. P., Anderson, L. G., and Kattner, G.: On the intermediate depth waters of the Arctic Ocean, in: Polar Oceans and Their Role in Shaping the Global Environment, edited by: Johanessen, O. M., Muench, R. D., and Overland, J. E., Geophysical Monograph 85, American Geophysical Union, Washington, 33-46, 1994.

Rudels, B., Anderson, L. G., and Jones, E. P.: Formation and evolution of the surface mixed layer and halocline of the Arctic Ocean, J. Geophys. Res., 101, 8807-8822, 1996.

Rudels, B., Jones, E. P., Schauer, U., and Eriksson, P.: Atlantic sources of the Arctic Ocean surface and halocline waters, Polar Res., 23, 181-208, 2004.

Rudels, B.: Constraints on exchanges in the Arctic Mediterranean do they exist and can they be of use?, Tellus Series A, 62, 109122, 2010.

Rudels, B., Schauer, U., Björk, G., Korhonen, M., Pisarev, S., Rabe, B., and Wisotzki, A.: Observations of water masses and circulation in the Eurasian basin of the Arctic Ocean from the 1990 s to the late 2000s, Ocean Sci., 9, 147-169, doi:10.5194/os9-147-2013, 2013.

Schauer, U., Muench, R. D., Rudels, B., and Timokhov, L.: Impact of Eastern Arctic shelf waters on the Nansen Basin intermediate waters, J. Geophys. Res., 102, 3371-3382, 1997.

Schauer, U. and Rohardt, G.: Physical oceanography during POLARSTERN cruise ARK-XII, Alfred Wegener Institute, Helmholtz Center for Polar and Marine Research, Bremerhaven, doi:10.1594/PANGAEA.742617, 1998.

Schauer, U., Fahrbach, E., Osterhus, S., and Rohardt, G.: Arctic warming through the Fram Strait: oceanic heat transport from 3 yr of measurements, J. Geophys. Res., 109, C06026, doi:10.1029/2003JC001823, 2004.

Schauer, U. and Wisotzki, A.: Physical oceanography during POLARSTERN cruise ARK-XXII/2 (SPACE), Alfred Wegener Institute, Helmholtz Center for Polar and Marine Research, Bremerhaven, doi:10.1594/PANGAEA.733418, 2010.

Schauer, U., Rabe, B., and Wisotzki, A.: Physical oceanography during POLARSTERN cruise ARK-XXVI/3, Alfred Wegener Institute, Helmholtz Center for Polar and Marine Research, Bremerhaven, doi:10.1594/PANGAEA.774181, 2012.

Serreze, M. C., Barrett, A. P., Slater, A. G.,Woodgate, R. A., Aagaard, K., Lammers, R. B., Steele, M., Moritz, R., Meredith, M., and Lee, C. M.: The large-scale freshwater cycle of the Arctic, J. Geophys. Res., 111, C11010, doi:10.1029/2005JC003424, 2006.

Shimada, K., Carmack, E. C., Hatakeyama, K., and Takizawa, T.: Varieties of shallow temperature maximum waters in the Western Canadian Basin of the Arctic Ocean, Geophys. Res. Lett, 28, 3441-3444, 2001

Shimada, K., Itoh, M., Nishino, S., McLaughlin, F. A., Carmack, E. C., and Proshutinsky, A.: Halocline structure in the Canada Basin of the Arctic Ocean, Geophys. Res. Lett., 32, L03605, doi:10.1029/2004GL021358, 2005.

Shimada, K., Kamoshida, T., Itoh, M., Nishino, S., Carmack, E. C., McLaughlin, F. A., Zimmermann, S., and Proshutinsky, A.: Pa- 
cific Ocean inflow: influence on catastrophic reduction of sea ice cover in the Arctic Ocean, Geophys. Res. Lett., 33, L08605, doi:10.1029/2005GL025624, 2006.

Steele, M. and Boyd, T.: Retreat of the cold halocline layer in the Arctic Ocean, J. Geophys. Res., 103, 10419-10436, 1998.

Steele, M., Morley, R., and Ermold, W.: PHC: A global ocean hydrography with a high quality Arctic Ocean, J. Climate, 14, 2079-2087, 2001.

Steele, M., Morison, J., Ermold, W., Rigor, I., Ortmeyer, M., and Shimada, K.: Circulation of summer Pacific halocline water in the Arctic Ocean, J. Geophys. Res., 109, 2027-2044, 2004.

Stigebrandt, A.: The North Pacific: a global-scale estuary, J.Phys. Oceanogr., 14, 464-470, 1984.

Stroeve, J. C., Serreze, M. C., Holland, M. M., Kay, J. E., Maslanik, J., Barrett, A. P.: The Arctic's rapidly shrinking sea ice cover: a research synthesis, Climatic Change, 110, 1005-1027, 2012.

Swift, J. H., Jones, E. P., Aagaard, K., Carmack, E. C., Hingston, M., Macdonald, R. W., McLaughlin, F. A., and Perkin, R. G.: Waters of the Makarov and Canada basins, DeepSea Res. II, 44, 1503-1529, 1997.

Swift, J. H., Aagaard, K., Timokhov, L., and Nikiforov, E. G.: Longterm variability of Arctic Ocean waters: Evidence from a reanalysis of the EWG data set, J. Geophys. Res., 110, C03012, doi:10.1029/2004JC002312, 2005.

Thompson, D. W. J. and Wallace, J. M.: The Arctic oscillation signature in the wintertime geopotential height and temperature fields, Geophys. Res. Lett., 25, 1297-1300, 1998.

Vinje, T.: Fram Strait ice fluxes and atmospheric circulation: 19502000, J. Clim., 14, 3508-3517, 2001.
Wang, J., Zhang, J., Watanabe, E., Ikeda, M., Mizobata, K., Walsh, J. E., Bai, X., and Wu, B.: Is the dipole anomaly a major driver to record lows in Arctic summer sea ice extent?, Geophys. Res. Lett., 36, L05706, doi:10.1029/2008GL036706, 2009.

Williams, B. and Zimmermann, S.: Joint Ocean Ice Study (JOIS) 2011 Cruise Report, Fisheries and Oceans Canada Institute of Ocean Sciences, Sidney, B.C., 68 pp., 2011.

Woodgate, R. A., Aagaard, K., Swift, J. H., Smethie, W. M., and Falkner, K. K.: Atlantic water circulation over the Mendeleev Ridge and Chukchi Borderland from thermohaline intrusions and water mass properties, J. Geophys.Res., 112, C02005, doi:10.1029/2005JC003416, 2007.

Woodgate, R. A., Weingartner, T., and Lindsay, R.: The 2007 Bering Strait oceanic heat flux and anomalous Arctic sea-ice retreat, Geophys. Res. Lett., 37, L01602, doi:10.1029/2009GL041621, 2010.

Yamamoto-Kawai, M., McLaughlin, F. A., Carmack, E. C., Nishino, S., Shimada, K., and Kurita, N.: Surface freshening of the Canada Basin, 2003-2007: river runoff versus sea ice meltwater, J. Geophys.Res., 114, C00A05, doi:10.1029/2008JC005000, 2009.

Zhang, Z. (Ed.): The Report of 2003 Chinese Arctic Research Expedition, China Ocean Press, Beijing, 229 pp., 2004.

Zimmermann, S., Eert, J., and McLaughlin, F.: Joint Ocean Ice Study (JOIS) 2007 Cruise Report, Fisheries and Oceans Canada Institute of Ocean Sciences, edited by: Sidney, B. C., 39 pp., 2007. 